\title{
Convergent Synthesis of Complex Diketopiperazines Derived from Pipecolic Acid Scaffolds and Parallel Screening against GPCR Targets
}

\author{
Sivaraman Dandapani, ${ }^{\dagger}$ Aaron Beeler, ${ }^{\dagger}$ Ping Lan, ${ }^{\dagger}$ Scott Beischel,,${ }^{\ddagger}$ Athier Abbas, ${ }^{\ddagger}$ \\ Bryan R. Roth, ${ }^{\star, \S}$ John A. Porco, Jr., ${ }^{\dagger *}$ and James S. Panek ${ }^{\dagger *}$ \\ ${ }^{\dagger}$ Department of Chemistry and Center for Chemical Methodology and Library Development \\ (CMLD-BU), Boston University, 590 Commonwealth Avenue, Boston, Massachusetts 02215, and \\ ${ }^{*}$ National Institute of Mental Health Psychoactive Drug Screening Program and Department of \\ Biochemistry, Case Western Reserve University Medical School, Cleveland, Ohio 44106 \\ ${ }^{\S}$ Current Address: School of Medicine and Division of Medicinal Chemistry and Natural Products, School of \\ Pharmacy, University of North Carolina Chapel Hill Medical School, Chapel Hill, NC 27599
}

\section{Supporting Information}

\section{Contents:}

1. General Experimental Information ------------------------------------------------------------ S2

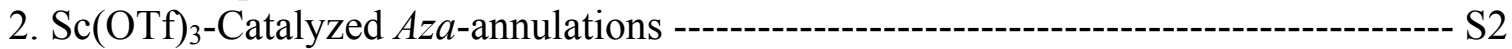

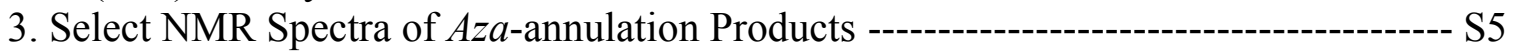

4. Hydrogenation and Trifluoroacetamide Deprotection -----------------------------------S10

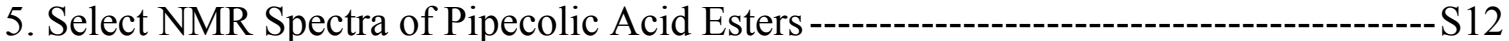

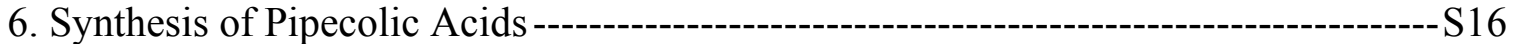

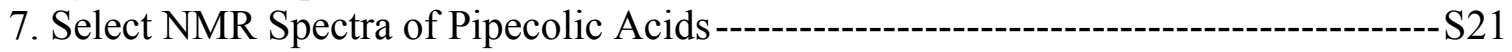

8. Synthesis of $\beta$-Carboline Amino Acids---------------------------------------S28

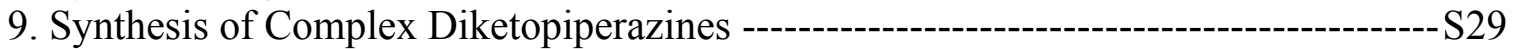

10. Select NMR Spectra of Diketopiperazines --------------------------------------------S36

11. DBU-Mediated Epimerization of Cis-Cis DKP 37 ------------------------S50

12. X-Ray Crystal Structure Analysis of Diketopiperazine 33 --------------------------S52

13. Select LC/MS/ELS Traces for Cyclodimerizations ------------------------------------S54

14. Biological Experiments: GTP $\gamma$ S protocol -------------------------------------------S57 
1. General Experimental Information: ${ }^{1} \mathrm{H}$ NMR and ${ }^{13} \mathrm{C}$ spectra were recorded at 400 $\mathrm{MHz}$ and $100.0 \mathrm{MHz}$ respectively at ambient temperature with $\mathrm{CDCl}_{3}$ as solvent unless otherwise stated. Chemical shifts are reported in parts per million relative to $\mathrm{CDCl}_{3}\left({ }^{1} \mathrm{H}, \delta\right.$ 7.26; ${ }^{13} \mathrm{C}, \delta$ 77.0). Data are reported as follows: chemical shift, multiplicity (overlp=overlapping, $\mathrm{s}=$ singlet, $\mathrm{d}=$ doublet, $\mathrm{t}=$ triplet, $\mathrm{q}=$ quartet, $\mathrm{m}=$ multiplet, $\mathrm{br}=$ broad), coupling constant, and integration. All ${ }^{13} \mathrm{C}$ NMR spectra were recorded with complete proton decoupling. Optical rotations were recorded at $589 \mathrm{~nm}$, and are reported as $[\alpha]_{\mathrm{D}}{ }^{20}$ (concentration in grams $/ 100 \mathrm{~mL}$ solvent). Analytical and preparative HPLC were performed with a mass spectrometer, diode array, and a ELS detector. An Xterra 4.6 x $30 \mathrm{~mm} \mathrm{RP} 8$ column was used for analytical HPLC and an Xterra 19 × $50 \mathrm{~mm} \mathrm{RP_{18 }}$ column was used for preparative HPLC. Analytical thin layer chromatography was performed on $0.25 \mathrm{~mm}$ silica gel 60-A plates. Methylene chloride, THF and toluene were purified by passing through two packed columns of neutral alumina. Microwave reactions were performed using the Discover ${ }^{\mathrm{TM}}$ Explorer System.

\section{2. $\operatorname{Sc}(\mathrm{OTf})_{3}$-Catalyzed $\boldsymbol{A z a - a n n u l a t i o n}$ Reactions.}

(2S,5S,6S)-methyl 6-(4-bromophenyl)-1-(2,2,2-trifluoroacetyl)-1,2,5,6-tetrahydro-5methylpyridine-2-carboxylate (trans-8a): This compound<smiles>COC(=O)C1(C(F)(F)F)C=CC(C)C(c2ccc(Br)cc2)N1C(=O)C(F)(F)F</smiles>
was synthesized using general procedure 1 described in the Experimental Section of the paper. Yield 81\%. Colorless oil; $[\alpha]_{\mathrm{D}}^{20}-82.0^{\circ}\left(\mathrm{c}=0.2, \mathrm{CHCl}_{3}\right)$; IR (thin film) $v_{\max } 2956$, 2360, 1755, 1694, 1434, 1276, 1200, 1147, 1008, $790 \mathrm{~cm}^{-1}$; ${ }^{1} \mathrm{H}$ NMR $\left(400 \mathrm{MHz}, \mathrm{CDCl}_{3}\right) \delta 7.43(\mathrm{~d}, J=8.8 \mathrm{~Hz}, 1 \mathrm{H}), 6.93$ (d, $J=8.8 \mathrm{~Hz}, 1 \mathrm{H}), 5.95(\mathrm{t}, J=10.0 \mathrm{~Hz}, 1 \mathrm{H}), 5.77(\mathrm{dd}, J=4.4,10.4 \mathrm{~Hz}, 1 \mathrm{H}), 5.14$ (brs, 1H), 4.98 (brs, $1 \mathrm{H}), 3.79(\mathrm{~s}, 3 \mathrm{H}), 2.82-2.76(\mathrm{~m}, 1 \mathrm{H}), 1.45(\mathrm{~d}, J=6.8 \mathrm{~Hz}, 3 \mathrm{H}) ;{ }^{13} \mathrm{C}$ NMR $\left(100 \mathrm{MHz}, \mathrm{CDCl}_{3}\right) . \delta 168.6,158.9,141.0,131.9,127.0,121.6,120.2,60.7,60.5,57.6$, 53.1, 36.8, 20.1; HRMS (CI/NH $) \mathrm{m} / \mathrm{z}$ calcd for $\mathrm{C}_{16} \mathrm{H}_{15} \mathrm{~F}_{3} \mathrm{NO}_{3} 405.0187$, found 405.0218.

(2S,5S,6S)-methyl 6-(2-bromophenyl)-1-(2,2,2-trifluoroacetyl)-1,2,5,6-tetrahydro-5-<smiles>CC(=O)C1C=CC([N+](=O)[O-])C(c2ccccc2Br)N1C(C)=O</smilesmethylpyridine-2-carboxylate (trans-8c): This compound was synthesized using general procedure 1 described in the Experimental Section of the paper. Yield $60 \%$. Colorless oil; $[\alpha]_{\mathrm{D}}{ }^{20}-89.6^{\mathrm{o}}\left(\mathrm{c}=0.5, \mathrm{CHCl}_{3}\right)$; IR (thin film) $v_{\max } 3357,3056$, $2958,2877,2360,1669,1465,1345,1223,1039,792 \mathrm{~cm}^{-1} ;{ }^{1} \mathrm{H}$ NMR (400 MHz, $\left.\mathrm{CDCl}_{3}\right) \delta 7.55(\mathrm{~d}, J=8.0 \mathrm{~Hz}, 1 \mathrm{H}), 7.24(\mathrm{t}, J$ $=8.0 \mathrm{~Hz}, 1 \mathrm{H}), 7.12(\mathrm{t}, \mathrm{J}=7.6 \mathrm{~Hz}, 1 \mathrm{H}), 6.85(\mathrm{~d}, J=8.0 \mathrm{~Hz}, 1 \mathrm{H}), 5.97-5.90(\mathrm{~m}, 2 \mathrm{H}), 5.50$ (s, $1 \mathrm{H}), 5.20$ (brs, $1 \mathrm{H}), 3.81(\mathrm{~s}, 3 \mathrm{H}), 2.77-2.70(\mathrm{~m}, 1 \mathrm{H}), 1.47(\mathrm{~d}, J=7.2 \mathrm{~Hz}, 3 \mathrm{H}) ;{ }^{13} \mathrm{C}$ NMR $\left(100 \mathrm{MHz}, \mathrm{CDCl}_{3}\right) \delta 168.8,142.2,133.4,131.7,129.1,127.8,126.5,121.7,119.7$, 60.6, 57.9, 53.2, 35.5, 20.2; HRMS $\left(\mathrm{CI} / \mathrm{NH}_{3}\right) \mathrm{m} / \mathrm{z}$ calcd for $\mathrm{C}_{16} \mathrm{H}_{15} \mathrm{~F}_{3} \mathrm{NO}_{3} 405.0187$, found 405.0159 . 
(2S,5S,6S)-methyl 1-(2,2,2-trifluoroacetyl)-1,2,5,6-tetrahydro-6-(3-methoxyphenyl)-<smiles>COc1cccc(C2C(C)C=CC(C(C)=O)(C(C)(F)F)N2C(=O)C(F)(F)F)c1</smiles>

5-methylpyridine-2-carboxylate (trans-8d): Anti-1 (0.60 $\mathrm{g}, 2.0 \mathrm{mmol})$ and 3-methoxy benzaldehyde $(0.29 \mathrm{~g}, 2.0$ $\mathrm{mmol})$ were dissolved in dichloromethane $(6 \mathrm{~mL})$ followed by addition of trimethylorthoformate $(1.0 \mathrm{~mL}$, $10.0 \mathrm{mmol})$. The solution was stirred at room temperature overnight $(15 \mathrm{~h})$ and concentrated under vacuum to remove all volatiles. The crude imine anti-7d was subjected to $\operatorname{Sc}(\mathrm{OTf})_{3}$ mediated azaannulation as described in general procedure 1 described in the Experimental Section of the paper. Yield $60 \%$. colorless oil; $[\alpha]_{\mathrm{D}}{ }^{20}-87.2^{\circ}\left(\mathrm{c}=0.51, \mathrm{CHCl}_{3}\right)$; IR (thin film) $v_{\max }$ $3048,2957,2840,1757,1685,1604,1450,1264,1049,888,841 \mathrm{~cm}^{-1} ;{ }^{1} \mathrm{H}$ NMR (400 $\left.\mathrm{MHz}, \mathrm{CDCl}_{3}\right) \delta 7.24(\mathrm{t}, J=8.0 \mathrm{~Hz}, 1 \mathrm{H}), 6.80(\mathrm{dd}, J=2.4,7.6 \mathrm{~Hz}, 1 \mathrm{H}), 6.64(\mathrm{~d}, J=8.0$ $\mathrm{Hz}, 1 \mathrm{H}), 6.60(\mathrm{~s}, 1 \mathrm{H}), 5.98$ (t, $J=8.4 \mathrm{~Hz}, 1 \mathrm{H}), 5.78(\mathrm{dd}, J=4.4,10.4 \mathrm{~Hz}, 1 \mathrm{H}), 5.18$ (s, $1 \mathrm{H}), 5.03(\mathrm{~d}, J=3.6 \mathrm{~Hz}, 1 \mathrm{H}), 3.81(\mathrm{~s}, 3 \mathrm{H}), 3.79(\mathrm{~s}, 3 \mathrm{H}), 2.91-2.84(\mathrm{~m}, 1 \mathrm{H}), 1.47(\mathrm{~d}, J=$ $7.2 \mathrm{~Hz}, 3 \mathrm{H}) ;{ }^{13} \mathrm{C} \mathrm{NMR}\left(100 \mathrm{MHz}, \mathrm{CDCl}_{3}\right) \delta 168.8,159.8,143.5,132.1,129.8,120.0$, $117.5,112.1,111.9,61.0,57.7,55.3,53.0,36.7,20.1 ; \mathrm{HRMS}\left(\mathrm{CI} / \mathrm{NH}_{3}\right) \mathrm{m} / \mathrm{z}$ calcd for $\mathrm{C}_{17} \mathrm{H}_{18} \mathrm{~F}_{3} \mathrm{NO}_{4} 357.1188$, found 357.1188.

(2S,5R,6R)-methyl 6-(3-bromophenyl)-1-(2,2,2-trifluoroacetyl)-1,2,5,6-tetrahydro-5-<smiles>CC(=O)N1C(c2cccc(Br)c2)C(C)C=CC1(C(C)=O)C(F)(F)F</smilesmethylpyridine-2-carboxylate (cis-8b): This compound was synthesized using general procedure 2 described in the Experimental Section of the paper. Yield 83\%. Colorless oil (ca. $1: 1.5$ rotamers, $*=\operatorname{rotamer} \mathrm{A}, * *=\operatorname{rotamer} \mathrm{B}) ;[\alpha]_{\mathrm{D}}{ }^{20}-$ $58.8^{\circ}\left(\mathrm{c}=0.8, \mathrm{CHCl}_{3}\right)$; IR (thin film) $v_{\max } 2959,1749,1693$, 1434, 1200, 1145, $786 \mathrm{~cm}^{-1} ;{ }^{1} \mathrm{H}$ NMR (400 MHz, $\left.\mathrm{CDCl}_{3}\right) \delta$ 7.57-7.55 (m, 2H), 7.43-7.7.35 (m, 4H), 7.18-7.12 (m, 2H), 6.26-6.22* (m, 1H), 6.176.12** (m, 1H), 6.03-5.98 (m, 2H), 5.79* (s, 1H), 5.46-5.44** (m, 1H), 5.08* $(\mathrm{s}, 1 \mathrm{H})$, $4.98-4.97 * *(\mathrm{~m}, 1 \mathrm{H}), 3.37 * *(\mathrm{~s}, 3 \mathrm{H}), 3.25 *(\mathrm{~s}, 3 \mathrm{H}), 2.88-2.78(\mathrm{~m}, 2 \mathrm{H}), 1.1$ * $^{* *}(\mathrm{~d}, J=7.2$ $\mathrm{Hz}, 3 \mathrm{H}), 1.14 *(\mathrm{~d}, J=6.8 \mathrm{~Hz}, 3 \mathrm{H}) ;{ }^{13} \mathrm{C} \mathrm{NMR}\left(75 \mathrm{MHz}, \mathrm{CDCl}_{3}\right) \delta 168.1,167.8,158.2$, $157.4,140.4,139.5,132.2$, 131.7, 131.4, 131.3, 130.4, 129.9, 128.1, 127.2, 122.3, 122.2, $121.4,120.3,118.3,118.0,115.4,115.1,59.2,56.3,54.0,52.7,52.6,33.0,32.0,19.9$, 19.2; HRMS $\left(\mathrm{CI} / \mathrm{NH}_{3}\right) \mathrm{m} / \mathrm{z}$ calcd for $\mathrm{C}_{16} \mathrm{H}_{15} \mathrm{~F}_{3} \mathrm{NO}_{3} 405.0187$, found 405.0181

(2S,5R,6R)-methyl 6-(2-bromophenyl)-1-(2,2,2-trifluoroacetyl)-1,2,5,6-tetrahydro-5-<smiles>[M]C1C=CC(C(C)=O)(C(F)(F)F)N(C(C)=O)C1c1ccccc1Br</smilesmethylpyridine-2-carboxylate (cis-8c): This compound was synthesized using general procedure 2 described in the Experimental Section of the paper. Yield 78\%. Colorless oil (ca. $1: 1$ rotamers, $*=\operatorname{rotamer} \mathrm{A}, * *=\operatorname{rotamer} \mathrm{B}) ;[\alpha]_{\mathrm{D}}{ }^{20}-38.7^{\circ}$ (c $=0.85, \mathrm{CHCl}_{3}$ ); IR (thin film) $v_{\max } 3383,3063,2965,1705$, 1426, 1373, 1209, 1040, $790 \mathrm{~cm}^{-1} ;{ }^{1} \mathrm{H}$ NMR (400 MHz, $\left.\mathrm{CDCl}_{3}\right) \delta 7.69(\mathrm{~d}, J=7.6 \mathrm{~Hz}$, $1 \mathrm{H}), 7.58(\mathrm{t}, J=8.0 \mathrm{~Hz}, 2 \mathrm{H}), 7.53(\mathrm{~d}, J=7.6 \mathrm{~Hz}, 1 \mathrm{H}), 7.24-7.20(\mathrm{~m}, 2 \mathrm{H}), 7.12(\mathrm{t}, J=7.6$ $\mathrm{Hz}, 2 \mathrm{H}), 6.24-6.21 *(\mathrm{~m}, 1 \mathrm{H}), 6.04-6.00^{* *}(\mathrm{~m}, 1 \mathrm{H}), 5.97$ (brs, 2H), 5.85* (s, 1H), 5.46** $(\mathrm{s}, 1 \mathrm{H}), 5.11^{* *}(\mathrm{~s}, 1 \mathrm{H}), 4.97 *(\mathrm{~d}, J=4.4 \mathrm{~Hz}, 1 \mathrm{H}), 3.37 * *(\mathrm{~s}, 3 \mathrm{H}), 3.25 *(\mathrm{~s}, 3 \mathrm{H}), 2.82-$ $2.75(\mathrm{~m}, 2 \mathrm{H}), 1.22 * *(\mathrm{~d}, J=7.2 \mathrm{~Hz}, 3 \mathrm{H}), 1.18^{*}(\mathrm{~d}, J=7.6 \mathrm{~Hz}, 3 \mathrm{H}) ;{ }^{13} \mathrm{C}$ NMR $(100 \mathrm{MHz}$, $\left.\mathrm{CDCl}_{3}\right) \delta 169.3,168.2,140.9,136.7,133.3,133.1,132.9,130.4,130.2,129.7,129.0$, 
$128.8,127.5,127.1,127.0,121.9,121.4,120.8,60.2,57.4,55.9,54.4,53.1,52.5,35.2$, 34.2, 19.2, 18.4; HRMS (CI/NH $) \mathrm{m} / \mathrm{z}$ calcd for $\mathrm{C}_{16} \mathrm{H}_{16} \mathrm{BrF}_{3} \mathrm{NO}_{3} 406.0187$, found $(\mathrm{M}+1)$ 406.0246 . 
3. Select NMR Spectra of $\boldsymbol{A z a - a n n u l a t i o n ~ P r o d u c t s . ~}$
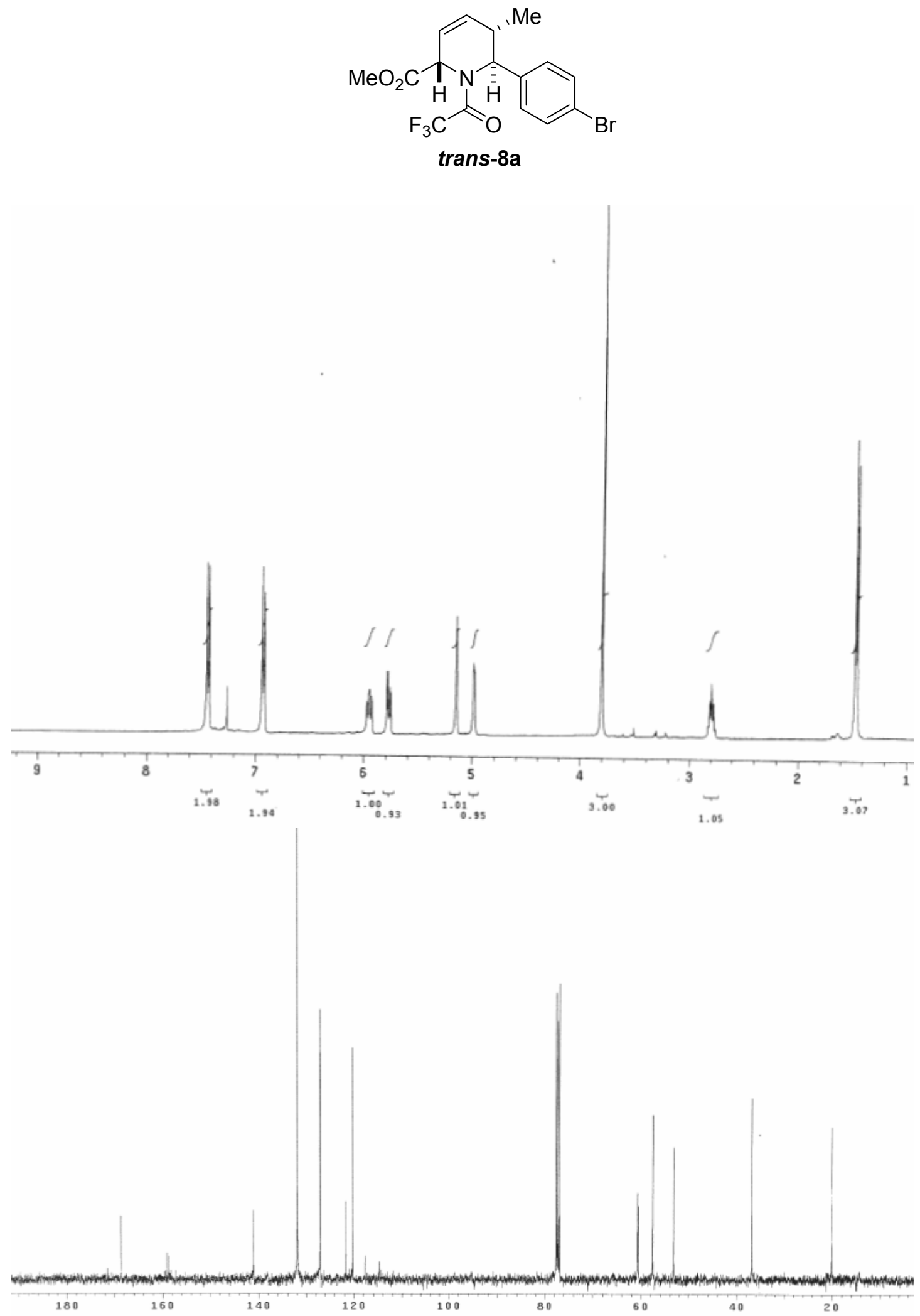

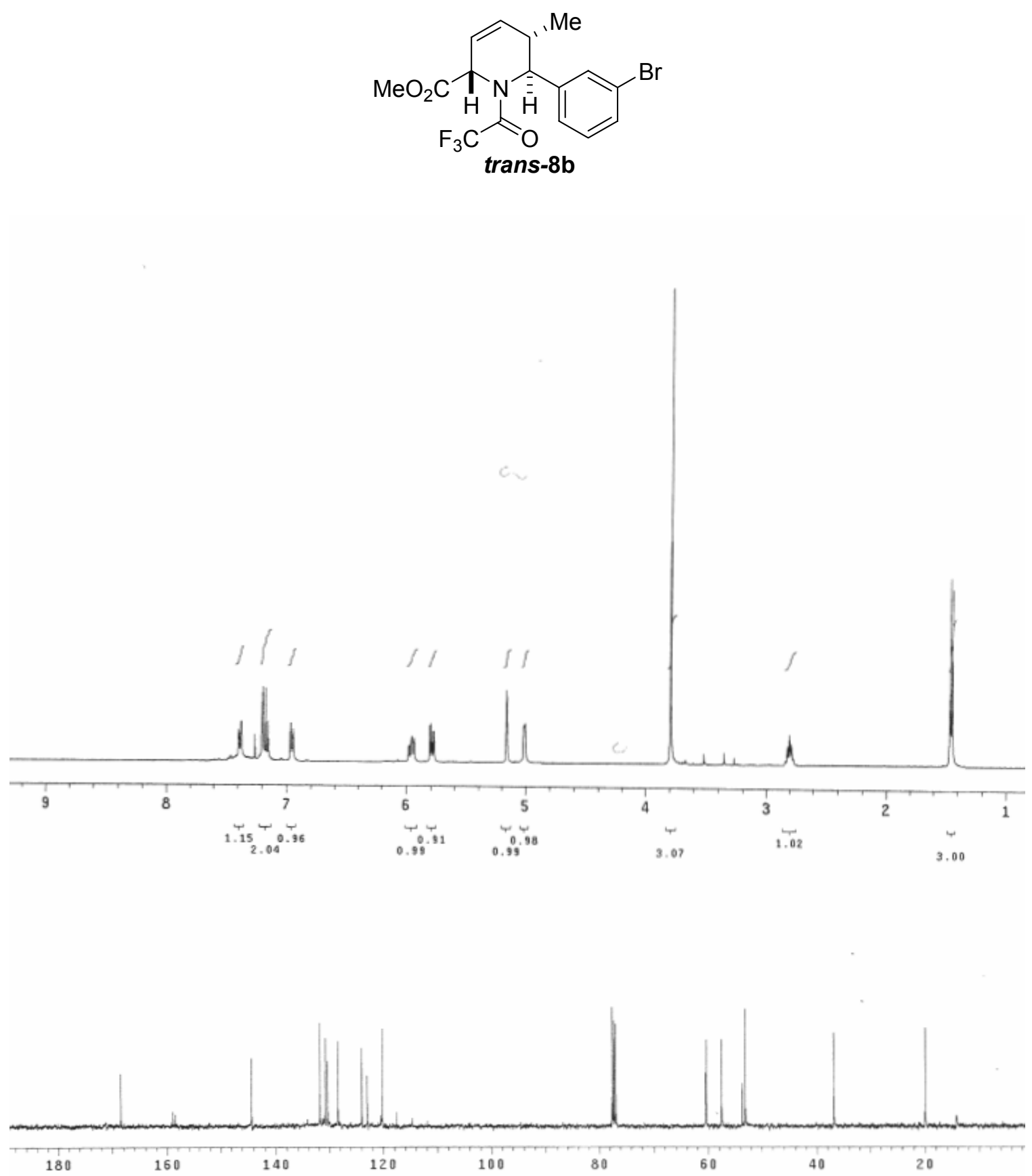

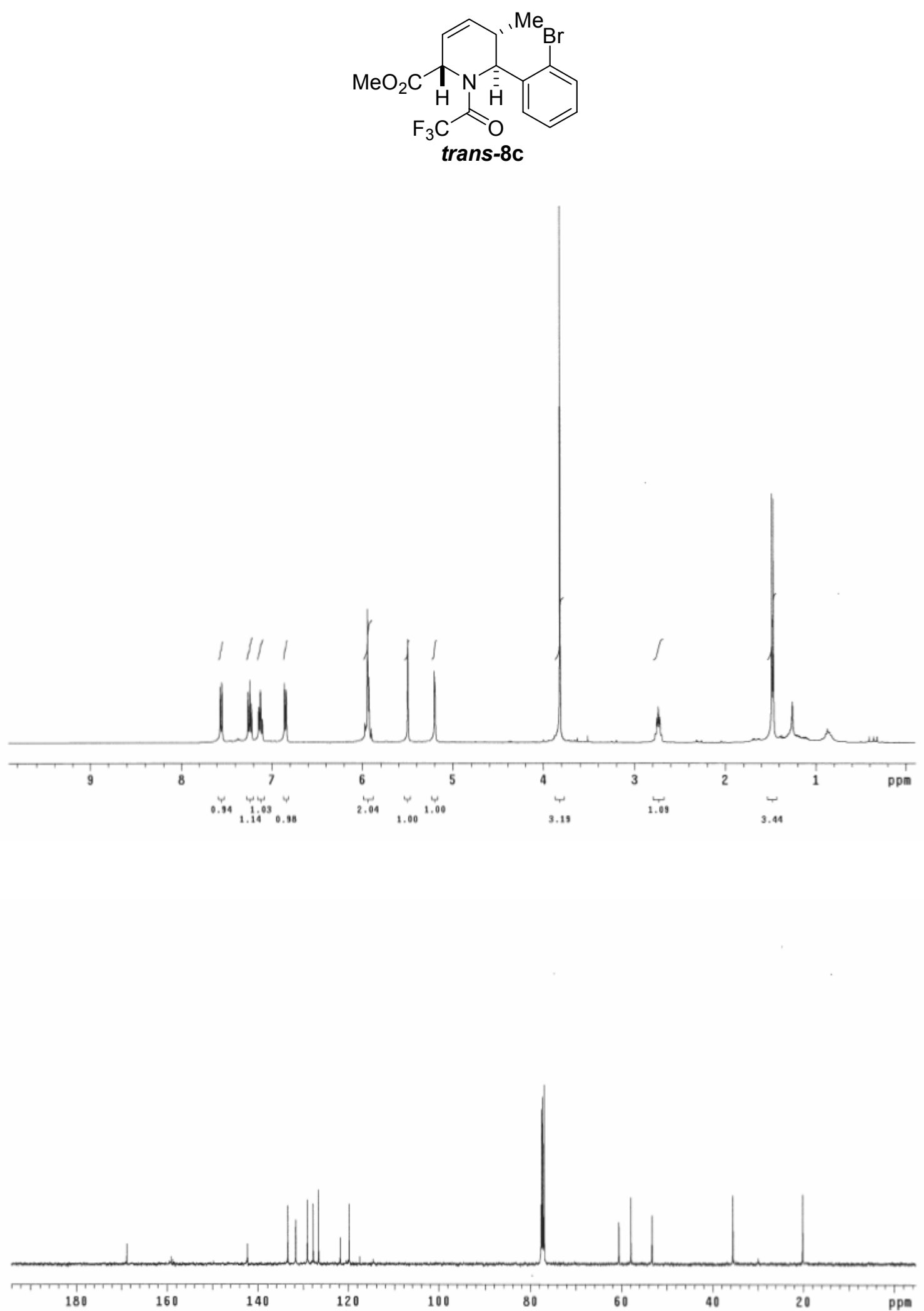

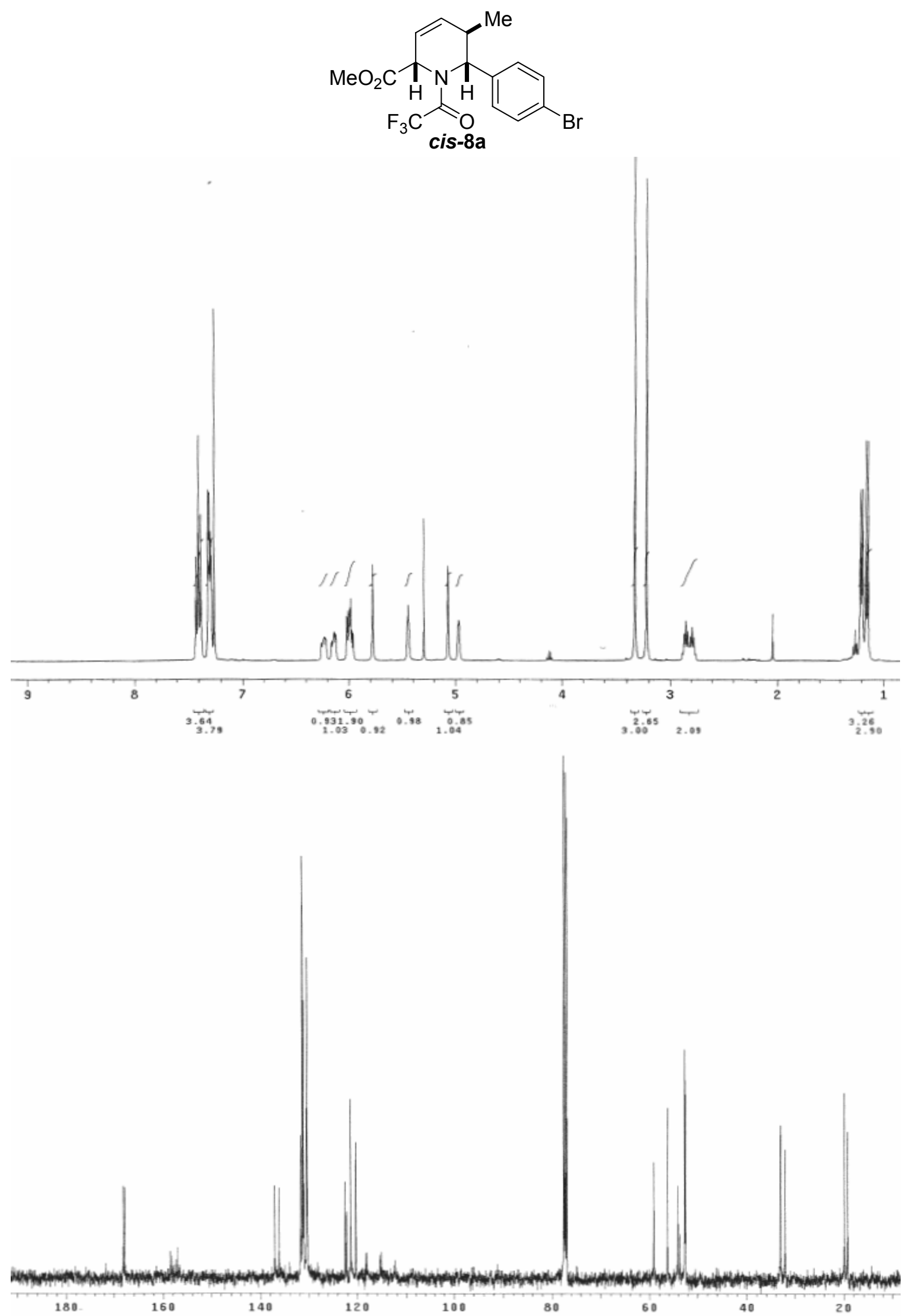

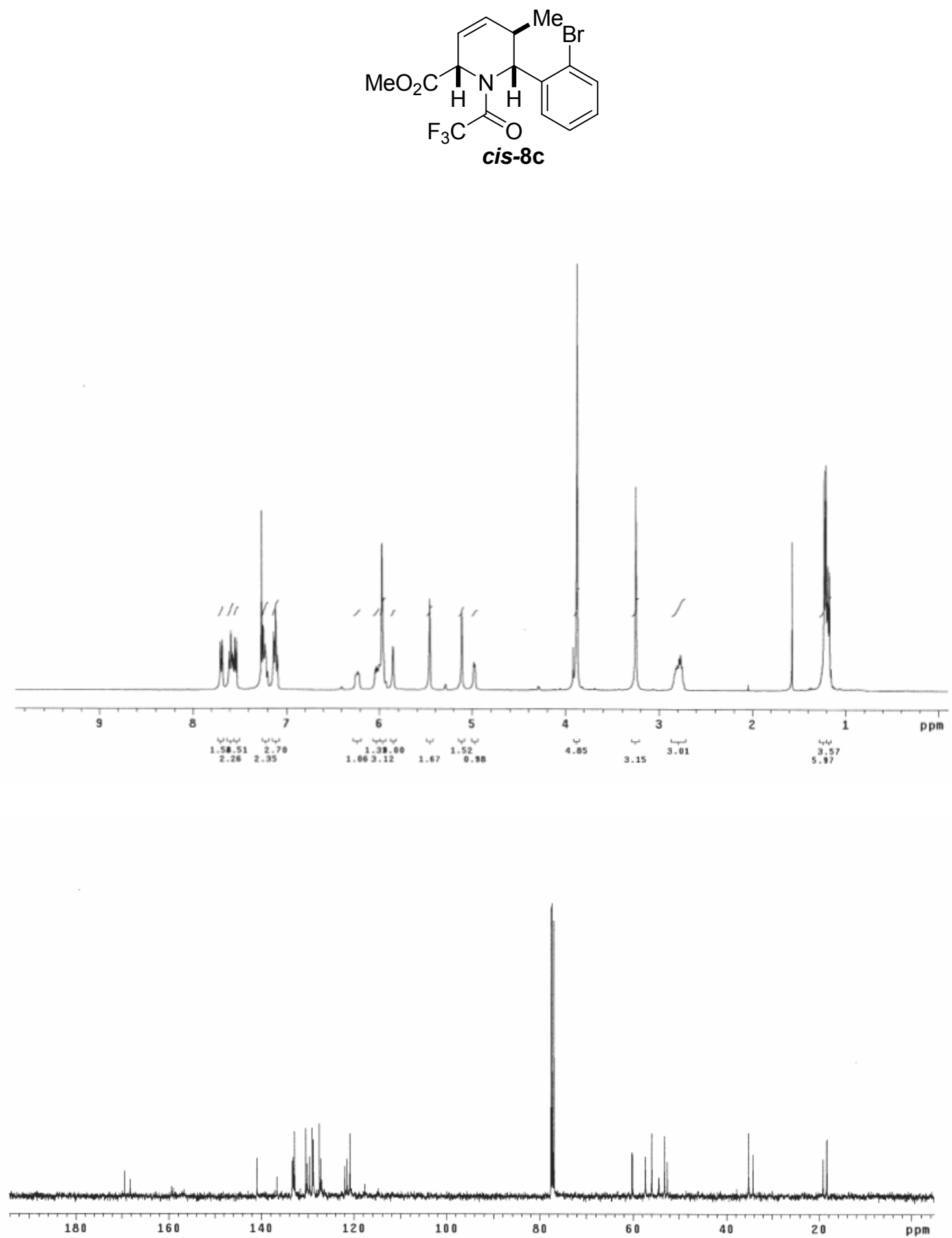


\section{Hydrogenation and Trifluoroacetamide Deprotection.}

General Procedure 6: Hydrogenation of trans-8a to trans-9a: Tetrahydropyridine trans-8a $(1.13 \mathrm{~g}, 2.7 \mathrm{mmol})$ was dissolved in ethyl acetate $(15 \mathrm{~mL})$ followed by addition of $\mathrm{PtO}_{2}$ (Adam's catalyst) $(126 \mathrm{mg}, 0.6 \mathrm{mmol})$. The suspension was purged with hydrogen and kept under hydrogen with stirring at room temperature overnight. The mixture was filtered through a tightly packed Celite ${ }^{\circledR}$ plug and washed with ethyl acetate. The filtrate was concentrated under vacuum to afford the crude product trans-9a.

General Procedure 7: Sodium borohydride reduction of trans-9a to trans-10a: A solution of trans-8a $(1.13 \mathrm{~g}, 2.7 \mathrm{mmol})$ in methanol $(16 \mathrm{~mL})$ was cooled to $0{ }^{\circ} \mathrm{C}$ for 10 min before the addition of $\mathrm{NaBH}_{4}(104 \mathrm{mg}, 2.7 \mathrm{mmol})$ in one portion as a solid. The solution was kept at $0{ }^{\circ} \mathrm{C}$ with stirring and vigorous bubbling was observed. After the bubbling ceased ( $c a .20$ minutes), TLC analysis indicated a small amount of starting material. Additional $\mathrm{NaBH}_{4}(104 \mathrm{mg}, 2.7 \mathrm{mmol})$ was added to afford complete conversion in $c a$. 20 minutes. The reaction was quenched with saturated $\mathrm{NaHCO}_{3}$ (aq.) and extracted with dichloromethane $(40 \mathrm{~mL} \times 3)$. The combined organic solution was dried over $\mathrm{NaSO}_{4}$, filtered, and concentrated. Silica gel chromatography ( $0 \%$ to $20 \%$ ethyl acetate in hexanes) afforded the desired product trans-10a as a white solid (675 mg, $78 \%$ yield).

(2S,5S,6S)-methyl 6-(4-bromophenyl)-5-methylpiperidine-2-carboxylate (trans-10a):<smiles>COC(=O)[C@@H]1CC[C@H](C)C(c2ccc(Br)cc2)N1</smiles>
This compound was synthesized using general procedures 6 and 7. Yield $78 \%$. White solid, m.p. $90-92{ }^{\circ} \mathrm{C} ;[\alpha]_{\mathrm{D}}{ }^{20}-$ $37.1^{\circ}\left(\mathrm{c}=3.18, \mathrm{CHCl}_{3}\right)$; IR (thin film) $v_{\max } 3323,3036$, 2939, 1728, 1451, 1407, 1235, 1009, $848 \mathrm{~cm}^{-1} ;{ }^{1} \mathrm{H}$ NMR $\left(400 \mathrm{MHz}, \mathrm{CDCl}_{3}\right) \delta 7.43(\mathrm{~d}, J=8.4 \mathrm{~Hz}, 2 \mathrm{H}), 7.24(\mathrm{~d}, J=$ $8.4 \mathrm{~Hz}, 2 \mathrm{H}), 3.79-3.77(\mathrm{~m}, 1 \mathrm{H}), 3.76(\mathrm{~s}, 3 \mathrm{H}), 3.38(\mathrm{~d}, J=9.6 \mathrm{~Hz}, 1 \mathrm{H}), 2.27-2.21(\mathrm{~m}, 2 \mathrm{H})$, 2.00-1.91 (m, 1H), 1.77-1.71 (m, 1H), 1.62-1.51 (m, 1H), 1.18-1.07 (m, 1H), $0.59(\mathrm{~d}, J=$ $6.0 \mathrm{~Hz}, 3 \mathrm{H}) ;{ }^{13} \mathrm{C} \mathrm{NMR}\left(100 \mathrm{MHz}, \mathrm{CDCl}_{3}\right) \delta 175.0,142.8,131.4,129.9,121.1,64.2,56.5$, 52.0, 37.1, 30.8, 26.6, 18.6 HRMS $\left(\mathrm{CI} / \mathrm{NH}_{3}\right) \mathrm{m} / \mathrm{z}$ calcd for $\mathrm{C}_{14} \mathrm{H}_{18} \mathrm{BrNO}_{2} 311.0521$, found 311.0529 .

(2S,5S,6S)-methyl 6-(3-bromophenyl)-5-methylpiperidine-2-carboxylate (trans-10b):<smiles>COC(=O)C1CCC(C)C(c2cccc(Br)c2)N1</smiles>
This compound was synthesized using general procedures 6 and 7. Yield 74\%. Colorless oil; $[\alpha]_{\mathrm{D}}{ }^{20}-25.9^{\circ}(\mathrm{c}=2.73$, $\mathrm{CHCl}_{3}$ ); IR (thin film) $v_{\max } 2951,2927,1733,1569,1457$, 1205, 1157, 994, $783 \mathrm{~cm}^{-1} ;{ }^{1} \mathrm{H}$ NMR (400 MHz, $\left.\mathrm{CDCl}_{3}\right) \delta$ $7.54(\mathrm{~s}, 1 \mathrm{H}), 7.38(\mathrm{~d}, J=8.0 \mathrm{~Hz}, 1 \mathrm{H}), 7.27(\mathrm{~d}, J=8.0 \mathrm{~Hz}$, $1 \mathrm{H}), 7.17(\mathrm{t}, J=8.0 \mathrm{~Hz}, 1 \mathrm{H}), 3.79-3.77(\mathrm{~m}, 1 \mathrm{H}), 3.76(\mathrm{~s}, 3 \mathrm{H}), 3.38(\mathrm{~d}, J=10.4 \mathrm{~Hz}, 1 \mathrm{H})$, 2.26-2.21 (m, 2H), 2.00-1.91 (m, 1H), 1.77-1.71 (m, 1H), 1.62-1.54 (m, 1H), 1.18-1.07 $(\mathrm{m}, 1 \mathrm{H}), 0.61(\mathrm{~d}, J=6.8 \mathrm{~Hz}, 3 \mathrm{H}) ;{ }^{13} \mathrm{C} \mathrm{NMR}\left(100 \mathrm{MHz}, \mathrm{CDCl}_{3}\right) \delta 175.0,146.2,131.1$, 130.6, 129.9, 127.0, 122.5, 64.3, 56.4, 52.0, 37.1, 30.7, 26.6, 18.7; HRMS $\left(\mathrm{CI} / \mathrm{NH}_{3}\right) \mathrm{m} / \mathrm{z}$ calcd for $\mathrm{C}_{14} \mathrm{H}_{18} \mathrm{BrNO}_{2} 311.0521$, found $(\mathrm{M}+1) 312.0624$. 
(2S,5R,6R)-methyl 6-(4-bromophenyl)-5-methylpiperidine-2-carboxylate (cis-10a):

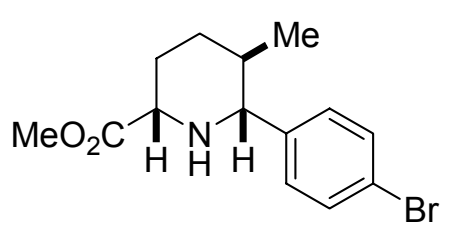

This compound was synthesized using general procedures 6 and 7. Yield $72 \%$. White solid, m.p. $90-91^{\circ} \mathrm{C} ;[\alpha]_{\mathrm{D}}{ }^{20}$ $+6.3^{\circ}\left(\mathrm{c}=2.73, \mathrm{CHCl}_{3}\right)$; IR (thin film) $v_{\max } 3322,2943$, $2847,1737,1432,1214,1125,1010,816,763 \mathrm{~cm}^{-1} ;{ }^{1} \mathrm{H}$

NMR $\left(400 \mathrm{MHz}, \mathrm{CDCl}_{3}\right) \delta 7.42(\mathrm{~d}, J=8.8 \mathrm{~Hz}, 2 \mathrm{H}), 7.22$

$(\mathrm{d}, J=8.8 \mathrm{~Hz}, 2 \mathrm{H}), 3.69(\mathrm{~s}, 3 \mathrm{H}), 3.44(\mathrm{dd}, J=2.4,11.6 \mathrm{~Hz}, 1 \mathrm{H}), 3.14(\mathrm{~d}, J=10.0 \mathrm{~Hz}$, $1 \mathrm{H}), 2.15$ (brs, $1 \mathrm{H}), 2.11-2.06(\mathrm{~m}, 1 \mathrm{H}), 1.98-1.92(\mathrm{~m}, 1 \mathrm{H}), 1.69-1.58(\mathrm{~m}, 2 \mathrm{H}), 1.27-1.17$ $(\mathrm{m}, 1 \mathrm{H}), 0.60(\mathrm{~d}, J=6.4 \mathrm{~Hz}, 3 \mathrm{H}) ;{ }^{13} \mathrm{C}$ NMR $\left(100 \mathrm{MHz}, \mathrm{CDCl}_{3}\right) \delta 173.3,142.2,131.5$, 129.8, 121.3, 68.6, 59.6, 52.1, 37.1, 33.9, 29.1, 18.4; HRMS $\left(\mathrm{CI} / \mathrm{NH}_{3}\right) \mathrm{m} / \mathrm{z}$ calcd for $\mathrm{C}_{14} \mathrm{H}_{18} \mathrm{BrNO}_{2} 311.0521$, found 311.0505 .

(2S,5R,6R)-methyl 6-(3-bromophenyl)-5-methylpiperidine-2-carboxylate (cis-10b):

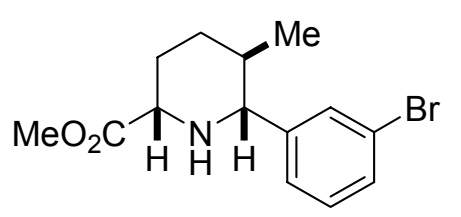

This compound was synthesized using general procedures 6 and 7. Yield $79 \%$. Colorless oil; $[\alpha]_{\mathrm{D}}{ }^{20}+9.4^{\circ}(\mathrm{c}=3.36$, $\mathrm{CHCl}_{3}$ ); IR (thin film) $v_{\max } 3331,3059,2925,2847,2804$, 1732, 1568, 1435, 1232, 1058, $786 \mathrm{~cm}^{-1} ;{ }^{1} \mathrm{H}$ NMR $(400$ $\left.\mathrm{MHz}, \mathrm{CDCl}_{3}\right) \delta 7.53(\mathrm{~s}, 1 \mathrm{H}), 7.39(\mathrm{~d}, J=8.0 \mathrm{~Hz}, 1 \mathrm{H}), 7.26$ $(\mathrm{d}, J=8.0 \mathrm{~Hz}, 1 \mathrm{H}), 7.18(\mathrm{t}, J=8.0 \mathrm{~Hz}, 1 \mathrm{H}), 7.22(\mathrm{~d}, J=8.8 \mathrm{~Hz}, 2 \mathrm{H}), 3.71(\mathrm{~s}, 3 \mathrm{H}), 3.44$ (dd, $J=2.4,11.6 \mathrm{~Hz}, 1 \mathrm{H}), 3.15$ (d, $J=10.0 \mathrm{~Hz}, 1 \mathrm{H}), 2.19$ (brs, $1 \mathrm{H}), 2.13-2.07$ (m, $1 \mathrm{H}$ ), 2.00-1.94 (m, 1H), 1.71-1.62 (m, 1H), 1.62-1.55 (m, 1H), 1.29-1.18 (m, 1H), $0.64(\mathrm{~d}, J=$ $6.8 \mathrm{~Hz}, 3 \mathrm{H}) ;{ }^{13} \mathrm{C}$ NMR $\left(100 \mathrm{MHz}, \mathrm{CDCl}_{3}\right) \delta 173.2,145.4,130.9,130.7,129.9,126.8$, $122.6,68.6,59.5,52.1,37.0,33.8,29.0,18.4 \mathrm{HRMS}\left(\mathrm{CI} / \mathrm{NH}_{3}\right) \mathrm{m} / \mathrm{z}$ calcd for $\mathrm{C}_{14} \mathrm{H}_{18} \mathrm{BrNO}_{2} 311.0521$, found (M+1) 312.0627 . 
5. Select NMR Spectra of Pipecolic Acid Esters.
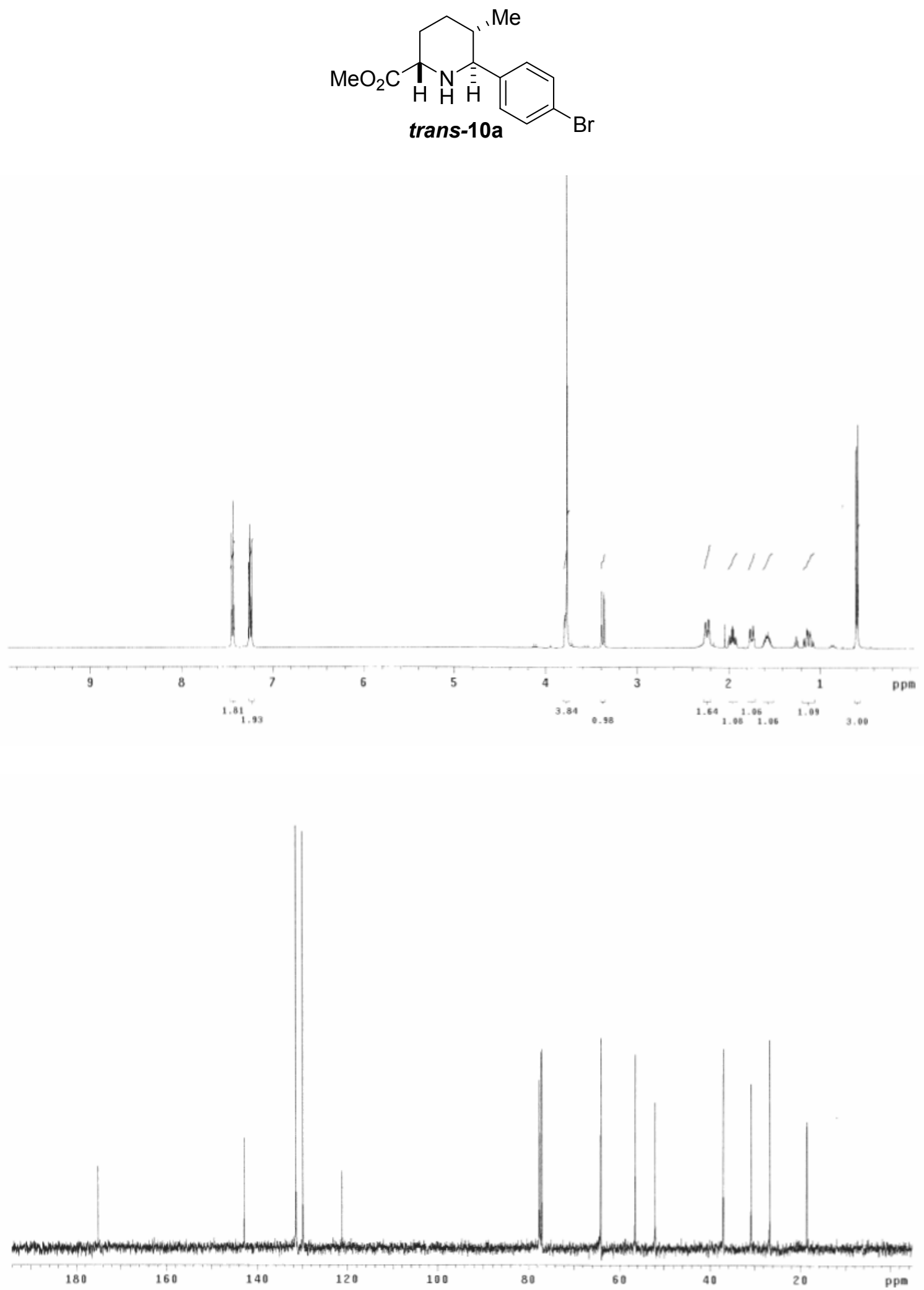

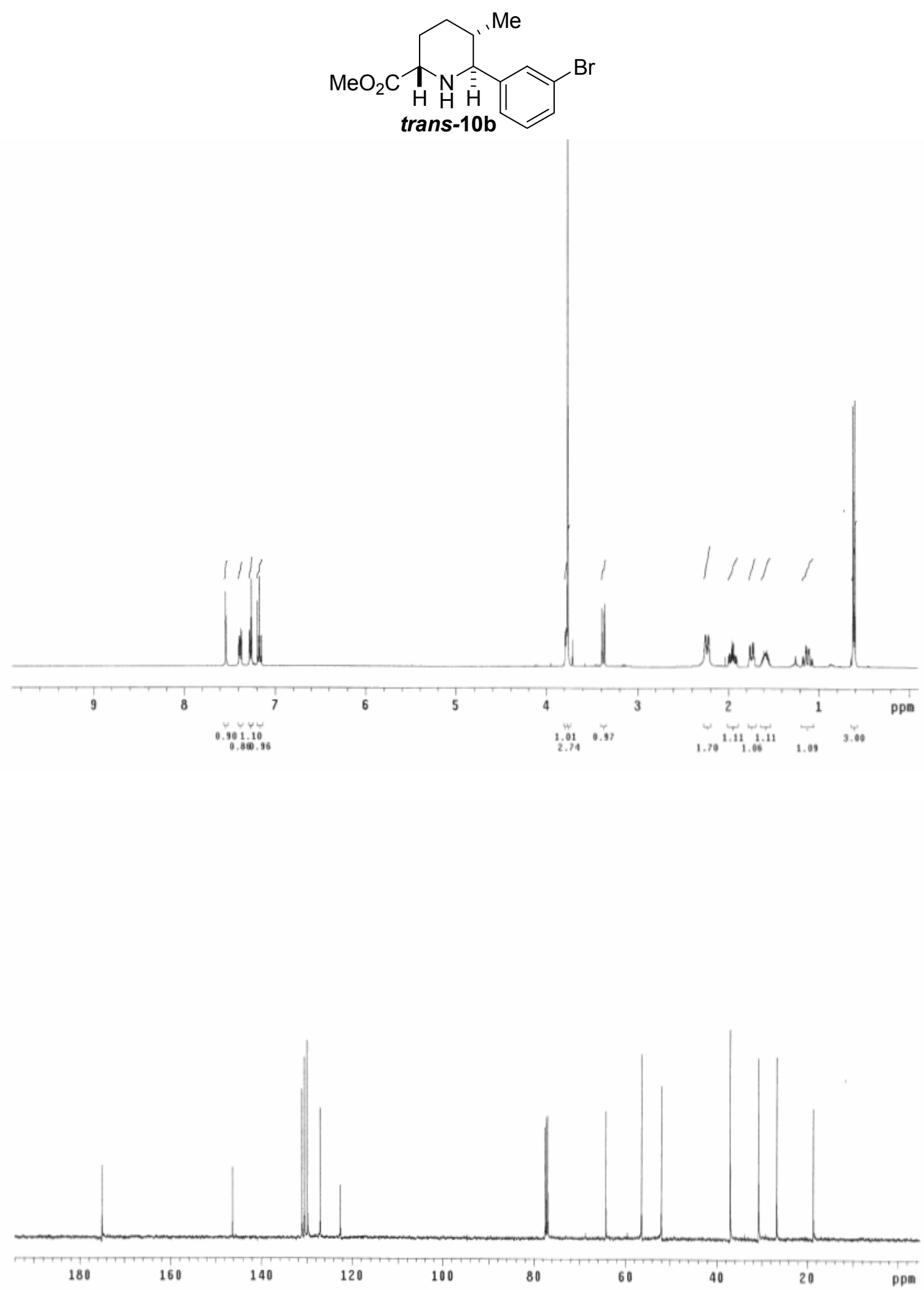

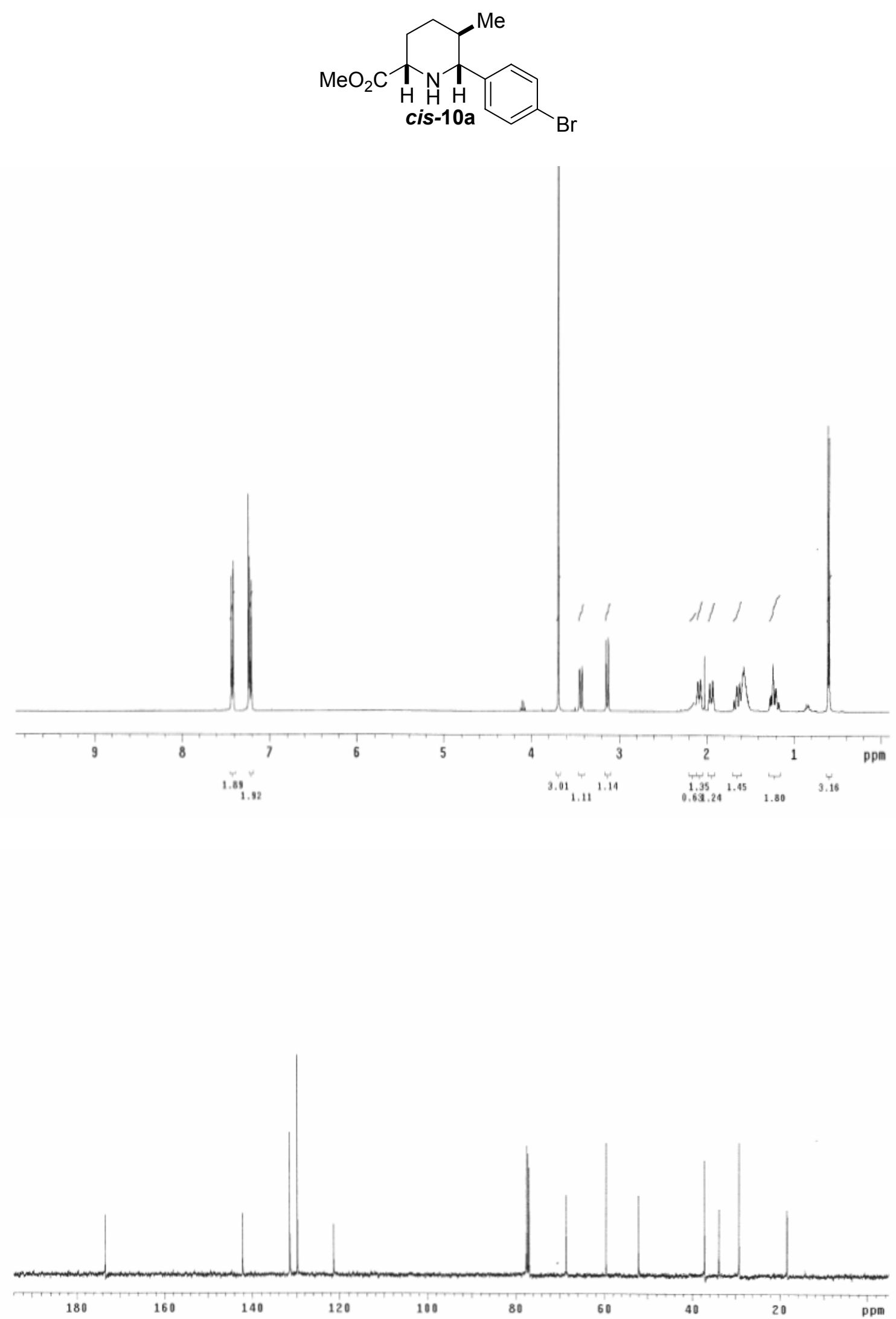

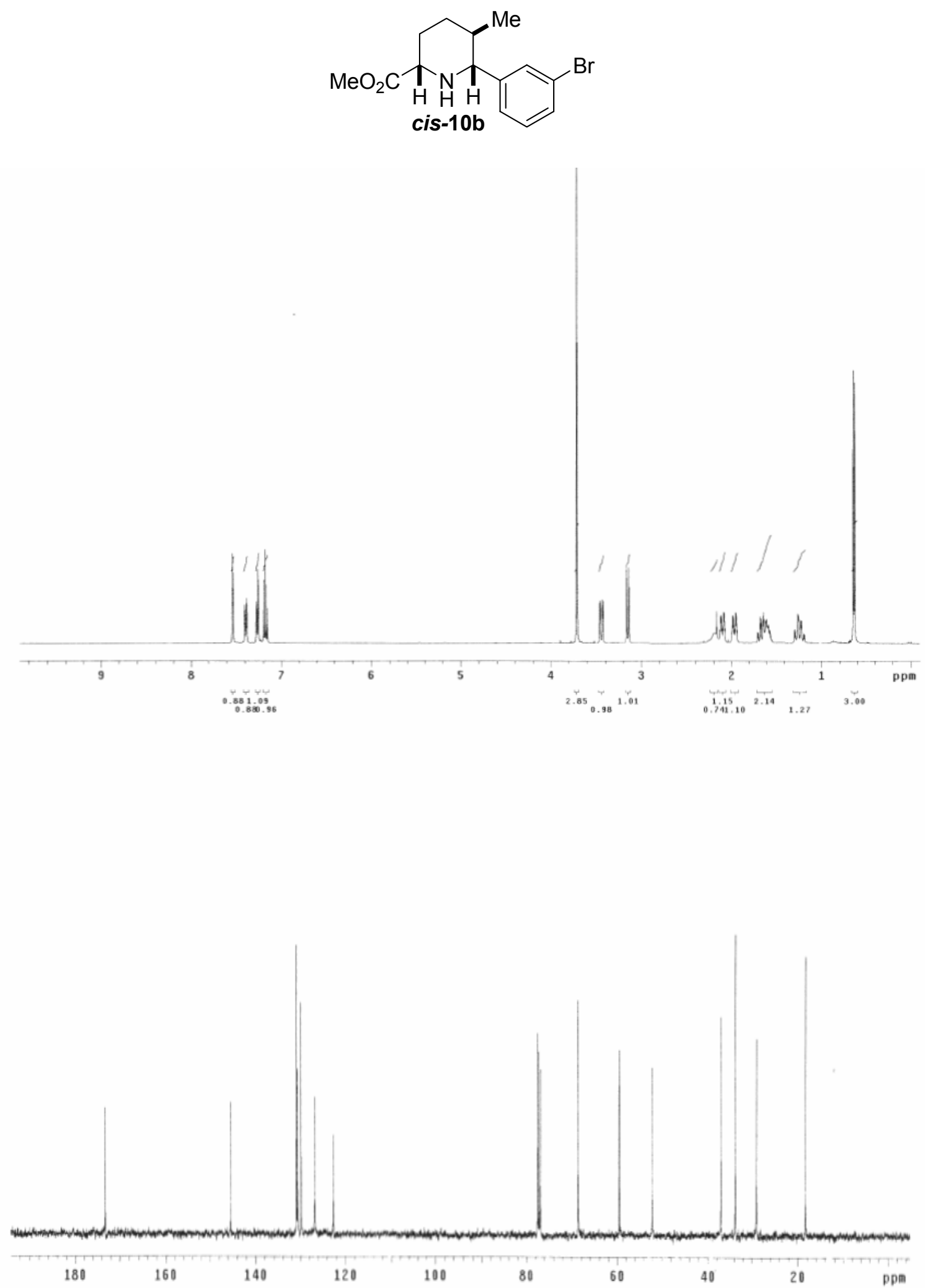


\section{Synthesis of Pipecolic Acids.}

General Procedure 8: Sonogashira cross-coupling of trans-10a and 15: ${ }^{s 1}$ Trans-10a (640 mg, $2.0 \mathrm{mmol}$ ) was weighed into a $25-\mathrm{mL}$ Schlenk tube followed by addition of tetrakis(triphenylphosphine)palladium (0) $(237 \mathrm{mg}, 0.2 \mathrm{mmol})$, triphenylphosphine (108 $\mathrm{mg}, 0.4 \mathrm{mmol}$ ) and copper (I) iodide (39 $\mathrm{mg}, 0.2 \mathrm{mmol})$. The reaction tube was placed under vacuum and then purged with argon. Anhydrous DMF $(4 \mathrm{~mL})$ and triethylamine (2 $\mathrm{mL})$ were added to the tube, and $N, N$-dimethylpropargylamine $15(1 \mathrm{~mL}, 10 \mathrm{mmol})$ was added. The tube was sealed with a Teflon valve, the mixture was degassed using freezethaw method, and then heated to $90{ }^{\circ} \mathrm{C}$ for 15 hours. The mixture was concentrated, and filtered through a Celite ${ }^{\circledR}$ plug and the plug was washed with ethyl acetate. The filtrate was concentrated to afford 23.

General Procedure 9. Copper-catalyzed amidation of trans-10b and 16: ${ }^{2}$ Trans-10b (582 $\mathrm{mg}, 1.9 \mathrm{mmol}$ ) was weighed into a $25-\mathrm{mL}$ Schlenk tube followed by addition of copper iodide (71 mg, $0.4 \mathrm{mmol})$ and $\mathrm{K}_{2} \mathrm{CO}_{3}(515 \mathrm{mg}, 3.7 \mathrm{mmol})$. The tube was purged with argon and closed with a septum. 2-Pyrrolidinone $(0.17 \mathrm{~mL}, 2.2 \mathrm{mmol})$ followed by a solution of $N, N^{\prime}$-dimethyl-1,2-ethanediamine $(79 \mu \mathrm{L}, 0.7 \mathrm{mmol})$ in toluene $(3.7 \mathrm{~mL})$ were added via syringe. The tube was sealed with Teflon valve and heated at $100{ }^{\circ} \mathrm{C}$ for 15 hours. The mixture was filtered through a Celite ${ }^{\circledR}$ plug, the plug washed with ethyl acetate, and the filtrate concentrated to afford $\mathbf{2 4}$.

(2S,5S,6S)-6-(3-allylphenyl)-5-methylpiperidine-2-carboxylic acid 48: This compound<smiles>C=CCc1cccc(C2NC(C(=O)O)CCC2C)c1</smiles>
was synthesized from trans-9b using general procedures 3 and 4 described in the Experimental Section of the paper. Yield 73\% (2 steps). Yellow solid, m.p. $230-231{ }^{\circ} \mathrm{C} ;[\alpha]_{\mathrm{D}}{ }^{20}+13.2^{\circ} \quad(\mathrm{c}=0.42$, $\mathrm{MeOH}$ ); IR (thin film) $v_{\max } 3008,2926,2847,2365$, 1588, 1377, 1323, 911, $705 \mathrm{~cm}^{-1}$; ${ }^{1} \mathrm{H}$ NMR (400 MHz, CD $\left.{ }_{3} \mathrm{OD}\right) \delta$ 7.42-7.37 (m, 1H), 7.32-7.27 (m, 3H), 6.04-5.94 (m, 1H), 5.11-5.05 (m, 2H), $4.25(\mathrm{~d}, J=11.6 \mathrm{~Hz}, 1 \mathrm{H}), 3.91$ $(\mathrm{d}, J=4.8 \mathrm{~Hz}, 1 \mathrm{H}), 3.44(\mathrm{~d}, J=6.8 \mathrm{~Hz}, 2 \mathrm{H}), 2.48(\mathrm{dd}, J=2.0,14.8 \mathrm{~Hz}, 1 \mathrm{H}), 2.09-1.95$ $(\mathrm{m}, 2 \mathrm{H}), 1.88-1.84(\mathrm{~m}, 1 \mathrm{H}), 1.38-1.34(\mathrm{~m}, 1 \mathrm{H}), 0.72(\mathrm{~d}, J=6.4 \mathrm{~Hz}, 3 \mathrm{H}) ;{ }^{13} \mathrm{C}$ NMR $(100$ $\left.\mathrm{MHz}, \mathrm{CD}_{3} \mathrm{OD}\right) \delta 175.5,142.8,138.5,137.5,130.9,130.6,129.9,127.2,116.6,64.7$, 58.7, 41.1, 35.2, 30.3, 26.1, 19.0; HRMS $\left(\mathrm{CI} / \mathrm{NH}_{3}\right) \mathrm{m} / \mathrm{z}$ calcd for $\mathrm{C}_{16} \mathrm{H}_{21} \mathrm{NO}_{2} 259.1572$, found 259.1541 .

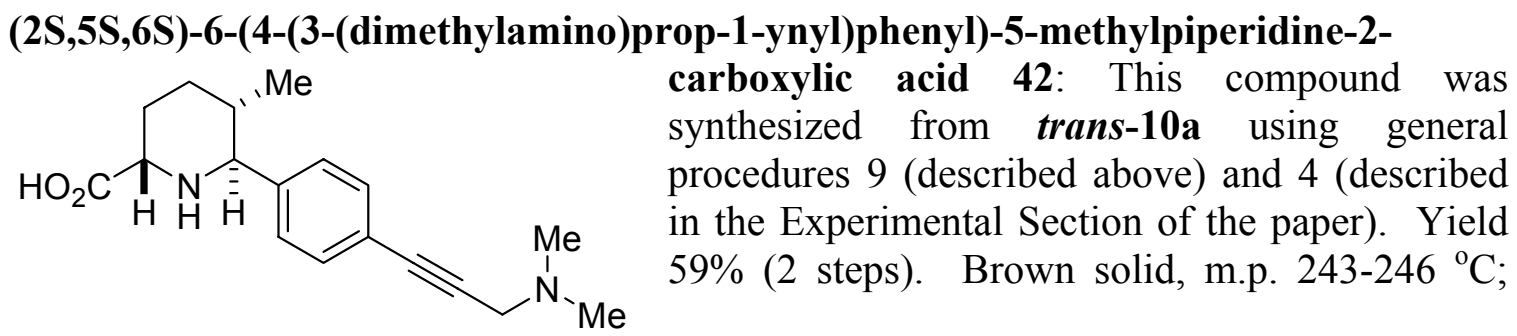

${ }^{s 1}$ Sonogashira, K. J. Organomet. Chem. 2002, 653, 46-49.

${ }^{s 2}$ Klapars, A.; Huang, X.; Buchwald, S. L. J. Am. Chem. Soc. 2002, 124, 7421-7428. 
$[\alpha]_{\mathrm{D}}^{20}-10.8^{\circ}(\mathrm{c}=0.45, \mathrm{MeOH})$; IR (thin film) $v_{\max } 2931,2848,2375,1713,1588,1380$, $1023,824 \mathrm{~cm}^{-1}$; ${ }^{1} \mathrm{H}$ NMR $\left(400 \mathrm{MHz}, \mathrm{CD}_{3} \mathrm{OD}\right) \delta 7.59(\mathrm{~d}, J=7.2 \mathrm{~Hz}, 2 \mathrm{H}), 7.49(\mathrm{~d}, J=7.2$ $\mathrm{Hz}, 2 \mathrm{H}), 4.30$ (d, $J=11.6 \mathrm{~Hz}, 1 \mathrm{H}), 3.90-3.86$ (m, ovrlap, 3H), 2.66 (brs, $6 \mathrm{H}$ ), 2.50-2.47 $(\mathrm{m}, 1 \mathrm{H}), 2.10-1.82(\mathrm{~m}, 3 \mathrm{H}), 1.41-1.28(\mathrm{~m}, 1 \mathrm{H}), 0.72(\mathrm{~d}, J=6.0 \mathrm{~Hz}, 3 \mathrm{H}) ;{ }^{13} \mathrm{C}$ NMR $(100$ $\left.\mathrm{MHz}, \mathrm{CD}_{3} \mathrm{OD}\right) \delta$ 176.0, 138.4, 133.9, 130.0, 124.2, 89.0, 81.4, 64.3, 48.2, 42.9, 35.1, 30.3, 26.1,18.9; HRMS (CI/NH $) \mathrm{m} / \mathrm{z}$ calcd for $\mathrm{C}_{18} \mathrm{H}_{24} \mathrm{~N}_{2} \mathrm{O}_{2} 300.1838$, found 300.1824.

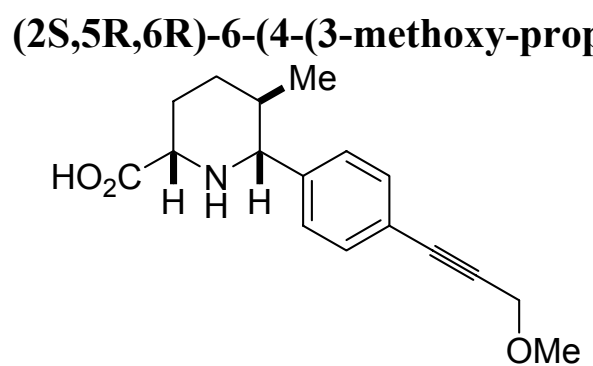

-1-ynyl)phenyl)-5-methylpiperidine-2-carboxylic acid 35: This compound was synthesized from cis-9a using general procedures 8 (described above) and 4 (described in the Experimental Section of the paper). Yield $89 \%$ (2 steps). Brown solid, m.p. $149-151{ }^{\circ} \mathrm{C}$; $[\alpha]_{\mathrm{D}}{ }^{20}+29.2\left(\mathrm{c}=0.70, \mathrm{CH}_{2} \mathrm{Cl}_{2}\right)$; IR (thin film) $v_{\max }$ $3427,3392,2970,2819,1695,1620,1395 \mathrm{~cm}^{-1} ;{ }^{1} \mathrm{H}$ NMR $\left(400 \mathrm{MHz}, \mathrm{CD}_{3} \mathrm{OD}\right) \delta 7.51(\mathrm{~s}, 4 \mathrm{H}), 4.33(\mathrm{~s}$, $2 \mathrm{H}), 3.84(\mathrm{~d}, J=10.8 \mathrm{~Hz}, 1 \mathrm{H}), 3.63-3.60(\mathrm{~m}, 1 \mathrm{H}), 3.34(\mathrm{~s}, 3 \mathrm{H}), 2.38-2.35(\mathrm{~m}, 1 \mathrm{H}), 2.15-$ $2.02(\mathrm{~m}, 1 \mathrm{H}), 1.91-1.83(\mathrm{~m}, 1 \mathrm{H}), 1.55-1.46(\mathrm{~m}, 1 \mathrm{H}), 0.73(\mathrm{~d}, J=6.0 \mathrm{~Hz}, 3 \mathrm{H}) ;{ }^{13} \mathrm{C} \mathrm{NMR}$ $\left(100 \mathrm{MHz}, \mathrm{CD}_{3} \mathrm{OD}\right) \delta 175.5,137.6,133.4,130.0,125.1,87.3,86.5,67.4,61.0 .58 .0$, 35.1, 33.6, 27.9, 18.5; HRMS $\left(\mathrm{CI} / \mathrm{NH}_{3}\right) \mathrm{m} / \mathrm{z}$ calcd for $(\mathrm{M}+\mathrm{H}) \mathrm{C}_{17} \mathrm{H}_{22} \mathrm{NO}_{3} 288.1521$, found 288.1617 .

(2S,5S,6S)-5-methyl-6-(3-(2-oxopyrrolidin-1-yl)phenyl)piperidine-2-carboxylic acid

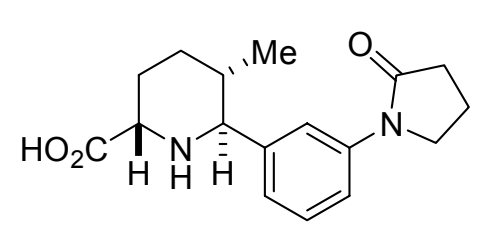

45: This compound was synthesized from trans-10b using general procedures 9 (described above) and 4 (described in the Experimental Section of the paper). Yield $87 \%(2$ steps). Light yellow solid, m.p. $255-260{ }^{\circ} \mathrm{C} ;[\alpha]_{\mathrm{D}}{ }^{20}+13.3^{\circ}$ $(\mathrm{c}=0.47, \mathrm{MeOH}) ; \mathrm{IR}$ (thin film) $v_{\max } 3375,2929,2360$, 1687, 1602, 1461, 1307, 1021, $793 \mathrm{~cm}^{-1}$; ${ }^{1} \mathrm{H}$ NMR $\left(400 \mathrm{MHz}, \mathrm{CD}_{3} \mathrm{OD}\right) \delta 7.77(\mathrm{~s}, 2 \mathrm{H})$, $7.67(\mathrm{~d}, J=8.0 \mathrm{~Hz}, 1 \mathrm{H}), 7.50(\mathrm{t}, J=8.0 \mathrm{~Hz}, 1 \mathrm{H}), 7.30(\mathrm{~d}, J=7.6 \mathrm{~Hz}, 1 \mathrm{H}), 4.30(\mathrm{~d}, J=$ $11.6 \mathrm{~Hz}, 1 \mathrm{H}), 3.98-3.91$ (m, ovrlap, 3H), 2.62-2.59 (m, 2H), 2.50-2.47 (m, 1H), 2.23$2.14(\mathrm{~m}, 2 \mathrm{H}), 2.12-2.01(\mathrm{~m}, 2 \mathrm{H}), 1.90-1.86(\mathrm{~m}, 1 \mathrm{H}), 1.42-1.32(\mathrm{~m}, 1 \mathrm{H}), 0.75(\mathrm{~d}, J=6.4$ $\mathrm{Hz}, 3 \mathrm{H}) ;{ }^{13} \mathrm{C}$ NMR $\left(100 \mathrm{MHz}, \mathrm{CD}_{3} \mathrm{OD}\right) \delta 177.3,175.5,141.6,138.0,131.1,126.0,122.8$, $121.8,64.6,50.6,35.1,33.7,30.2,26.3,21.0,19.1,18.9 ; \mathrm{HRMS}\left(\mathrm{CI} / \mathrm{NH}_{3}\right) \mathrm{m} / \mathrm{z}$ calcd for $\mathrm{C}_{17} \mathrm{H}_{23} \mathrm{~N}_{2} \mathrm{O}_{3} 303.1630$, found 303.1735.

(2S,5R,6R)-6-(4-acetamidophenyl)-5-methylpiperidine-2-carboxylic acid 47: This<smiles>CC(=O)Nc1ccc(C2NC(C(=O)O)CCC2C)cc1</smiles>
compound was synthesized from cis-10a using general procedures 9 (described above) and 4 (described in the Experimental Section of the paper). Yield $72 \%(2$ steps). Off-white solid, m.p. $227-230{ }^{\circ} \mathrm{C} ;[\alpha]_{\mathrm{D}}{ }^{20}-12.3^{\circ}$ $\left(\mathrm{c}=0.45, \mathrm{MeOH}\right.$ ); IR (thin film) $v_{\max } 3455,3341,2900$, 1428, 1313, 1156, $967 \mathrm{~cm}^{-1}$; ${ }^{1} \mathrm{H}$ NMR $(400 \mathrm{MHz}$,

$\left.\mathrm{CD}_{3} \mathrm{OD}\right) \delta 7.64(\mathrm{~d}, J=8.8 \mathrm{~Hz}, 2 \mathrm{H}), 7.45(\mathrm{~d}, J=8.8 \mathrm{~Hz}, 2 \mathrm{H}), 3.77(\mathrm{~d}, J=10.8 \mathrm{~Hz}, 1 \mathrm{H})$, $3.61(\mathrm{~d}, J=12.4 \mathrm{~Hz}, 1 \mathrm{H}), 2.38-2.34(\mathrm{~m}, 1 \mathrm{H}), 2.14-2.04(\mathrm{~m}, 2 \mathrm{H}), 2.13(\mathrm{~s}, 3 \mathrm{H}), 1.94-1.81$ $(\mathrm{m}, 1 \mathrm{H}), 1.54-1.45(\mathrm{~m}, 1 \mathrm{H}), 0.73(\mathrm{~d}, J=6.0 \mathrm{~Hz}, 3 \mathrm{H}) ;{ }^{13} \mathrm{C} \mathrm{NMR}\left(100 \mathrm{MHz}, \mathrm{CD}_{3} \mathrm{OD}\right) \delta$ 
175.6, 172.0, 141.1, 132.5, 130.2, 121.5, 67.5, 35.2, 33.7, 28.1, 24.0, 21.1, 18.5; HRMS $\left(\mathrm{CI} / \mathrm{NH}_{3}\right) \mathrm{m} / \mathrm{z}$ calcd for $\mathrm{C}_{15} \mathrm{H}_{20} \mathrm{~N}_{2} \mathrm{O}_{3} 276.1474$, found 276.1476 .

2S,5R,6R)-5-methyl-6-(3-morpholinophenyl)piperidine-2-carboxylic acid 40: ${ }^{3}$ Cis-<smiles>CC1CCC(C(=O)O)NC1c1cccc(N2CCOCC2)c1</smiles10b (439 mg, $1.4 \mathrm{mmol}$ ) was weighed into a $25-\mathrm{mL}$ Schlenk tube followed by addition of tris(dibenzylidineacetone)dipalladium (0) (129 mg, 0.1 mmol), 2-(dicyclohexylphosphino)biphenyl (197 mg, $0.6 \mathrm{mmol}$ ) and potassium phosphate $(448 \mathrm{mg}, 1.5$ mmol). The tube was purged with argon and closed with a septum. Morpholine 18 (245 $\mu \mathrm{L}, 2.8 \mathrm{mmol})$ and 1,2-dimethoxyethane $(3 \mathrm{~mL})$ were added via syringe. The tube was sealed with a Teflon valve and heated at $100{ }^{\circ} \mathrm{C}$ for 15 hours. The mixture was filtered through a Celite ${ }^{\circledR}$ plug, the plug washed with ethyl acetate. The filtrate was concentrated and the crude product $\mathbf{2 6}$ was subjected to the Amberlyst resin-mediated catch-andrelease using general procedure 4 described in the Experimental Section of the paper. Yield 58\% (2 steps). Solid, m.p. $150-153{ }^{\circ} \mathrm{C} ;[\alpha]_{\mathrm{D}}{ }^{20}-8.6^{\circ}(\mathrm{c}=0.45, \mathrm{MeOH})$; IR (thin film) $v_{\max } 2960,2854,2532,1626,1397,1247,1121,954,783 \mathrm{~cm}^{-1} ;{ }^{1} \mathrm{H}$ NMR $(400 \mathrm{MHz}$, $\left.\mathrm{CD}_{3} \mathrm{OD}\right) \delta 7.32(\mathrm{t}, J=8 \mathrm{~Hz}, 1 \mathrm{H}), 7.11(\mathrm{~s}, 1 \mathrm{H}), 7.01(\mathrm{dd}, J=2,8 \mathrm{~Hz}, 1 \mathrm{H}), 6.95(\mathrm{~d}, J=8$ $\mathrm{Hz}, 1 \mathrm{H}), 3.85-3.82(\mathrm{~m}, 4 \mathrm{H}), 3.74(\mathrm{~d}, J=11.2 \mathrm{~Hz}, 1 \mathrm{H}), 3.60(\mathrm{dd}, J=2.4,12.8 \mathrm{~Hz}, 1 \mathrm{H})$, 3.19-3.17 (m, 4H), 2.39-2.36 (m, 1H), 2.08-2.04 (m, 2H), 1.92-1.82 (m, 1H), 1.60-1.45 $(\mathrm{m}, 1 \mathrm{H}), 0.74(\mathrm{~d}, J=6.8 \mathrm{~Hz}, 3 \mathrm{H}) ;{ }^{13} \mathrm{C}$ NMR $\left(100 \mathrm{MHz}, \mathrm{CD}_{3} \mathrm{OD}\right) \delta 157.9,138.1,131.1$, 120.7, 117.7, 116.4, 68.3, 68.1, 62.6, 50.5, 35.5, 33.7, 28.2, 18.5; HRMS (CI/NH $\left.\mathrm{NH}_{3}\right) \mathrm{m} / \mathrm{z}$ calcd for $\mathrm{C}_{17} \mathrm{H}_{24} \mathrm{~N}_{2} \mathrm{O}_{3} 304.1787$, found 304.1751.

(2S,5R,6R)-6-(2-(4-methoxyphenyl)phenyl)-5-methylpiperidine-2-carboxylic acid 49:

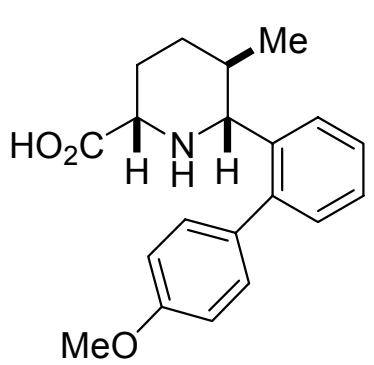
Cis-9c (30 mg, $0.07 \mathrm{mmol}$ ), 2-(dicyclohexylphosphino)-2',6'dimethoxy-1,1'-biphenyl (6 $\mathrm{mg}, 0.01 \quad \mathrm{mmol})$, tris(dibenzylineacetone)dipalladium (0) $(6.7 \mathrm{mg}, 0.01 \mathrm{mmol}), 4-$ methoxyphenylboronic acid $(22 \mathrm{mg}, 0.14 \mathrm{mmol})$ and potassium phosphate $(47 \mathrm{mg}, 0.22 \mathrm{mmol})$ were added to a Schlenk flask. Toluene $(0.5 \mathrm{~mL})$ was added and the mixture was heated at $90{ }^{\circ} \mathrm{C}$ for $15 \mathrm{~h}$. The mixture was filtered through a Celite ${ }^{\circledR}$ plug, the plug was washed with ethyl acetate. The filtrate was concentrated and the crude product 21 subjected to Amberlyst resin-mediated catch-and-release process using general procedure 4 described in the Experimental Section of the paper. Yield $87 \%$ (2 steps). Colorless oil; $[\alpha]_{\mathrm{D}}^{20}+72.5^{\circ}(\mathrm{c}=0.58, \mathrm{MeOH})$; IR (thin film) $v_{\max } 3028,2929$, $2849,2283,1579,1375,1320,1073,1013,814 \mathrm{~cm}^{-1} ;{ }^{1} \mathrm{H}$ NMR $\left(400 \mathrm{MHz}, \mathrm{CD}_{3} \mathrm{OD}\right) \delta$ $7.61(\mathrm{~d}, J=8.0 \mathrm{~Hz}, 1 \mathrm{H}), 7.49(\mathrm{t}, J=8.4 \mathrm{~Hz}, 1 \mathrm{H}), 7.44(\mathrm{t}, J=7.2 \mathrm{~Hz}, 1 \mathrm{H}), 7.35$ (brs, $2 \mathrm{H})$, $7.31(\mathrm{~d}, J=8.0 \mathrm{HZ}, 1 \mathrm{H}), 7.02(\mathrm{~d}, J=8.4 \mathrm{~Hz}, 2 \mathrm{H}), 4.52(\mathrm{~d}, J=11.6 \mathrm{~Hz}, 1 \mathrm{H}), 3.91(\mathrm{~d}, J=$ $4.8 \mathrm{~Hz}, 1 \mathrm{H}), 3.84(\mathrm{~s}, 3 \mathrm{H}), 2.43(\mathrm{~d}, J=14.4 \mathrm{~Hz}, 1 \mathrm{H}), 2.01-1.81(\mathrm{~m}, 2 \mathrm{H}), 1.72-1.68(\mathrm{~m}$, $1 \mathrm{H}), 1.16-1.05(\mathrm{~m}, 1 \mathrm{H}), 0.44(\mathrm{~d}, J=6.0 \mathrm{~Hz}, 3 \mathrm{H}) ;{ }^{13} \mathrm{C} \mathrm{NMR}\left(100 \mathrm{MHz}, \mathrm{CD}_{3} \mathrm{OD}\right) \delta 175.6$, $160.8,145.2,135.6,133.4,132.4,132.3,130.0,129.4,127.0,115.1,60.5,59.0,55.8$, $60.5,59.0,55.8,38.0,30.1,26.1,18.5 ;$ HRMS $\left(\mathrm{CI} / \mathrm{NH}_{3}\right) \mathrm{m} / \mathrm{z}$ calcd for $\mathrm{C}_{20} \mathrm{H}_{23} \mathrm{NO}_{3}$ 325.1678 , found 325.1689 .

\footnotetext{
${ }^{3}$ Wolfe, J. P.; Tomori, H.; Sadighi, J. P.; Yin, J.; Buchwald, S. L. J. Org. Chem. 2000, 65, 1158-1174.
} 
(2S,5S,6S)-6-(3-methoxyphenyl)-5-methylpiperidine-2-carboxylic acid 46: This<smiles>COc1cccc(C2NC(C(=O)O)CCC2C)c1</smiles>
compound was synthesized from trans-8d using general procedure 4 described in the Experimental Section of the paper. Yield 51\% (2 steps). Light yellow solid, m.p. 220$224^{\circ} \mathrm{C} ;[\alpha]_{\mathrm{D}}^{20}+18.2^{\circ}(\mathrm{c}=0.42, \mathrm{MeOH}) ;$ IR (thin film) $v_{\max }$ $2933,2838,2347,1607,1491,1374,1267,1041,783 \mathrm{~cm}^{-1}$;

${ }^{1} \mathrm{H}$ NMR $\left(400 \mathrm{MHz}, \mathrm{CD}_{3} \mathrm{OD}\right) \delta 7.38(\mathrm{t}, J=8.0 \mathrm{~Hz}, 1 \mathrm{H}), 7.05-7.03$ (m, ovrlap, 2H), 7.01$6.98(\mathrm{~m}, 1 \mathrm{H}), 4.24(\mathrm{~d}, J=11.6 \mathrm{~Hz}, 1 \mathrm{H}), 3.91(\mathrm{~d}, J=4.8 \mathrm{~Hz}, 1 \mathrm{H}), 3.83(\mathrm{~s}, 3 \mathrm{H}), 2.49-2.46$ (m, 1H), 2.08-1.95 (m, 2H), 1.88-1.82 (m, 1H), 1.41-1.30 (m, 1H), $0.74(\mathrm{~d}, J=6.4 \mathrm{~Hz}$, $3 \mathrm{H}) ;{ }^{13} \mathrm{C}$ NMR $\left(100 \mathrm{MHz}, \mathrm{CD}_{3} \mathrm{OD}\right) \delta 175.6,161.8,138.8,131.6,121.6,115.9,115.2$, 64.7, 58.7, 56.0, 35.3, 30.3, 26.1, 21.2, 19.0; HRMS $\left(\mathrm{CI} / \mathrm{NH}_{3}\right) \mathrm{m} / \mathrm{z}$ calcd for $\mathrm{C}_{14} \mathrm{H}_{19} \mathrm{NO}_{3}$ 250.1365 , found 250.1436 .

(2S,5S,6S)-6-(4-bromophenyl)-5-methylpiperidine-2-carboxylic acid 28: This<smiles>CC1CCC(C(=O)O)NC1c1ccc(Br)cc1</smiles>
compound was synthesized from trans-8a using general procedure 4 described in the Experimental Section of the paper. Yield 98\% (2 steps). Off-yellow solid, m.p. $>250{ }^{\circ} \mathrm{C}$, decomposed; $[\alpha]_{\mathrm{D}}{ }^{20}+2.1^{\mathrm{o}}(\mathrm{c}=0.48, \mathrm{MeOH})$; IR (thin film) $v_{\max } 3028,2929,2849,2283,1579,1375,1320,1073,1013$, $814 \mathrm{~cm}^{-1} ;{ }^{1} \mathrm{H}$ NMR $\left(400 \mathrm{MHz}, \mathrm{CD}_{3} \mathrm{OD}\right) \delta 7.65(\mathrm{~d}, J=6.8$ $\mathrm{Hz}, 1 \mathrm{H}), 7.44(\mathrm{~d}, J=6.8 \mathrm{~Hz}, 1 \mathrm{H}), 4.28(\mathrm{~d}, J=12.0 \mathrm{~Hz}, 1 \mathrm{H}), 3.91(\mathrm{~d}, J=4.8 \mathrm{~Hz}, 1 \mathrm{H})$, $2.48(\mathrm{~d}, J=14.4 \mathrm{~Hz}, 1 \mathrm{H}), 2.08-1.94(\mathrm{~m}, 2 \mathrm{H}), 1.89-1.85(\mathrm{~m}, 1 \mathrm{H}), 1.41-1.31(\mathrm{~m}, 1 \mathrm{H}), 0.73$ $(\mathrm{d}, J=6.8 \mathrm{~Hz}, 3 \mathrm{H}) ;{ }^{13} \mathrm{C}$ NMR $\left(100 \mathrm{MHz}, \mathrm{CD}_{3} \mathrm{OD}\right) \delta 172.6,136.5,133.7,131.6,124.7$, 64.0, 58.8, 35.1, 30.2, 26.2, 18.9; HRMS $\left(\mathrm{CI} / \mathrm{NH}_{3}\right) \mathrm{m} / \mathrm{z}$ calcd for $\mathrm{C}_{13} \mathrm{H}_{16} \mathrm{BrNO}_{2} 297.0364$, found 297.0331 .

(2S,5R,6R)-6-(3-bromophenyl)-5-methylpiperidine-2-carboxylic acid 39: This<smiles>CC1CCC(C(=O)O)NC1c1cccc(Br)c1</smiles>
compound was synthesized from cis-8b using general procedure 4 described in the Experimental Section of the paper. Yield 77\% (2 steps). Off-white solid, m.p. 155-157 ${ }^{\circ} \mathrm{C} ;[\alpha]_{\mathrm{D}}{ }^{20}-8.8^{\circ}(\mathrm{c}=0.45, \mathrm{MeOH})$; IR (thin film) $v_{\max } 3730$, 2960, 2363, 1603, 1395, 1250, $786 \mathrm{~cm}^{-1} ;{ }^{1} \mathrm{H}$ NMR (400 $\left.\mathrm{MHz}, \mathrm{CD}_{3} \mathrm{OD}\right) \delta 7.78(\mathrm{~s}, 1 \mathrm{H}), 7.59(\mathrm{~d}, J=7.6 \mathrm{~Hz}, 1 \mathrm{H}), 7.52(\mathrm{~d}, J=8.0 \mathrm{~Hz}, 1 \mathrm{H}), 7.37$ (t, $J=8.0 \mathrm{~Hz}, 1 \mathrm{H}), 3.84(\mathrm{~d}, J=10.8 \mathrm{~Hz}, 1 \mathrm{H}), 3.63(\mathrm{dd}, J=2.4,12.8 \mathrm{~Hz}, 1 \mathrm{H}), 2.35(\mathrm{dd}, J=$ $2.4,14.0 \mathrm{~Hz}, 1 \mathrm{H}), 2.15-2.02(\mathrm{~m}, 2 \mathrm{H}), 1.92-1.81(\mathrm{~m}, 1 \mathrm{H}), 1.55-1.44(\mathrm{~m}, 1 \mathrm{H}), 0.73(\mathrm{~d}, J=$ $6.8 \mathrm{~Hz}, 3 \mathrm{H}) ;{ }^{13} \mathrm{C}$ NMR $\left(100 \mathrm{MHz}, \mathrm{CD}_{3} \mathrm{OD}\right) \delta 175.6,139.8,133.6,132.7,132.1,128.7$, 124.0, 67.0, 62.2, 35.1, 33.6, 27.9, 18.4 .

(2S,5R,6R)-6-(4-bromophenyl)-5-methylpiperidine-2-carboxylic acid 36: This<smiles>CC1CCC(C(=O)O)NC1c1ccc(Br)cc1</smiles>
compound was synthesized from cis-8a using general procedure 4 described in the Experimental Section of the paper. Yield 88\% (2 steps). Off-white solid, m.p. 151-153 ${ }^{\circ} \mathrm{C} ;[\alpha]_{\mathrm{D}}{ }^{20}-14.0^{\circ}(\mathrm{c}=0.43, \mathrm{MeOH}) ;{ }^{1} \mathrm{H} \mathrm{NMR}(400 \mathrm{MHz}$, $\left.\mathrm{CD}_{3} \mathrm{OD}\right) \delta 7.61(\mathrm{~d}, J=8.8 \mathrm{~Hz}, 2 \mathrm{H}), 7.46(\mathrm{~d}, J=8.8 \mathrm{~Hz}$, $2 \mathrm{H}), 3.83(\mathrm{~d}, J=11.2 \mathrm{~Hz}, 1 \mathrm{H}), 3.62(\mathrm{dd}, J=3.2,12.8 \mathrm{~Hz}$, 
$1 \mathrm{H}), 2.36(\mathrm{dd}, J=2.8,14.0 \mathrm{~Hz}, 1 \mathrm{H}), 2.14-2.04(\mathrm{~m}, 2 \mathrm{H}), 1.91-1.80(\mathrm{~m}, 1 \mathrm{H}), 1.55-1.45(\mathrm{~m}$, $1 \mathrm{H}), 0.73(\mathrm{~d}, J=6.0 \mathrm{~Hz}, 3 \mathrm{H}) ;{ }^{13} \mathrm{C}$ NMR $\left(100 \mathrm{MHz}, \mathrm{CD}_{3} \mathrm{OD}\right) \delta 173.7,136.5,133.3$, $131.8,124.4,67.0,62.2,34.9,33.6,27.9,18.4$.

(2S,5S,6S)-6-(2-bromophenyl)-5-methylpiperidine-2-carboxylic acid 52: This<smiles>C[C@H]1CC[C@@H](C(=O)O)N[C@H]1c1ccccc1Br</smiles>
compound was prepared from trans-8c using general procedure 4 described in the Experimental Section of the paper. Yield $67 \%$ ( 2 steps). Light yellow solid, m.p. $>250^{\circ} \mathrm{C}$, decomposed; $[\alpha]_{\mathrm{D}}{ }^{20}+42.3^{\circ}(\mathrm{c}=0.53, \mathrm{MeOH}) ;{ }^{1} \mathrm{H}$ NMR $\left(400 \mathrm{MHz}, \mathrm{CD}_{3} \mathrm{OD}\right)$ $\delta 7.73(\mathrm{~d}, J=7.6 \mathrm{~Hz}, 1 \mathrm{H}), 7.62(\mathrm{~d}, J=8.0 \mathrm{~Hz}, 1 \mathrm{H}), 7.51$ (t, $J=$ $8.0 \mathrm{HZ}, 1 \mathrm{H}), 7.34(\mathrm{t}, J=7.6 \mathrm{~Hz}, 1 \mathrm{H}), 5.07(\mathrm{~d}, J=11.6 \mathrm{~Hz}$, $1 \mathrm{H}), 3.95(\mathrm{~d}, J=4.8 \mathrm{~Hz}, 1 \mathrm{H}), 2.50(\mathrm{~d}, J=14.0 \mathrm{~Hz}, 1 \mathrm{H}), 2.07-2.02(\mathrm{~m}, 2 \mathrm{H}), 1.90-1.86(\mathrm{~m}$, $1 \mathrm{H}), 1.47-1.37(\mathrm{~m}, 1 \mathrm{H}), 0.75(\mathrm{~d}, J=6.4 \mathrm{~Hz}, 3 \mathrm{H}) ;{ }^{13} \mathrm{C} \mathrm{NMR}\left(100 \mathrm{MHz}, \mathrm{CD}_{3} \mathrm{OD}\right) \delta 172.7$, $137.2,134.8,132.1,129.9,129.7,126.8,62.4,58.7,36.6,30.3,26.1,18.3$. 
7. Select NMR Spectra of Pipecolic Acids.
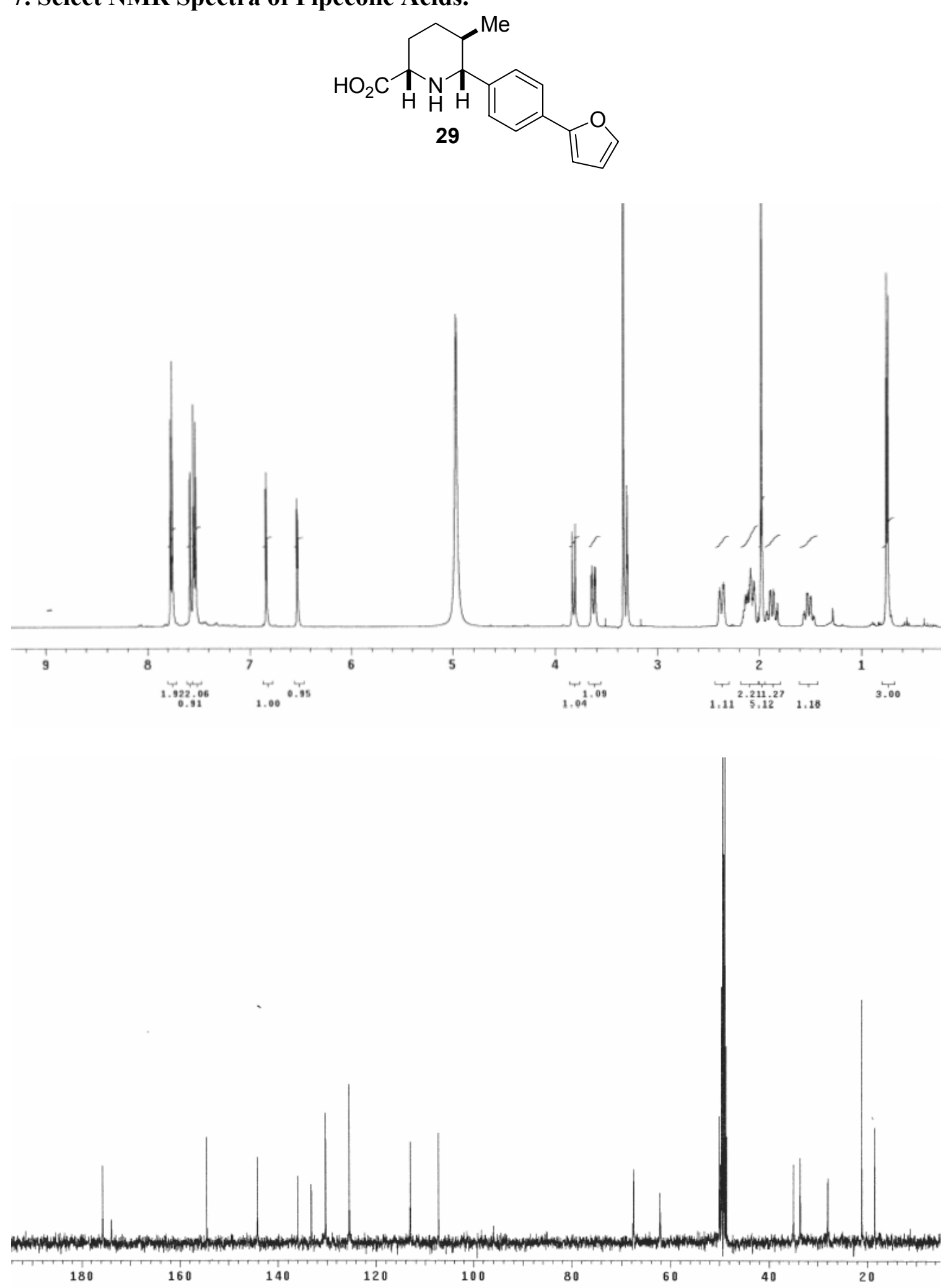

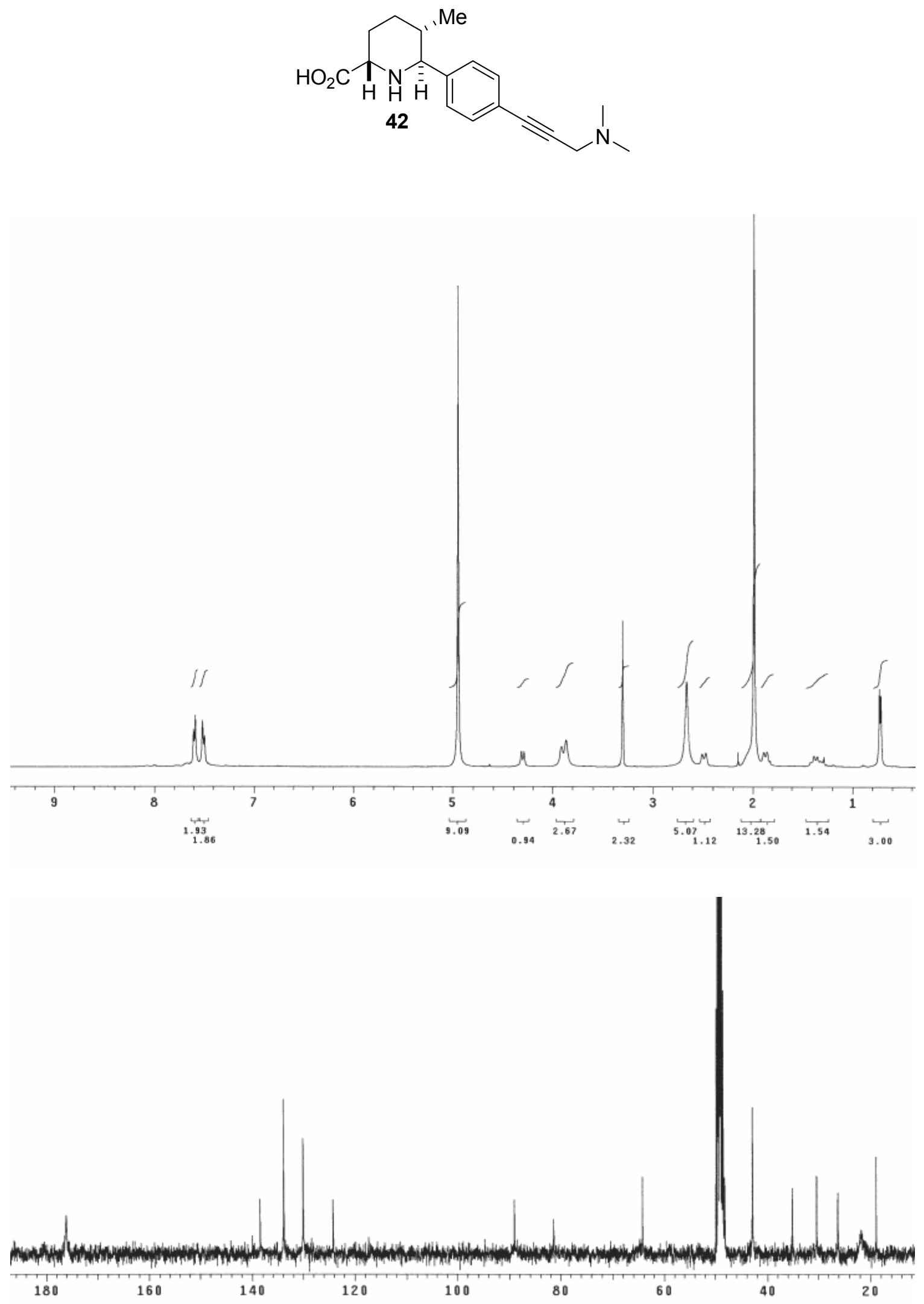

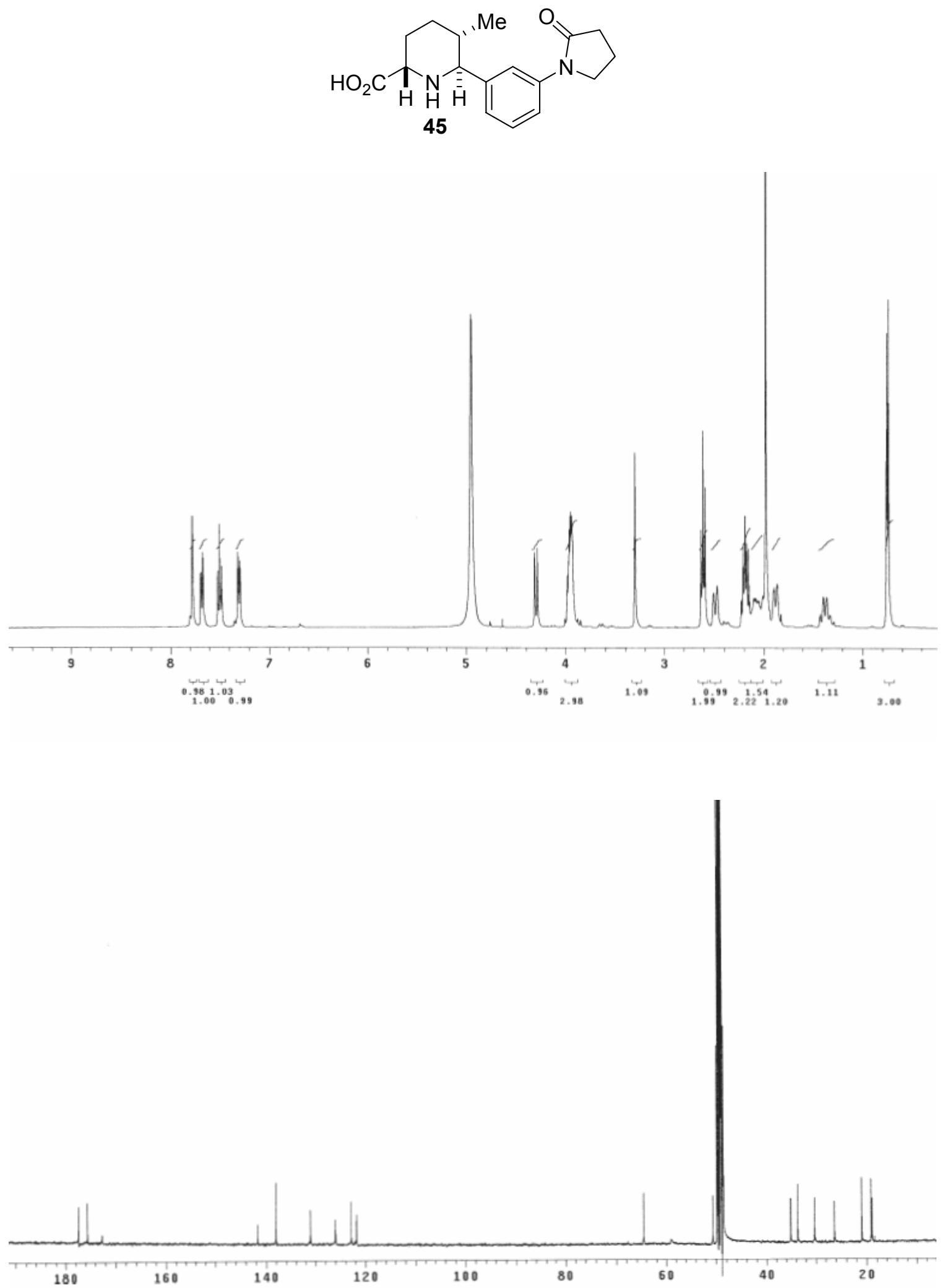

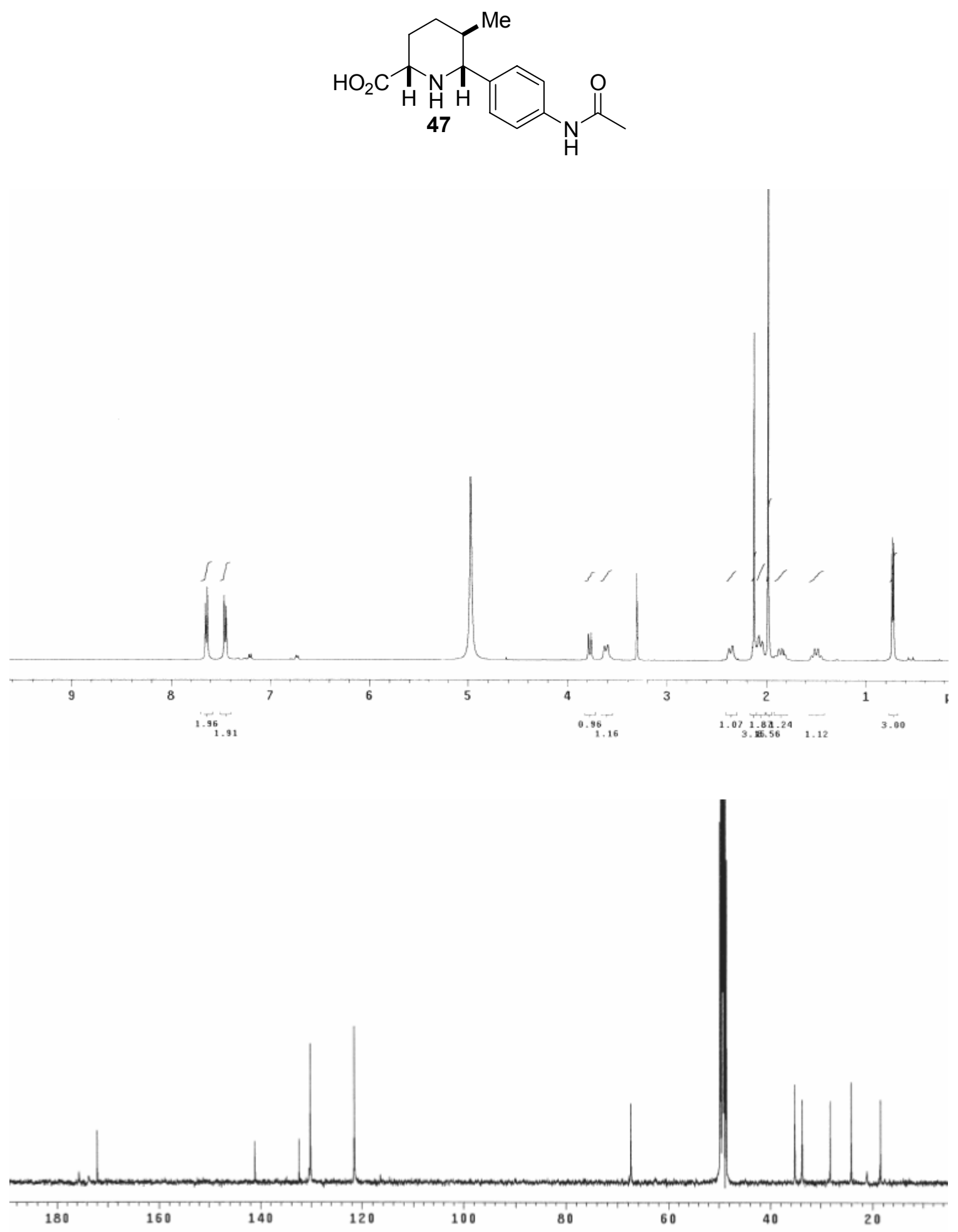

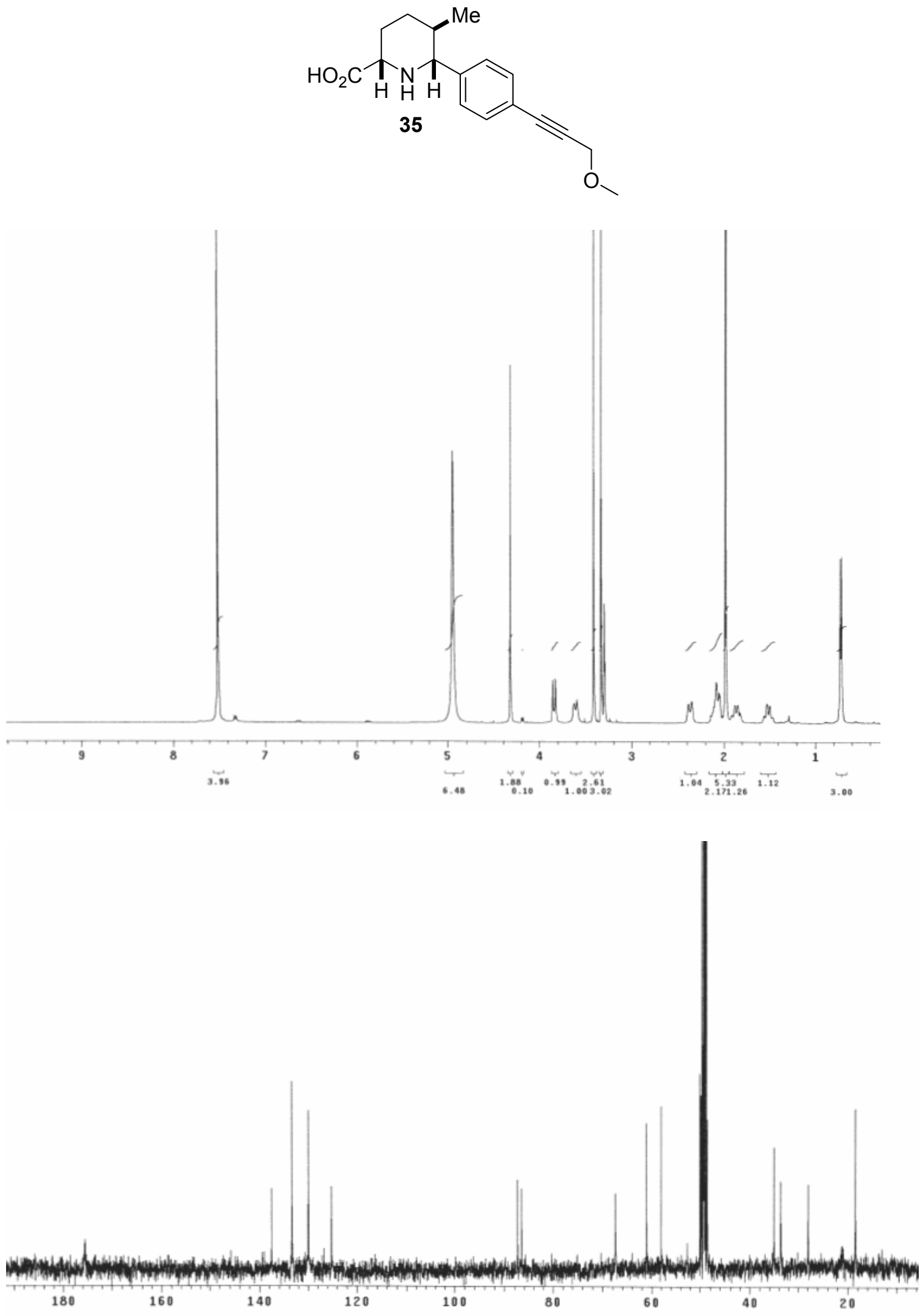

S25 

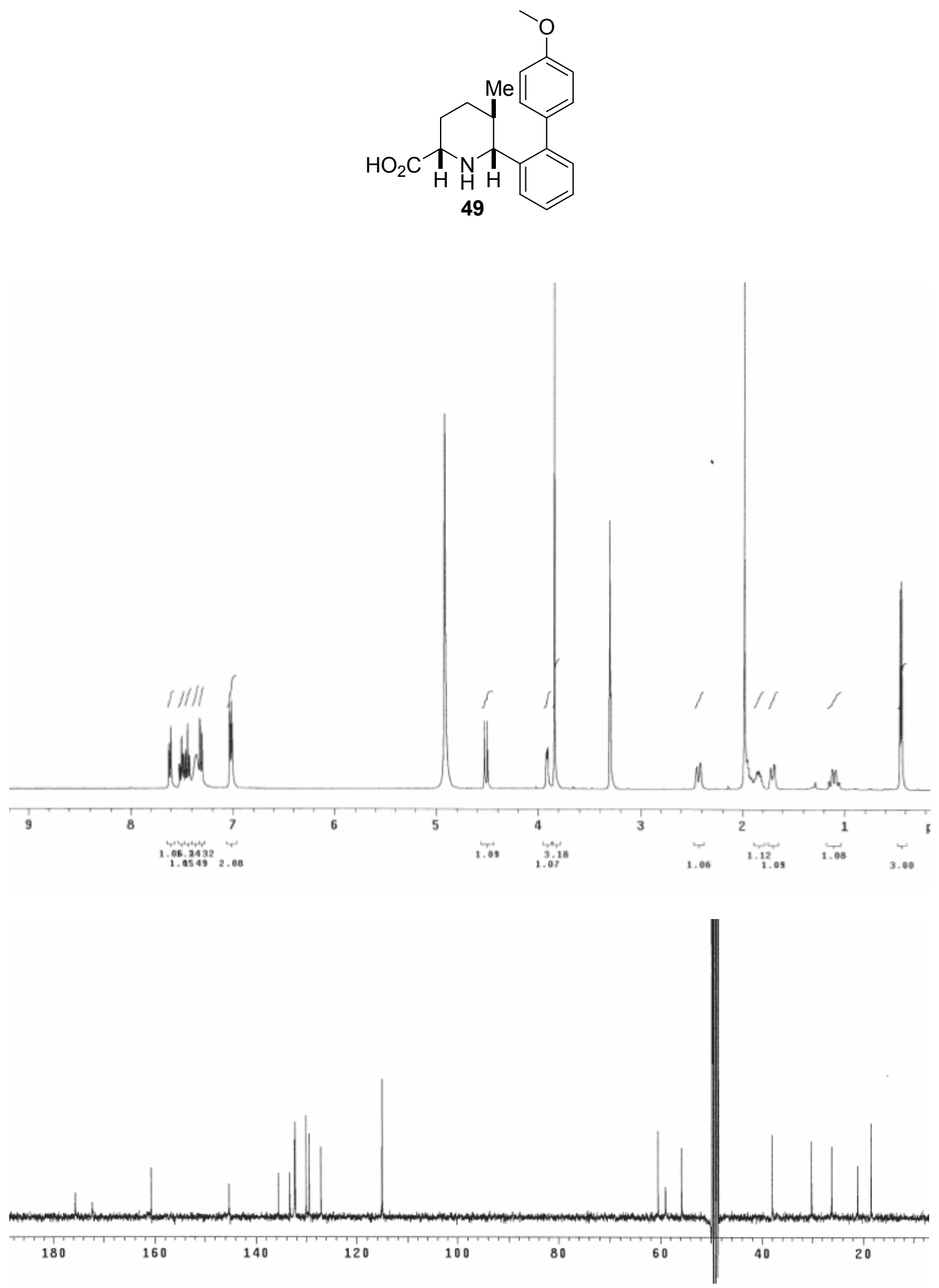

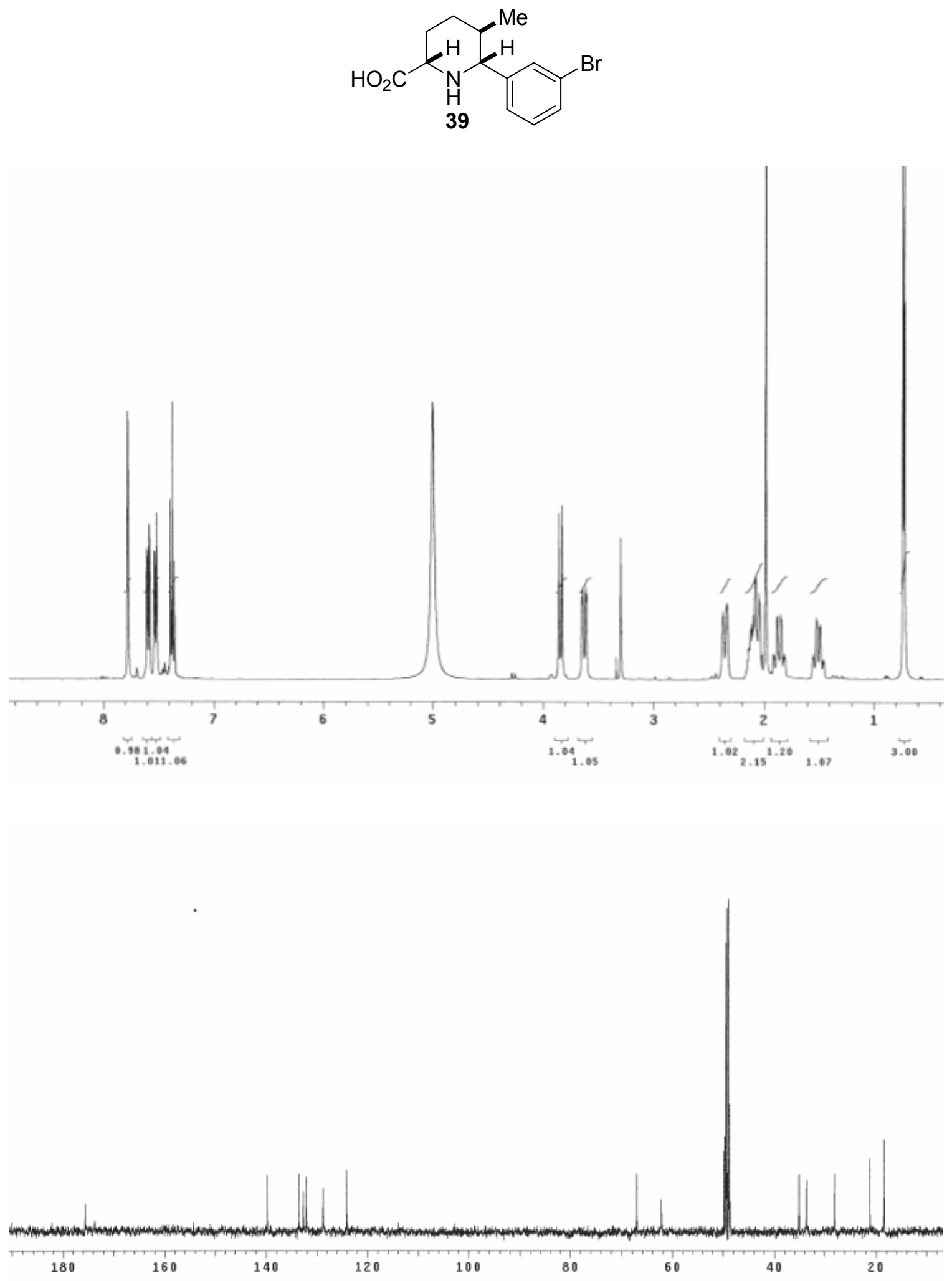


\section{Synthesis of $\beta$-Carboline Amino Acids.}

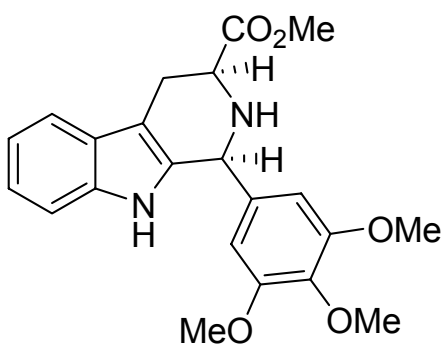

A
1) Amberlyst $\mathrm{OH}$ resin

2) $\mathrm{AcOH} / \mathrm{H}_{2} \mathrm{O}$

$86 \%$

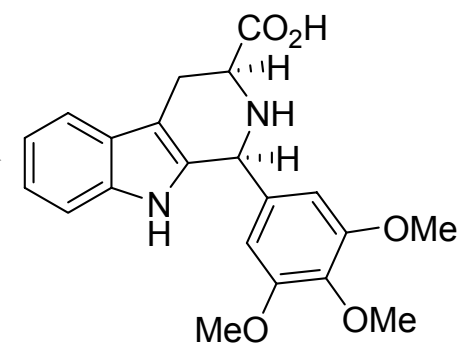

51

(1S,3S)-2,3,4,9-tetrahydro-1-(3,4,5-trimethoxyphenyl)-1H-pyrido[3,4-b]indole-3-

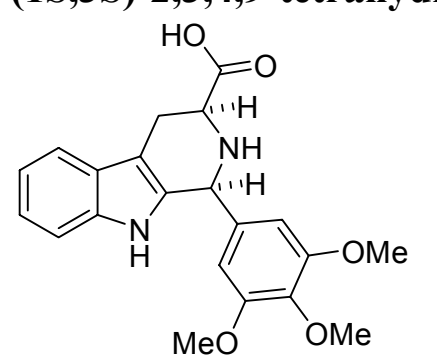

carboxylic acid 51: The previously known $^{s 4}$ tetrahydro- $\beta$ carboline methyl ester $\mathbf{A}$ was synthesized according to the literature procedure ${ }^{s 4}$ and subjected to hydrolysis by general procedure 4 described in the Experimental Section of the paper to afford 51. Yield $86 \%$. Yellow solid, m.p. $165-170^{\circ} \mathrm{C} ;[\alpha]_{\mathrm{D}}{ }^{20}$ $-60.0^{\circ}$ (c $0.45, \mathrm{MeOH}$ ); IR (thin film) $v_{\max } 3028,2929,2849$, 2283, 1579, 1375, 1320, 1073, 1013, $814 \mathrm{~cm}^{-1}$; ${ }^{1} \mathrm{H}$ NMR (400 $\left.\mathrm{MHz}, \mathrm{CD}_{3} \mathrm{OD}\right) \delta 7.53(\mathrm{~d}, J=7.2 \mathrm{~Hz}, 1 \mathrm{H}), 7.28(\mathrm{~d}, J=8.0 \mathrm{~Hz}$, $1 \mathrm{H}), 7.13(\mathrm{t}, J=7.6 \mathrm{~Hz}, 1 \mathrm{H}), 7.06(\mathrm{t}, J=7.2 \mathrm{~Hz}, 1 \mathrm{H}), 6.84(\mathrm{~s}, 2 \mathrm{H}), 5.75(\mathrm{~s}, 1 \mathrm{H}), 4.16$ (dd, $J=4.8,11.6 \mathrm{~Hz}, 1 \mathrm{H}), 3.82(\mathrm{~s}, 6 \mathrm{H}), 3.80(\mathrm{~s}, 3 \mathrm{H}), 3.52(\mathrm{dd}, J=4.8,16.0 \mathrm{~Hz}, 1 \mathrm{H}), 3.21$ (dd, $J=12.4,16.0 \mathrm{~Hz}, 1 \mathrm{H}) ;{ }^{13} \mathrm{C} \mathrm{NMR}\left(100 \mathrm{MHz}, \mathrm{CD}_{3} \mathrm{OD}\right) \delta 173.5,154.9,140.3,138.8$, 130.9 , 129.7, 127.4, 123.7, 120.7, 119.4, 112.6, 109.7, 108.4, 61.2, 60.3, 60.2, 56.8, 24.2; HRMS $\left(\mathrm{CI} / \mathrm{NH}_{3}\right) \mathrm{m} / \mathrm{z}$ calcd for $\mathrm{C}_{21} \mathrm{H}_{23} \mathrm{~N}_{2} \mathrm{O}_{5} 383.1529$, found 383.1616.

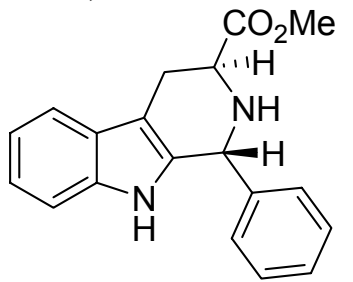

B

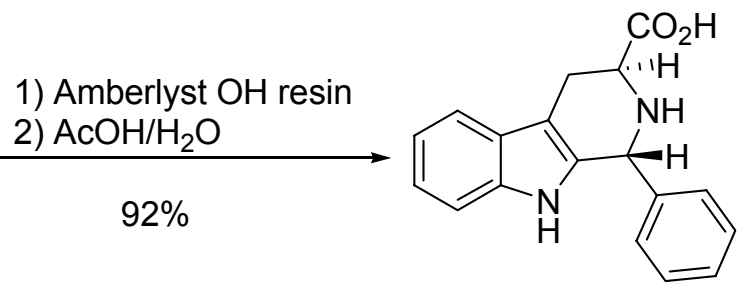

50

(1R,3S)-2,3,4,9-tetrahydro-1-phenyl-1H-pyrido[3,4-b]indole-3-carboxylic acid 50:

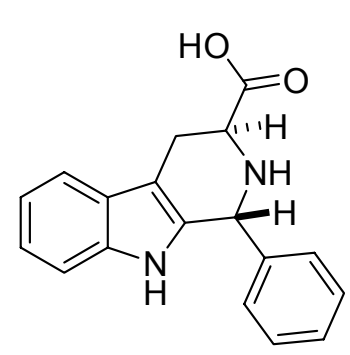

The previously known ${ }^{4}$ tetrahydro- $\beta$-carboline methyl ester $\mathbf{B}$ was synthesized according to the literature procedure ${ }^{4}$ and subjected to hydrolysis by general procedure 4 described in the Experimental Section of the paper to afford 50. Yield 92\%. Yellow oil; $[\alpha]_{\mathrm{D}}{ }^{20}-$ $52.1^{\circ}$ (c 0.52, MeOH); IR (thin film) $v_{\max } 3234,2950,2847,2337$, 1629, 1387, 1006, $976 \mathrm{~cm}^{-1} ;{ }^{1} \mathrm{H}$ NMR (400 MHz, DMSO) $\delta 10.7$ $(\mathrm{s}, 1 \mathrm{H}), 7.45(\mathrm{~d}, J=8.0 \mathrm{~Hz}, 1 \mathrm{H}), 7.35-7.28(\mathrm{~m}, 3 \mathrm{H}), 7.26-7.21(\mathrm{~m}$, $3 \mathrm{H}), 7.02(\mathrm{t}, J=8.0 \mathrm{~Hz}, 1 \mathrm{H}), 6.96(\mathrm{t}, J=8.0 \mathrm{~Hz}, 1 \mathrm{H}), 5.42(\mathrm{~s}, 1 \mathrm{H})$,

\footnotetext{
${ }^{s 4}$ Wang, H.; Usui, T.; Osada, H.; Ganesan, A. J. Med. Chem. 2000, 43, 1577-1585.
} 
$3.57(\mathrm{dd}, J=5.6,8.0 \mathrm{~Hz}, 1 \mathrm{H}), 3.06(\mathrm{dd}, J=5.6,15.2 \mathrm{~Hz}, 1 \mathrm{H}), 2.86(\mathrm{dd}, J=8.0,15.2 \mathrm{~Hz}$, $1 \mathrm{H}) ;{ }^{13} \mathrm{C}$ NMR $\left(100 \mathrm{MHz}, \mathrm{CD}_{3} \mathrm{OD}\right) \delta 173.6,138.7,136.1,131.2,130.3,128.6,127.4$, 123.7, 120.7, 119.4, 112.5, 109.1, 96.0, 56.7, 55.0, 23.9; HRMS $\left(\mathrm{CI} / \mathrm{NH}_{3}\right) \mathrm{m} / \mathrm{z}$ calcd for $\mathrm{C}_{18} \mathrm{H}_{16} \mathrm{~N}_{2} \mathrm{O}_{2}$ 292.1212, found 292.1225.

\section{Synthesis of Complex Diketopiperazines.}

Hetero-cyclodimerization of pipecolic acids $\mathbf{5 0}$ and $\mathbf{4 2}$ using general procedure 5 described in the Experimental Section of the paper afforded heterodimer 56 and homodimers 57 and $\mathbf{5 8}$.

Heterodimer 56: Yield, 23\%. Oil; $[\alpha]_{\mathrm{D}}{ }^{20}-56.1^{\circ}$ (c 0.91 , acetone); IR (thin film) $v_{\max }$

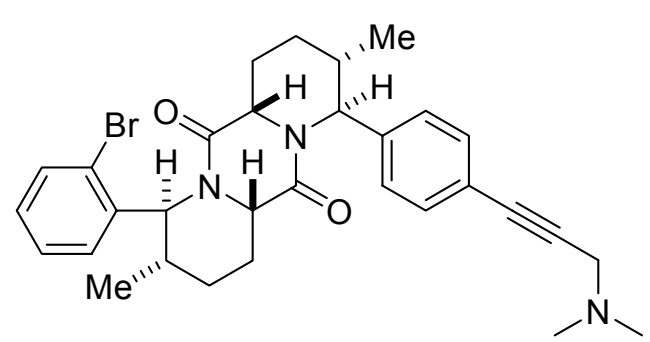
$3400,3203,2962,2867,1655,1450,1324,753$ $\mathrm{cm}^{-1} ;{ }^{1} \mathrm{H}$ NMR $\left(400 \mathrm{MHz}\right.$, acetone- $\left.d_{6}\right) \delta 7.64(\mathrm{~d}$, $J=8.0 \mathrm{~Hz}, 1 \mathrm{H}), 7.61(\mathrm{~d}, J=8.0 \mathrm{~Hz}, 1 \mathrm{H}), 7.47-$ $7.34(\mathrm{~m}, 5 \mathrm{H}), 7.19(\mathrm{t}, J=8.0 \mathrm{~Hz}, 1 \mathrm{H}), 5.61(\mathrm{~s}$, $1 \mathrm{H}), 5.37$ (d, $J=6.0 \mathrm{~Hz}, 1 \mathrm{H}), 4.63$ (dd, $J=4.8$, $12.0 \mathrm{~Hz}, 1 \mathrm{H}), 3.78(\mathrm{~d}, J=11.6 \mathrm{~Hz}, 1 \mathrm{H}), 3.43$ (s, $2 \mathrm{H}), 2.96$ (brs, $1 \mathrm{H}), 2.78-2.72(\mathrm{~m}, 1 \mathrm{H}), 2.46-2.35$ $(\mathrm{m}, 2 \mathrm{H}), 2.28(\mathrm{~s}, 6 \mathrm{H}), 2.03-1.98(\mathrm{~m}, 2 \mathrm{H}), 1.90-$ $1.84(\mathrm{~m}, 2 \mathrm{H}), 1.62-1.57(\mathrm{~m}, 2 \mathrm{H}), 1.16(\mathrm{~d}, J=6.8 \mathrm{~Hz}, 3 \mathrm{H}), 1.07(\mathrm{~d}, J=7.2 \mathrm{~Hz}, 3 \mathrm{H}) ;{ }^{13} \mathrm{C}$ NMR $\left(100 \mathrm{MHz}\right.$, acetone- $\left.d_{6}\right) \delta 166.4,166.0,141.6,141.4,139.6,134.2,132.8,129.7$, 129.4, 128.8, 128.0, 124.6, 123.0, 86.0, 85.4, 60.9, 57.4, 55.6, 55.1, 48.8, 44.3, 33.3, 28.9, 27.6, 27.3, 26.6, 18.7, 18.2; HRMS $\left(\mathrm{CI} / \mathrm{NH}_{3}\right) \mathrm{m} / \mathrm{z}$ calcd for $\mathrm{C}_{31} \mathrm{H}_{36} \mathrm{BrN}_{3} \mathrm{O}_{2}$ 561.1991, found 561.1998 .

Homodimer 57: Yield, $16 \%$. Off-white solid, m.p. $142-144^{\circ} \mathrm{C}$; $[\alpha]_{\mathrm{D}}{ }^{20}-258.7^{\circ}$ (c 0.58 ,

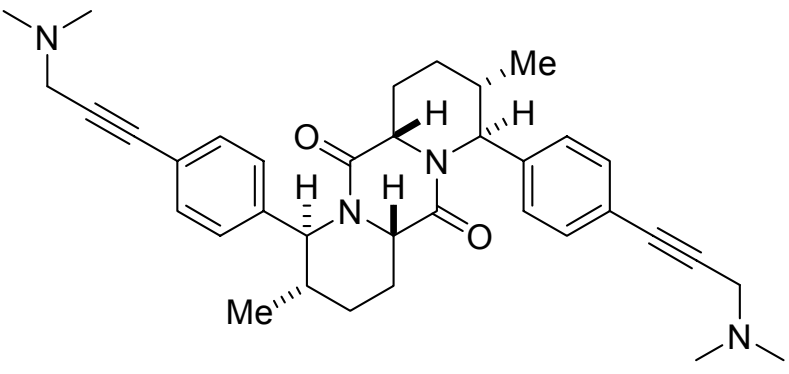
acetone); IR (thin film) $v_{\max } 3528,2938$, $2768,1636,1460,1325,863 \mathrm{~cm}^{-1} ;{ }^{1} \mathrm{H}$ NMR $\left(400 \mathrm{MHz}\right.$, acetone- $\left.d_{6}\right) \delta 7.46(\mathrm{~d}$, $J=8.8 \mathrm{~Hz}, 4 \mathrm{H}), 7.38(\mathrm{~d}, J=8.8 \mathrm{~Hz}$, $4 \mathrm{H}), 5.61(\mathrm{~s}, 2 \mathrm{H}), 3.92(\mathrm{dd}, J=2.8,11.6$ $\mathrm{Hz}, 2 \mathrm{H}), 3.4$ (s, 4H), 2.83-2.75 (m, 4H), $2.28(\mathrm{~s}, 12 \mathrm{H}), 2.15-2.11(\mathrm{~m}, 2 \mathrm{H}), 2.00-$ $1.92(\mathrm{~m}, 2 \mathrm{H}), 1.66-1.63(\mathrm{~m}, 2 \mathrm{H}), 1.17$

$(\mathrm{d}, J=6.8 \mathrm{~Hz}, 6 \mathrm{H}) ;{ }^{13} \mathrm{C}$ NMR $\left(100 \mathrm{MHz}\right.$, acetone-d $\left.{ }_{6}\right) \delta 166.1,139.6,132.9,128.1,123.1$, 86.2, 85.4, 57.5, 55.2, 48.9, 44.4, 28.0, 26.8, 18.3; HRMS $\left(\mathrm{CI} / \mathrm{NH}_{3}\right) \mathrm{m} / \mathrm{z}$ calcd for $\mathrm{C}_{36} \mathrm{H}_{45} \mathrm{~N}_{4} \mathrm{O}_{2}$ 565.3464, found 565.3500.

Homodimer 58: Yield, $16 \%$. Off-white solid, m.p. $172-175^{\circ} \mathrm{C} ;[\alpha]_{\mathrm{D}}^{20}+50.9^{\circ}$ (c 1.32,

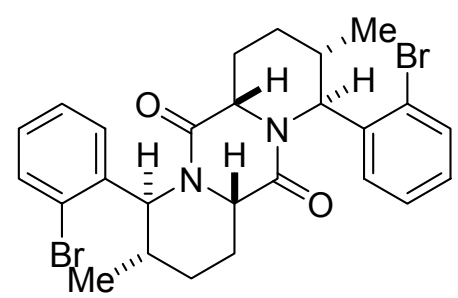
ethyl acetate); IR (thin film) $v_{\max } 2923,2852,2360,2338$, 1659, 1460, $737 \mathrm{~cm}^{-1} ;{ }^{1} \mathrm{H}$ NMR $\left(400 \mathrm{MHz}, \mathrm{CDCl}_{3}\right) \delta 7.56$ $(\mathrm{d}, J=7.6 \mathrm{~Hz}, 2 \mathrm{H}), 7.30-7.24(\mathrm{~m}, 4 \mathrm{H}), 7.13-7.08(\mathrm{~m}, 2 \mathrm{H})$, $5.37(\mathrm{~d}, J=7.2 \mathrm{~Hz}, 2 \mathrm{H}), 4.43(\mathrm{dd}, J=4.8,12.0 \mathrm{~Hz}, 2 \mathrm{H})$, 2.46-2.38 (m, 2H), 2.36-2.28 (m, 2H), 2.01-1.84 (m, 4H), $1.58-1.49(\mathrm{~m}, 2 \mathrm{H}), 1.06(\mathrm{~d}, J=6.8 \mathrm{~Hz}, 6 \mathrm{H}) ;{ }^{13} \mathrm{C}$ NMR $(100$ 
$\left.\mathrm{MHz}, \mathrm{CDCl}_{3}\right) \delta 166.1,139.9,133.9,129.0,127.9,127.8,124.2,60.6,54.8,32.5,27.8$, $26.8,18.5$.

Hetero-cyclodimerization of pipecolic acids $\mathbf{4 5}$ and 29 using general procedure 5 described in the Experimental Section of the paper afforded heterodimer 59 and homodimers 60 and 61.

Heterodimer 59: Yield, 31\%. Oil, $[\alpha]_{D}^{20}-65.9^{\circ}$ (c 1.1, acetone); IR (thin film) $v_{\max }$

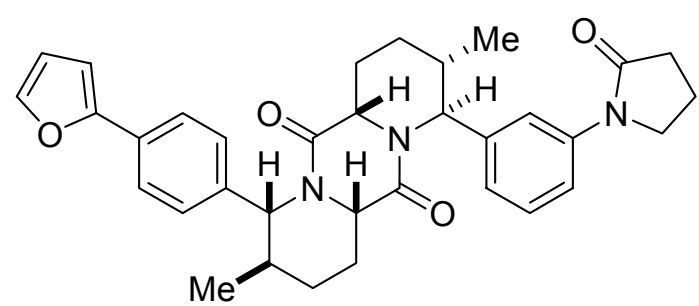
2929, 2871, 1653, 1491, 1445, 1390, 1304, 1228, $728 \mathrm{~cm}^{-1}$; ${ }^{1} \mathrm{H}$ NMR $\left(400 \mathrm{MHz}, \mathrm{CDCl}_{3}\right)$ $\delta 7.77(\mathrm{~s}, 1 \mathrm{H}), 7.58(\mathrm{~d}, J=8.8 \mathrm{HZ}, 2 \mathrm{H}), 7.41$ (s, 1H), 7.32-7.26 (m, 4H), $6.97(\mathrm{~d}, J=7.6$ $\mathrm{Hz}, 1 \mathrm{H}), 6.58(\mathrm{~d}, J=3.2 \mathrm{~Hz}, 1 \mathrm{H}), 6.41(\mathrm{~s}$, $1 \mathrm{H}), 5.56(\mathrm{~s}, 1 \mathrm{H}), 4.07(\mathrm{dd}, J=2.8,12.8 \mathrm{~Hz}$, $1 \mathrm{H}), 3.95(\mathrm{~d}, \underline{\mathrm{J}}=9.6 \mathrm{~Hz}, 1 \mathrm{H}), 3.84-3.79(\mathrm{~m}$, $3 \mathrm{H}), 2.60-2.52(\mathrm{~m}, 4 \mathrm{H}), 2.17-2.09(\mathrm{~m}, 2 \mathrm{H}), 2.05-2.02(\mathrm{~m}, 2 \mathrm{H}), 1.89-1.69(\mathrm{~m}, 4 \mathrm{H}), 1.46-$ $1.36(\mathrm{~m}, 2 \mathrm{H}), 1.16(\mathrm{~d}, J=6.8 \mathrm{~Hz}, 3 \mathrm{H}), 0.90(\mathrm{~d}, J=6.0 \mathrm{~Hz}, 3 \mathrm{H}) ;{ }^{13} \mathrm{C}$ NMR $(100 \mathrm{MHz}$, $\left.\mathrm{CDCl}_{3}\right) \delta 174.5,170.3,167.7,154.2,142.0,140.6,140.2,139.6,129.6,129.4,128.4$, $123.4,122.8,118.5,118.0,111.8,104.9,67.3,59.6,57.6,54.9,48.9,35.8,33.1,31.8$, 29.7, 29.6, 25.5, 19.8, 18.3, 18.1; HRMS (CI/ $\left./ \mathrm{NH}_{3}\right) \mathrm{m} / \mathrm{z}$ calcd for $\mathrm{C}_{34} \mathrm{H}_{37} \mathrm{~N}_{3} \mathrm{O}_{4} 551.2784$, found 551.2769 .

Homodimer 60: Yield, 31\%. Oil, $[\alpha]_{D}^{20}-127.7^{\circ}$ (c 0.74 , acetone); IR (thin film) $v_{\max }$

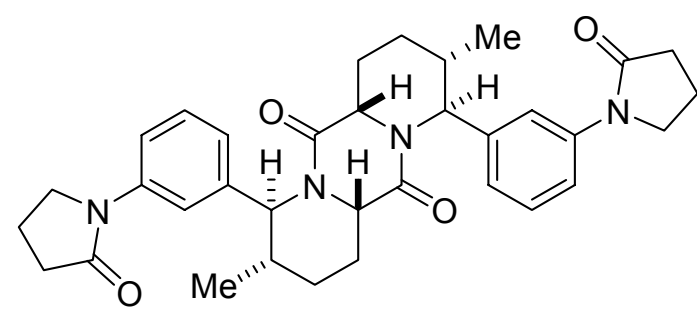
$3505,3411,2921,1664,1582,1454,1307$, 1228, 1118, 1032, $792 \mathrm{~cm}^{-1} ;{ }^{1} \mathrm{H}$ NMR $(400$ $\left.\mathrm{MHz}, \mathrm{CDCl}_{3}\right) \delta 7.76(\mathrm{~s}, 2 \mathrm{H}), 7.41(\mathrm{~d}, J=8.0$ $\mathrm{Hz}, 2 \mathrm{H}), 7.35$ (t, $J=7.2 \mathrm{~Hz}, 2 \mathrm{H}), 7.08(\mathrm{~d}, J=$ $8.0 \mathrm{~Hz}, 2 \mathrm{H}), 5.68(\mathrm{~s}, 2 \mathrm{H}), 4.03(\mathrm{dd}, J=2.8$, $12.0 \mathrm{~Hz}, 2 \mathrm{H}), 3.90-3.80(\mathrm{~m}, 4 \mathrm{H}), 2.73-2.71$ (m, 2H), 2.61 (t, $J=8.0 \mathrm{~Hz}, 4 \mathrm{H}), 2.26-2.20$ $(\mathrm{m}, 2 \mathrm{H}), 2.16(\mathrm{t}, J=8.0 \mathrm{~Hz}, 4 \mathrm{H}), 2.10-2.01(\mathrm{~m}, 2 \mathrm{H}), 1.93-1.83(\mathrm{~m}, 2 \mathrm{H}), 1.65-1.61(\mathrm{~m}$, $2 \mathrm{H}), 1.18(\mathrm{~d}, J=6.8 \mathrm{~Hz}, 6 \mathrm{H}) ;{ }^{13} \mathrm{C}$ NMR $\left(100 \mathrm{MHz}, \mathrm{CDCl}_{3}\right) \delta 174.4,165.9,140.3,138.7$, $129.6,123.1,118.8,118.6,57.0,54.6,48.9,33.0,28.9,27.5,26.3,18.2 ; \mathrm{HRMS}\left(\mathrm{CI} / \mathrm{NH}_{3}\right)$ $\mathrm{m} / \mathrm{z}$ calcd for $\mathrm{C}_{34} \mathrm{H}_{41} \mathrm{~N}_{4} \mathrm{O}_{4} 569.3050$, found 569.3105 .

Homodimer 61: Yield, $13 \%$, Orange solid, m.p. $165-168^{\circ} \mathrm{C} ;[\alpha]_{\mathrm{D}}{ }^{20}-113.2^{\circ}$ (c 0.37 ,

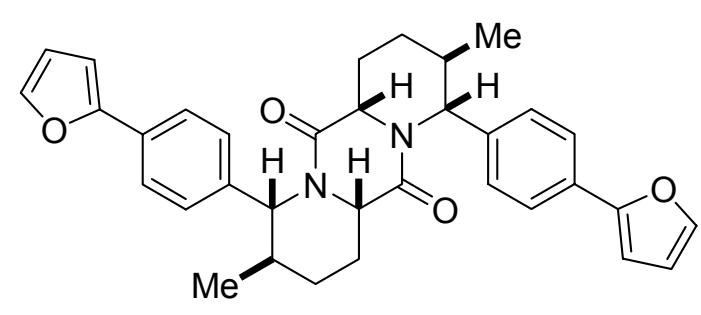
acetone); IR (thin film) $v_{\max } 2959,2870$, $1660,1515,1383,1007,736 \mathrm{~cm}^{-1} ;{ }^{1} \mathrm{H}$ NMR $\left(400 \mathrm{MHz}, \mathrm{CDCl}_{3}\right) \delta 7.60(\mathrm{~d}, J=8.0 \mathrm{~Hz}, 4 \mathrm{H})$, $7.46(\mathrm{~d}, J=2.0 \mathrm{~Hz}, 2 \mathrm{H}), 7.19(\mathrm{~d}, J=8.0 \mathrm{~Hz}$, $4 \mathrm{H}), 6.61(\mathrm{~d}, J=3.6 \mathrm{~Hz}, 2 \mathrm{H}), 6.47(\mathrm{dd}, J=$ $2.0,3.6 \mathrm{~Hz}, 2 \mathrm{H}), 4.67(\mathrm{~d}, J=6.4 \mathrm{~Hz}, 2 \mathrm{H})$, $4.03(\mathrm{dd}, J=4.8,12.4 \mathrm{~Hz}, 2 \mathrm{H}), 2.25-2.18(\mathrm{~m}$, $2 \mathrm{H}), 2.08-2.00(\mathrm{~m}, 2 \mathrm{H}), 1.95-1.88(\mathrm{~m}, 2 \mathrm{H}), 1.84-1.73(\mathrm{~m}, 2 \mathrm{H}), 1.30-1.20(\mathrm{~m}, 2 \mathrm{H}), 1.06$ $(\mathrm{d}, J=6.8 \mathrm{~Hz}, 6 \mathrm{H}) ;{ }^{13} \mathrm{C}$ NMR $\left(100 \mathrm{MHz}, \mathrm{CDCl}_{3}\right) \delta 171.1,154.1,143.2,142.1,129.5$, 
126.8, 124.0, 111.8, 104.9, 62.2, 56.1, 36.1, 27.1, 23.8, 21.4; HRMS (CI/NH $) \mathrm{m} / \mathrm{z}$ calcd for $\mathrm{C}_{34} \mathrm{H}_{34} \mathrm{~N}_{2} \mathrm{O}_{4} 534.2519$, found 534.2491.

Hetero-cyclodimerization of pipecolic acids $\mathbf{2 8}$ and proline $\mathbf{4 0}$ using general procedure 5 described in the Experimental Section of the paper afforded heterodimer $\mathbf{6 2}$ and homodimer 37.

Heterodimer 62: Yield, 22\%. Oil, $[\alpha]_{\mathrm{D}}^{20}-88.1^{\circ}$ (c 0.75 , acetone); IR (thin film) $v_{\max }$ 2960, 2874, 1652, 1418, $842 \mathrm{~cm}^{-1} ;{ }^{1} \mathrm{H}$ NMR $(400 \mathrm{MHz}$,

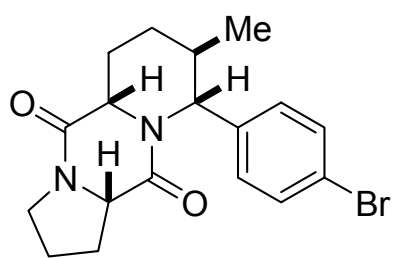
$\left.\mathrm{CD}_{3} \mathrm{OD}\right) \delta 7.42(\mathrm{~d}, J=8.0 \mathrm{~Hz}, 1 \mathrm{H}), 7.08(\mathrm{~d}, J=8.0 \mathrm{~Hz}, 1 \mathrm{H})$, $4.63(\mathrm{~d}, J=3.2 \mathrm{~Hz}, 1 \mathrm{H}), 4.30-4.26(\mathrm{~m}, 2 \mathrm{H}), 3.56-3.52(\mathrm{~m}$, $2 \mathrm{H}), 2.32-2.24(\mathrm{~m}, 1 \mathrm{H}), 2.19-2.05(\mathrm{~m}, 2 \mathrm{H}), 2.01-1.88(\mathrm{~m}$, $3 \mathrm{H}), 1.80-1.69(\mathrm{~m}, 1 \mathrm{H}), 1.40-1.23(\mathrm{~m}, 2 \mathrm{H}), 1.05(\mathrm{~d}, J=6.8$ $\mathrm{Hz}, 3 \mathrm{H}) ;{ }^{13} \mathrm{C}$ NMR $\left(100 \mathrm{MHz}, \mathrm{CD}_{3} \mathrm{OD}\right) \delta 173.9,168.9,144.7$, 132.7, 129.5, 121.4, 63.5, 60.6, 57.7, 50.2, 46.6, 36.8, 29.7, 27.4, 24.4, 21.7; HRMS $\left(\mathrm{CI} / \mathrm{NH}_{3}\right) \mathrm{m} / \mathrm{z}$ calcd for $\mathrm{C}_{18} \mathrm{H}_{22} \mathrm{BrN}_{2} \mathrm{O}_{2} 377.0786$, found 377.0856 .

Homodimer 37: Yield, 13\%, Oil, $[\alpha]_{\mathrm{D}}{ }^{20}-113.6^{\circ}$ (c 0.64, acetone); IR (thin film) $v_{\max }$

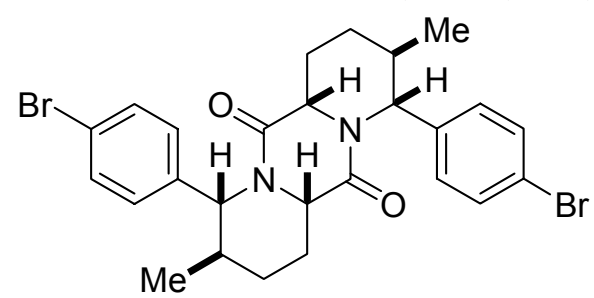
$2959,2930,1669,1486,1378,1319,1007,810 \mathrm{~cm}^{-}$ ${ }^{1}$; ${ }^{1} \mathrm{H}$ NMR $\left(400 \mathrm{MHz}, \mathrm{CDCl}_{3}\right) \delta 7.29(\mathrm{~d}, J=8.47$ $\mathrm{Hz}, 1 \mathrm{H}), 6.85(\mathrm{~d}, J=8.4 \mathrm{~Hz}, 1 \mathrm{H}), 4.34(\mathrm{~d}, J=7.2$ $\mathrm{Hz}, 1 \mathrm{H}), 3.25(\mathrm{dd}, J=12.4,4.96 \mathrm{~Hz}, 1 \mathrm{H}), 2.02$ (dddd, $J=14.4,3.9,3.9,3.9 \mathrm{~Hz}, 1 \mathrm{H}), 1.55$ (dddd, $J$ $=14.5,12.9,12.9,4.7 \mathrm{~Hz}, 1 \mathrm{H}), 1.42$ (dddq, $J=13.3$, 7.2, 6.7, $4.3 \mathrm{~Hz}, 1 \mathrm{H}$ ), 1.31 (dddd, $J=13.3,3.9,3.9$, $3.9 \mathrm{~Hz}, 1 \mathrm{H}), 0.75-0.63(\mathrm{~m}, 1 \mathrm{H}), 0.64(\mathrm{~d}, J=7.0 \mathrm{~Hz}, 3 \mathrm{H}) ;{ }^{13} \mathrm{C} \mathrm{NMR}\left(100 \mathrm{MHz}, \mathrm{CDCl}_{3}\right) \delta$ $171.3,143.2,131.6,128.1,120.6,62.6,56.2,36.7,27.3,24.2,20.9 ; \mathrm{HRMS}\left(\mathrm{CI} / \mathrm{NH}_{3}\right) \mathrm{m} / \mathrm{z}$ calcd for $\mathrm{C}_{26} \mathrm{H}_{28} \mathrm{Br}_{2} \mathrm{~N}_{2} \mathrm{O}_{2}$ 558.0518, found 558.0472.

Hetero-cyclodimerization of pipecolic acid $\mathbf{4 7}$ and isoleucine $\mathbf{4 4}$ using general procedure 5 described in the Experimental Section of the paper afforded heterodimer $\mathbf{6 4}$ and homodimer 65 .

Heterodimer 64: Yield, 39\%, oil, $[\alpha]_{\mathrm{D}}^{20}-49.7^{\circ}$ (c 1.23, acetone); IR (thin film) $v_{\max }$<smiles>COc1cccc(C2C(=O)N3CC4(CCC2C)CC4(C(C)C)N(C)C3=O)c1</smiles>
$3446,2965,2876,1640,1467,1257,1047,845 \mathrm{~cm}^{-1} ;{ }^{1} \mathrm{H}$ NMR $\left(400 \mathrm{MHz}, \mathrm{CD}_{3} \mathrm{Cl}\right) \delta 7.29-7.23(\mathrm{~m}, 1 \mathrm{H}), 6.87(\mathrm{~d}, J$ $=7.2 \mathrm{~Hz}, 1 \mathrm{H}), 6.83(\mathrm{~s}, 1 \mathrm{H}), 6.79(\mathrm{~d}, J=8.0 \mathrm{~Hz}, 1 \mathrm{H}), 5.50$ (s, 1H), 3.93-3.89 (m, 2H), $3.78(\mathrm{~s}, 3 \mathrm{H}), 2.97(\mathrm{~s}, 3 \mathrm{H})$, $2.62-2.58(\mathrm{~m}, 1 \mathrm{H}), 2.34-2.26(\mathrm{~m}, 1 \mathrm{H}), 2.20-2.13(\mathrm{~m}, 1 \mathrm{H})$, 2.04-1.94 (m, 1H), 1.85-1.75 (m, 1H), 1.58-1.52 (m, 1H), $1.21(\mathrm{~d}, J=6.8 \mathrm{~Hz}, 3 \mathrm{H}), 1.15(\mathrm{~d}, J=6.8 \mathrm{~Hz}, 3 \mathrm{H}), 1.07(\mathrm{~d}$, $J=6.8 \mathrm{~Hz}, 3 \mathrm{H}) ;{ }^{13} \mathrm{C}$ NMR $\left(100 \mathrm{MHz}, \mathrm{CD}_{3} \mathrm{OD}\right) \delta 168.3,166.3,161.9,140.8,131.2$, 120.1, 114.5, 113.4, 68.6, 59.3, 55.8, 50.0, 34.4, 32.8, 30.2, 27.3, 27.1, 20.2, 19.0, 18.4; HRMS (CI/NH $\left.\mathrm{NH}_{3}\right) \mathrm{m} / \mathrm{z}$ calcd for $\mathrm{C}_{20} \mathrm{H}_{29} \mathrm{~N}_{2} \mathrm{O}_{3} 345.2100$, found 345.2191 . 
Homodimer 65: Yield, $26 \%$. Oil, $[\alpha]_{\mathrm{D}}{ }^{20}-148.8^{\circ}$ (c 1.2, acetone); IR (thin film) $v_{\max }$ $3279,2925,2867,1650,1599,1489,1451$, 1324, 1252, 1153, 1038, $795 \mathrm{~cm}^{-1} ;{ }^{1} \mathrm{H} \mathrm{NMR}$<smiles>COc1cccc(C2[C@H](C)CCC34C(=O)N2C2(CCC3C)C(=O)N4[C@@H]2c2cccc(OC)c2)c1</smiles>
$\left(400 \mathrm{MHz}, \mathrm{CDCl}_{3}\right) \delta 7.28(\mathrm{t}, J=8.4 \mathrm{~Hz}, 2 \mathrm{H})$, $6.87(\mathrm{~d}, J=7.2 \mathrm{~Hz}, 2 \mathrm{H}), 6.82-6.80(\mathrm{~m}, 4 \mathrm{H})$, $5.66(\mathrm{brs}, 2 \mathrm{H}), 4.02(\mathrm{dd}, J=3.2,12.0 \mathrm{~Hz}, 2 \mathrm{H})$, $3.79(\mathrm{~s}, 6 \mathrm{H}), 2.71-2.68(\mathrm{~m}, 2 \mathrm{H}), 2.25-2.21(\mathrm{~m}$, $2 \mathrm{H}), 2.10-2.01(\mathrm{~m}, 2 \mathrm{H}), 1.93-1.82(\mathrm{~m}, 2 \mathrm{H})$, $1.64-1.58(\mathrm{~m}, 2 \mathrm{H}), 1.19(\mathrm{~d}, J=6.8 \mathrm{~Hz}, 6 \mathrm{H}) ;{ }^{13} \mathrm{C}$

NMR $\left(100 \mathrm{MHz}, \mathrm{CDCl}_{3}\right) \delta 165.9,160.4,139.5,130.2,119.2,113.1,112.6,56.8,55.4$, 54.7, 28.8, 27.5, 26.3, 18.2; HRMS $\left(\mathrm{CI} / \mathrm{NH}_{3}\right) \mathrm{m} / \mathrm{z}$ calcd for $\mathrm{C}_{28} \mathrm{H}_{34} \mathrm{~N}_{2} \mathrm{O}_{4} 462.2519$, found 462.2484 .

Hetero-cyclodimerization of pipecolic acid 47 and $\beta$-carboline 50 by general procedure 5 described in the Experimental Section of the paper afforded heterodimer 67 and homodimers 68 and 69.

Heterodimer 67: Yield, 39\%. Oil, $[\alpha]_{\mathrm{D}}{ }^{20}-64.4^{\circ}$ (c 1.6, acetone); IR (thin film) $v_{\max }$

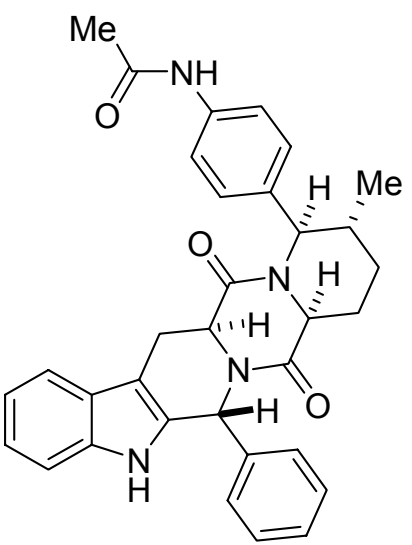
$3647,3398,3060,2930,1651,1519,1455,1374,1146,828$ $\mathrm{cm}^{-1} ;{ }^{1} \mathrm{H}$ NMR $\left(400 \mathrm{MHz}, \mathrm{CD}_{3} \mathrm{OD}\right) \delta 7.44(\mathrm{dd}, J=2.0,8.4$ $\mathrm{Hz}, 2 \mathrm{H}), 7.31-7.23(\mathrm{~m}, 8 \mathrm{H}), 7.10(\mathrm{t}, J=7.2 \mathrm{~Hz}, 1 \mathrm{H}), 7.02(\mathrm{t}$, $J=8.0 \mathrm{~Hz}, 1 \mathrm{H}), 6.96(\mathrm{~s}, 1 \mathrm{H}), 4.14(\mathrm{~d}, J=12.4 \mathrm{~Hz}, 1 \mathrm{H}), 4.04$ $(\mathrm{dd}, J=4.0,11.6 \mathrm{~Hz}, 1 \mathrm{H}), 3.85(\mathrm{~d}, J=10.4 \mathrm{~Hz}, 1 \mathrm{H}), 3.28$ $(\mathrm{dd}, J=4.4,15.2 \mathrm{~Hz}, 1 \mathrm{H}), 2.91(\mathrm{dd}, J=12.8,15.2 \mathrm{~Hz}, 1 \mathrm{H})$, 2.44-2.39 (m, 1H), 2.19-2.15 (m, 2H), $2.10(\mathrm{~s}, 3 \mathrm{H}), 1.77-$ $1.66(\mathrm{~m}, 1 \mathrm{H}), 1.51-1.41(\mathrm{~m}, 1 \mathrm{H}), 0.83(\mathrm{~d}, J=6.0 \mathrm{~Hz}, 3 \mathrm{H})$; ${ }^{13} \mathrm{C}$ NMR (100 MHz, CD $\left.{ }_{3} \mathrm{OD}\right) \delta 171.7,169.8,167.3,140.4$, $138.7,138.4,136.4,131.1,131.0,129.9,129.8,127.6,123.2$, $120.4,120.2,119.1,112.3,108.8,70.0,62.8,54.4,53.8$, 35.7, 34.3 , 32.7, 29.1, 24.0, 19.8; HRMS (CI/NH $\left.{ }_{3}\right) \mathrm{m} / \mathrm{z}$ calcd for $\mathrm{C}_{33} \mathrm{H}_{33} \mathrm{~N}_{4} \mathrm{O}_{3}$ 533.2474, found 533.2584.

Homodimer 68: Yield, $12 \%$. Oil, $[\alpha]_{\mathrm{D}}{ }^{20}-47.8^{\circ}$ (c 0.42 , acetone); IR (thin film) $v_{\max }$<smiles>CC(=O)Nc1ccc(C2(c3ccc(NC(C)=O)cc3)C(C)CC34CCC(C)C3(C)CC(C)N2C4=O)cc1</smiles>
$3315,3278,2959,1679,1602,1538,1446$, $1318,830 \mathrm{~cm}^{-1} ;{ }^{1} \mathrm{H}$ NMR (400 MHz, acetone$\left.d_{6}\right) \delta 9.18(\mathrm{~s}, 2 \mathrm{H}), 7.52(\mathrm{~d}, J=8.8 \mathrm{~Hz}, 4 \mathrm{H})$, $7.11(\mathrm{~d}, J=8.4 \mathrm{~Hz}, 4 \mathrm{H}), 4.74(\mathrm{~d}, J=6.0 \mathrm{~Hz}$, 2H), 4.28 (dd, $J=4.8,12.4 \mathrm{~Hz}, 2 \mathrm{H}), 2.87$ (d, $J$ $=12.8 \mathrm{~Hz}, 2 \mathrm{H}), 2.21-2.14(\mathrm{~m}, 2 \mathrm{H}), 2.10(\mathrm{~s}$, $6 \mathrm{H}), 1.95-1.88(\mathrm{~m}, 2 \mathrm{H}), 1.73-1.62(\mathrm{~m}, 2 \mathrm{H})$, 
1.36-1.26 (m, 2H), $1.06(\mathrm{~d}, J=6.8 \mathrm{~Hz}, 6 \mathrm{H}) ;{ }^{13} \mathrm{C}$ NMR $\left(100 \mathrm{MHz}\right.$, acetone- $\left.d_{6}\right) \delta 171.7$, 169.0, 140.1，138.6，127.4，120.1，61.4，55.9, 35.8, 27.0, 24.3, 23.9, 27.8; HRMS $\left(\mathrm{CI} / \mathrm{NH}_{3}\right) \mathrm{m} / \mathrm{z}$ calcd for $\mathrm{C}_{30} \mathrm{H}_{37} \mathrm{~N}_{4} \mathrm{O}_{4}$ 517.2737, found 517.2846.

Homodimer 69: Yield, 7\%, Yellow solid, m.p. $>250^{\circ} \mathrm{C}$, decomposed; $[\alpha]_{\mathrm{D}}{ }^{20}-159.0^{\circ}$ (c

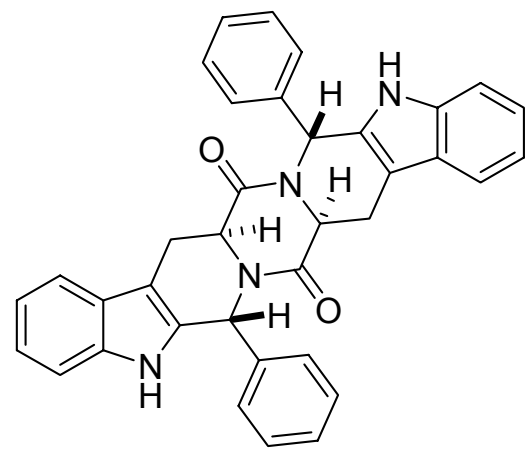
1.76, acetone); IR (thin film) $v_{\max } 3386,3190,3060$, 2937, 2252, 1654, 1453, 1326, 1154, 1027, $746 \mathrm{~cm}^{-1} ;{ }^{1} \mathrm{H}$ NMR $\left(400 \mathrm{MHz}, \mathrm{CD}_{3} \mathrm{OD}\right) \delta 7.51(\mathrm{~d}, J=8.0 \mathrm{~Hz}, 2 \mathrm{H})$, 7.34-7.30 (m, ovlp, 8H), 7.25-7.2 (m, 4H), 7.14 (t, $J=$ $7.6 \mathrm{~Hz}, 2 \mathrm{H}), 7.08(\mathrm{~s}, 2 \mathrm{H}), 7.05(\mathrm{t}, J=7.6 \mathrm{~Hz}, 2 \mathrm{H}), 4.39$ $(\mathrm{dd}, J=4.0,11.6 \mathrm{~Hz}, 2 \mathrm{H}), 3.53(\mathrm{dd}, J=4.0,15.2 \mathrm{~Hz}$, 2H), $3.02(\mathrm{dd}, J=11.6,15.2 \mathrm{~Hz}, 2 \mathrm{H}) ;{ }^{13} \mathrm{C}$ NMR $(100$ $\left.\mathrm{MHz}, \mathrm{DMSO}-d_{6}\right) \delta 163.9,138.8,136.3,130.1,128.9$, $128.5,128.3,125.9,121.8,119.0,118.2,111.4,107.4$, 52.2, 51.5, 27.9; HRMS $\left(\mathrm{CI} / \mathrm{NH}_{3}\right) \mathrm{m} / \mathrm{z}$ calcd for $\mathrm{C}_{36} \mathrm{H}_{29} \mathrm{~N}_{4} \mathrm{O}_{2} 549.2212$, found 549.2330 .

Hetero-cyclodimerization of pipecolic acid $\mathbf{4 8}$ and $\beta$-carboline $\mathbf{5 1}$ by general procedure 5 described in the Experimental Section of the paper afforded heterodimer $\mathbf{7 0}$ and homodimers $\mathbf{7 1}$ and $\mathbf{7 2 .}$

Heterodimer 70: Yield, 25\%. Oil, $[\alpha]_{D}^{20}-46.4^{\circ}$ (c 2.4, acetone); IR (thin film) $v_{\max }$

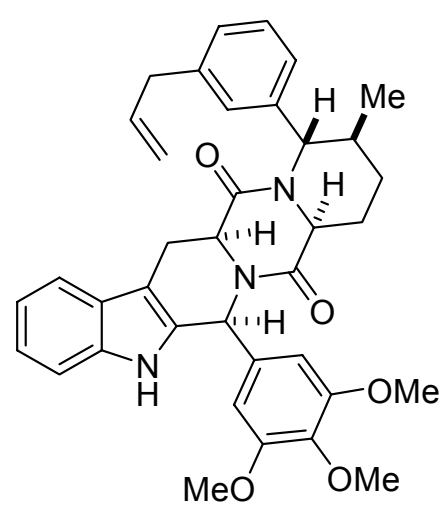
3423, 2923, 2852, 1638, 1597, 1458, 1319, 1230, 1121, $831,738 \mathrm{~cm}^{-1} ;{ }^{1} \mathrm{H}$ NMR $\left(400 \mathrm{MHz}, \mathrm{CDCl}_{3}\right) \delta 7.78(\mathrm{~s}, 1 \mathrm{H})$, $7.56(\mathrm{~d}, J=6.8 \mathrm{~Hz}, 1 \mathrm{H}), 7.19-7.25(\mathrm{~m}, 1 \mathrm{H}), 7.17-7.08(\mathrm{~m}$, $5 \mathrm{H}), 6.52(\mathrm{~s}, 2 \mathrm{H}), 5.98-5.89(\mathrm{~m}, 2 \mathrm{H}), 5.70(\mathrm{~s}, 1 \mathrm{H}), 5.07$ (brs, 1H), 5.03 (brs, 1H), 4.48 (dd, $J=2.4,10.8 \mathrm{~Hz}, 1 \mathrm{H})$, 3.97-3.90 (m, 2H), $3.77(\mathrm{~s}, 6 \mathrm{H}), 3.76(\mathrm{~s}, 3 \mathrm{H}), 3.37(\mathrm{~d}, J=$ $6.4 \mathrm{~Hz}, 2 \mathrm{H}), 3.18(\mathrm{dd}, J=12.4,15.2 \mathrm{~Hz}, 1 \mathrm{H}), 2.69-2.67$ $(\mathrm{m}, 1 \mathrm{H}), 1.98-1.91(\mathrm{~m}, 3 \mathrm{H}), 1.79-1.73(\mathrm{~m}, 1 \mathrm{H}), 1.54-1.51$ $(\mathrm{m}, 1 \mathrm{H}), 1.21(\mathrm{~d}, J=6.8 \mathrm{~Hz}, 3 \mathrm{H}) ;{ }^{13} \mathrm{C}$ NMR $(100 \mathrm{MHz}$, $\left.\mathrm{CDCl}_{3}\right) \delta 169.3,167.4,154.4,141.6,140.6,140.0,138.7$, $137.8,134.8,129.7,127.9,127.4,125.4,122.4,120.1$, 119.0, 116.0, 112.1, 106.9, 103.7, 60.6, 60.4, 58.1, 58.0, 57.8, 56.3, 55.6, 40.8, 26.8, 26.6, 25.8, 20.9, 18.3; HRMS (CI/NH3) m/z calcd for $\mathrm{C}_{37} \mathrm{H}_{39} \mathrm{~N}_{3} \mathrm{O}_{5}$ 605.2890, found 605.2881.

Homodimer 71: Yield, $10 \%$. Oil, $[\alpha]_{\mathrm{D}}{ }^{20}-149.4^{\circ}$ (c 1.1, acetone); IR (thin film) $v_{\max }$

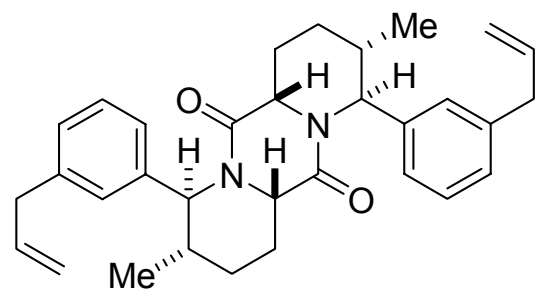
2961, 2930, 1657, 1450, 1324, 1213, 913, $748 \mathrm{~cm}^{-1}$; ${ }^{1} \mathrm{H}$ NMR $\left(400 \mathrm{MHz}, \mathrm{CDCl}_{3}\right) \delta 7.30(\mathrm{t}, J=8.0 \mathrm{~Hz}$, $2 \mathrm{H}), 7.13-7.10(\mathrm{~m}, 6 \mathrm{H}), 6.01-5.91(\mathrm{~m}, 2 \mathrm{H}), 5.68$ (brs, 2H), 5.10-5.09 (m, 2H), 5.07-5.05 (m, 2H), 4.01 (dd, $J=3.2,12.4 \mathrm{~Hz}, 2 \mathrm{H}), 3.39(\mathrm{~d}, J=6.0 \mathrm{~Hz}$, $4 \mathrm{H}), 2.74-2.72(\mathrm{~m}, 2 \mathrm{H}), 2.27-2.23(\mathrm{~m}, 2 \mathrm{H}), 2.11-$ $2.02(\mathrm{~m}, 2 \mathrm{H}), 1.94-1.84(\mathrm{~m}, 2 \mathrm{H}), 1.66-1.62(\mathrm{~m}, 2 \mathrm{H})$, $1.20(\mathrm{~d}, J=6.8 \mathrm{~Hz}, 6 \mathrm{H}) ;{ }^{13} \mathrm{C} \mathrm{NMR}\left(100 \mathrm{MHz}, \mathrm{CDCl}_{3}\right) \delta 166.0,141.0,138.1,137.4$, 
$129.2,127.9,127.3,124.8,116.3,56.9,54.6,40.5,28.7,27.6,26.3,18.2$; HRMS $\left(\mathrm{CI} / \mathrm{NH}_{3}\right) \mathrm{m} / \mathrm{z}$ calcd for $\mathrm{C}_{32} \mathrm{H}_{38} \mathrm{~N}_{2} \mathrm{O}_{2} 482.2933$, found 482.2951 .

Homodimer 72: Yield, 7\%. Off-white solid, m.p. $198-200^{\circ} \mathrm{C}$; $[\alpha]_{\mathrm{D}}{ }^{20}-46.7^{\circ}$ (c 0.52 ,

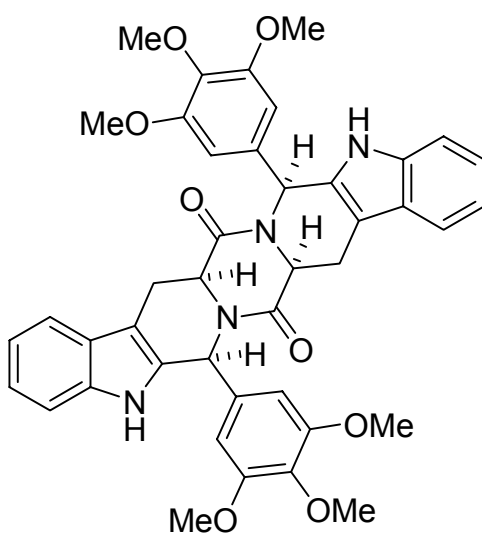
acetone); IR (thin film) $v_{\max } 3439,2943,1662,1595$, $1455,1325,1232,1121,842 \mathrm{~cm}^{-1}$; ${ }^{1} \mathrm{H}$ NMR $(400 \mathrm{MHz}$, $\left.\mathrm{CDCl}_{3}\right) \delta 8.25(\mathrm{~s}, 2 \mathrm{H}), 7.58(\mathrm{~d}, J=7.6 \mathrm{~Hz}, 2 \mathrm{H}), 7.34(\mathrm{~d}$, $J=8.0 \mathrm{~Hz}, 2 \mathrm{H}), 7.22-7.14(\mathrm{~m}, 4 \mathrm{H}), 6.51(\mathrm{~s}, 4 \mathrm{H}), 6.42(\mathrm{~s}$, $2 \mathrm{H}), 4.48(\mathrm{dd}, J=5.6,11.6 \mathrm{~Hz}, 2 \mathrm{H}), 3.76(\mathrm{~s}, 6 \mathrm{H}), 3.76-$ $3.71(\mathrm{~m}, 2 \mathrm{H}), 3.61(\mathrm{~s}, 12 \mathrm{H}), 3.35(\mathrm{dd}, J=10.8,15.2 \mathrm{~Hz}$, $2 \mathrm{H}) ;{ }^{13} \mathrm{C}$ NMR $\left(100 \mathrm{MHz}\right.$, acetone- $\left.d_{6}\right) \delta 170.4,154.5$, $139.9,138.0,137.5,134.9,127.2,122.5,120.2,119.0$, $112.2,105.3,103.6,60.4,56.1,56.0,55.9,22.6$; HRMS $\left(\mathrm{CI} / \mathrm{NH}_{3}\right) \mathrm{m} / \mathrm{z}$ calcd for $\mathrm{C}_{42} \mathrm{H}_{40} \mathrm{~N}_{4} \mathrm{O}_{8}$ 728.2846, found 728.2799 .

Homodimers $\mathbf{3 3}$ and $\boldsymbol{e n t} \mathbf{- 3 3}$ were synthesized from the corresponding pipecolic acids $\mathbf{2 8}$ and $\boldsymbol{e n t - 2 8}$ respectively employing reaction conditions described in general procedure 5

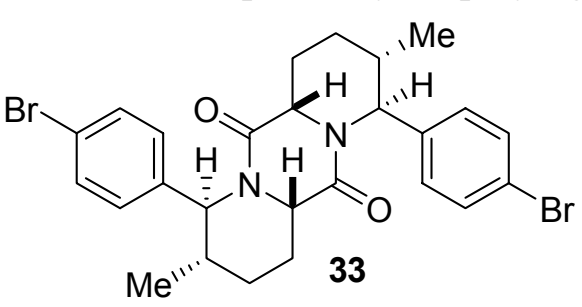
described in the Experimental Section of the paper. Yield, 87\%. White solid, m.p. $240-243{ }^{\circ} \mathrm{C}$ (decomposed); $[\alpha]_{\mathrm{D}}{ }^{20}$ for $33-212^{\circ}$ (c $0.60, \mathrm{CH}_{2} \mathrm{Cl}_{2}$ ) $[\alpha]_{\mathrm{D}}{ }^{20}$ for ent-33 $+200.3^{\mathrm{o}}\left(\mathrm{c} 0.85, \mathrm{CH}_{2} \mathrm{Cl}_{2}\right)$; IR (thin film) $v_{\max } 2967,1648,1447,1306,1003 \mathrm{~cm}^{-1} ;{ }^{1} \mathrm{H}$ NMR (400 MHz, $\left.\mathrm{CDCl}_{3}\right) \delta 7.50(\mathrm{~d}, J=8.4 \mathrm{~Hz}, 2 \mathrm{H})$, $7.16(\mathrm{~d}, J=8.4 \mathrm{~Hz}, 2 \mathrm{H}), 5.57(\mathrm{~d}, J=2.7 \mathrm{~Hz}, 1 \mathrm{H})$, 3.95 (dd, $J=12.2,3.3 \mathrm{~Hz}, 1 \mathrm{H}$ ), 2.64 (dddq, $J=6.9,4.3,4.4,2.7 \mathrm{~Hz}, 1 \mathrm{H}$ ), 2.25 (dddd, $J=$ $12.2,3.5,3.5,3.5,1 \mathrm{H}$ ), 2.02 (dddd, $J=11.7,11.7,4.3,4.3 \mathrm{~Hz}, 1 \mathrm{H}$ ), 1.88 (dddd, $J=12.0$, 12.0, 12.0, 4.4 Hz, 1H), 1.63 (dddd, $J=12.9,4.5,4.5,4.5 \mathrm{~Hz}, 1 \mathrm{H}), 1.16$ (d, $J=6.9 \mathrm{~Hz}$, $1 \mathrm{H}) ;{ }^{13} \mathrm{C}$ NMR (100 MHz, $\left.\mathrm{CDCl}_{3}\right) 165.6,136.9,132.1,128.7,121.4,56.7,54.3,28.7$, 27.5, 26.0, 18.0; HRMS (CI/NH $\left./ \mathrm{NH}_{3}\right) \mathrm{m} / \mathrm{z}$ calcd for $\mathrm{C}_{26} \mathrm{H}_{29} \mathrm{~N}_{2} \mathrm{O}_{2} \mathrm{Br}_{2}(\mathrm{M}+1)$, found 559.0572.

Homodimer 34 was synthesized from the corresponding pipecolic acid $\mathbf{3 5}$ employing reaction conditions described in general procedure 9. Yield, $79 \%$. Viscous oil; $[\alpha]_{\mathrm{D}}{ }^{20}$ $+280.0^{\circ}$ (c $1.2 \mathrm{CH}_{2} \mathrm{Cl}_{2}$ ); IR (thin film) $v_{\max } 2925,2853,1661,1508,1453 \mathrm{~cm}^{-1} ;{ }^{1} \mathrm{H}$ NMR

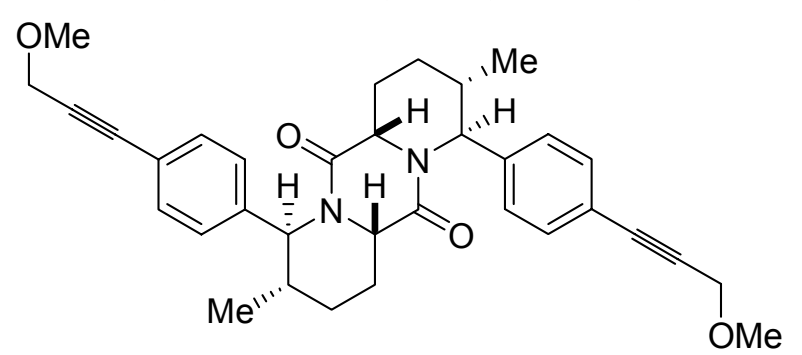
$\left(400 \mathrm{MHz}, \mathrm{CDCl}_{3}\right) \delta 7.41(\mathrm{~d}, J=8.0 \mathrm{~Hz}$, $2 \mathrm{H}), 7.13(\mathrm{~d}, J=8.0 \mathrm{~Hz}, 2 \mathrm{H}), 4.58(\mathrm{~d}$, $6.8 \mathrm{~Hz}, 1 \mathrm{H}), 4.34(\mathrm{~s}, 2 \mathrm{H}), 4.00(\mathrm{dd}, J=$ $4.8,12 \mathrm{~Hz}, 1 \mathrm{H}), 3.47(\mathrm{~s}, 3 \mathrm{H}), 2.26-2.2$ $(\mathrm{m}, 1 \mathrm{H}), 1.99-1.86(\mathrm{~m}, 2 \mathrm{H}), 1.78-1.67$ $(\mathrm{m}, 1 \mathrm{H}), 1.30-1.20(\mathrm{~m}, 1 \mathrm{H}), 1.03(\mathrm{~d}, J=$ $6.8 \mathrm{~Hz}, 3 \mathrm{H}) ;{ }^{13} \mathrm{C}$ NMR $(100 \mathrm{MHz}$, $\left.\mathrm{CDCl}_{3}\right)$ $\delta 171.8,146.3,132.5,127.4,121.6,86.6,86.1,62.2,60.6,57.5,55.9,36.2,27.3,24.4,21$. 4 ; HRMS $\left(\mathrm{CI} / \mathrm{NH}_{3}\right) \mathrm{m} / \mathrm{z}$ calcd for $\mathrm{C}_{34} \mathrm{H}_{38} \mathrm{~N}_{2} \mathrm{O}_{4}$ 538.2832, found 538.2873. 
Hetero-cyclodimerization of pipecolic acids ent-28 and $\mathbf{3 6}$ was conducted using general procedure 5 described in the Experimental Section of the paper. The crude reaction mixture was subjected normal silica gel chromatography with ethyl acetate in hexanes (from $10 \%$ to $50 \%$ ) to give the homodimers ent-33 (16\%) and $37(21 \%)$ along with the heterodimer 38 (37\%).

Heterodimer 38: Oil; $[\alpha]_{\mathrm{D}}^{20} 12.1^{\circ}$ (c $0.7 \mathrm{CH} 2 \mathrm{Cl} 2$ ); IR (thin film) $v_{\max } 2963,2926,2870$,

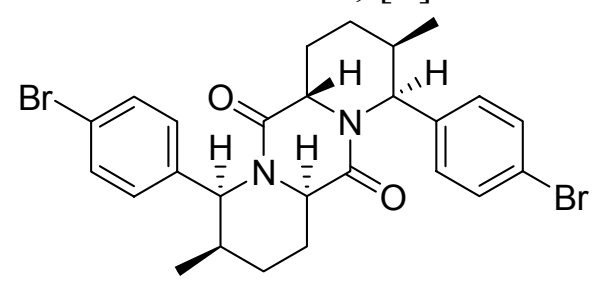
1666, 1481, 1395, $1312 \mathrm{~cm}^{-1}$; ${ }^{1} \mathrm{H}$ NMR $(400 \mathrm{MHz}$, $\left.\mathrm{CDCl}_{3}\right) \delta 7.50-7.46(\mathrm{~m}, 2 \mathrm{H}), 7.42-7.38(\mathrm{~m}, 2 \mathrm{H})$, 7.16-7.10 (m, 4H), $5.52(\mathrm{~d}, J=3.1 \mathrm{~Hz}, 1 \mathrm{H}), 4.05-$ $4.01(\mathrm{~m}, 2 \mathrm{H}), 3.72(\mathrm{dd}, J=12.2,3.70 \mathrm{~Hz}, 1 \mathrm{H}), 2.61-$ $2.52(\mathrm{~m}, 2 \mathrm{H}), 2.04-1.68(\mathrm{~m}, 5 \mathrm{H}), 1.55-1.47(\mathrm{~m}, 2 \mathrm{H})$, $1.38-1.15(\mathrm{~m}, 1 \mathrm{H}), 1.12(\mathrm{~d}, J=6.9 \mathrm{~Hz}, 3 \mathrm{H}), 0.90(\mathrm{~d}$, $J=6.6 \mathrm{~Hz}, \quad 3 \mathrm{H}) ; \quad{ }^{13} \mathrm{C} \quad \mathrm{NMR} \quad\left(100 \quad \mathrm{MHz}, \mathrm{CDCl}_{3}\right)$ $\delta 170.3,166.5,141.5,137.4,132.0,131.1,128.7,128.5,121.3,120.3,65.7,57.2,57,2,5$ 4.8, 36.4, 30.1, 29.1, 27.9, 26.1, 24.5, 19.7, 18.1; HRMS $\quad\left(\mathrm{CI} / \mathrm{NH}_{3}\right) \quad \mathrm{m} / \mathrm{z} \quad$ calcd for $\mathrm{C}_{26} \mathrm{H}_{29} \mathrm{~N}_{2} \mathrm{O}_{2} \mathrm{Br}_{2}(\mathrm{M}+1)$ 559.0596, found 559.0648. 
10. Select NMR Spectra of Diketopiperazines.

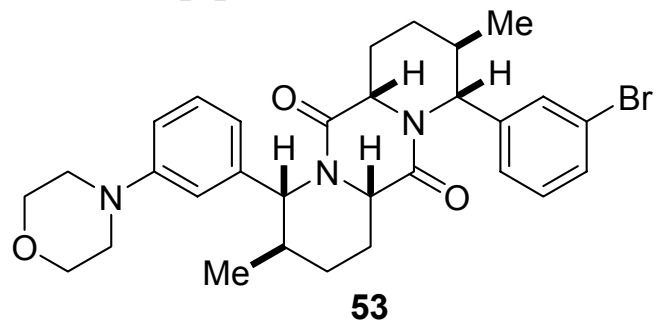
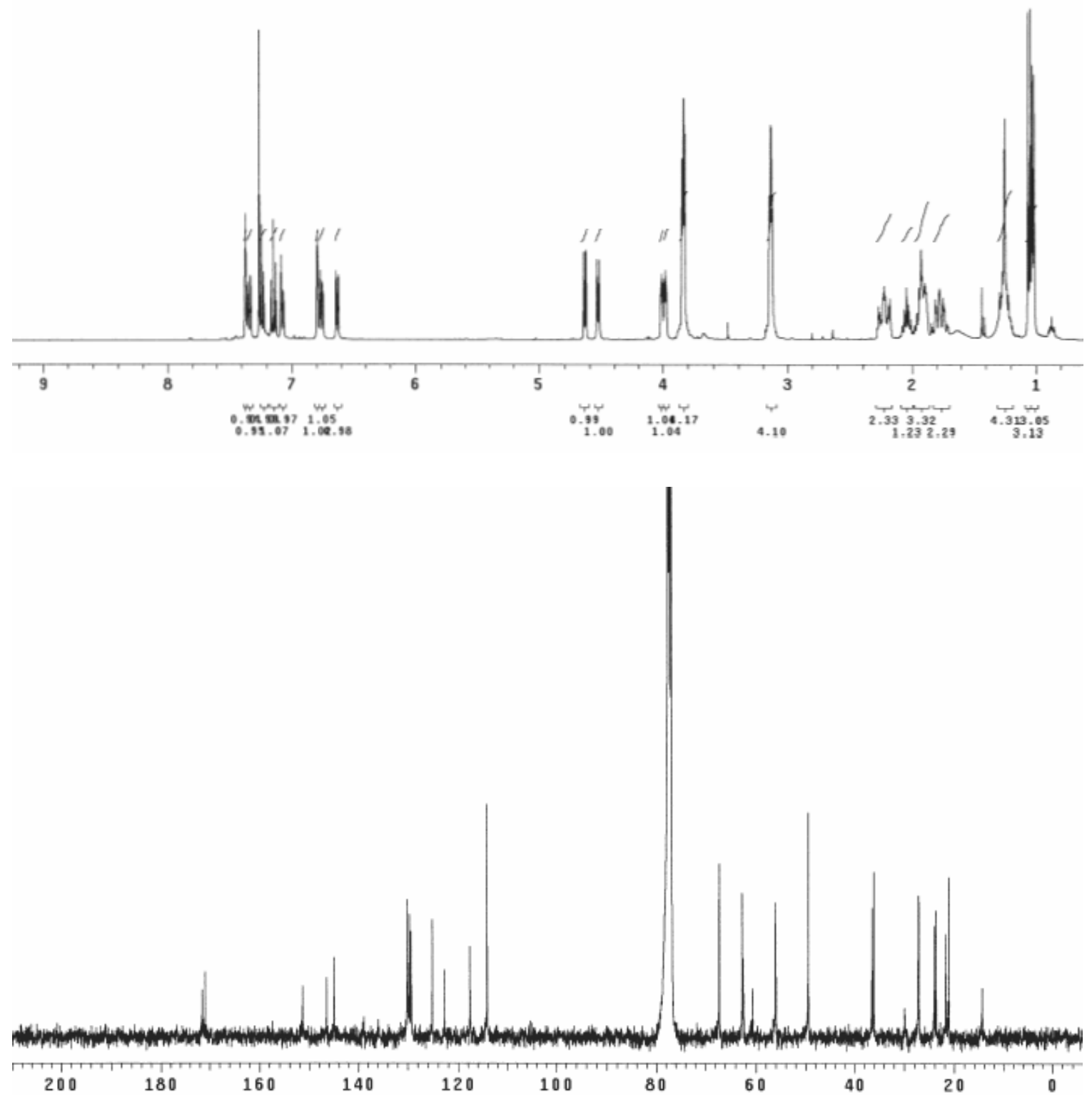

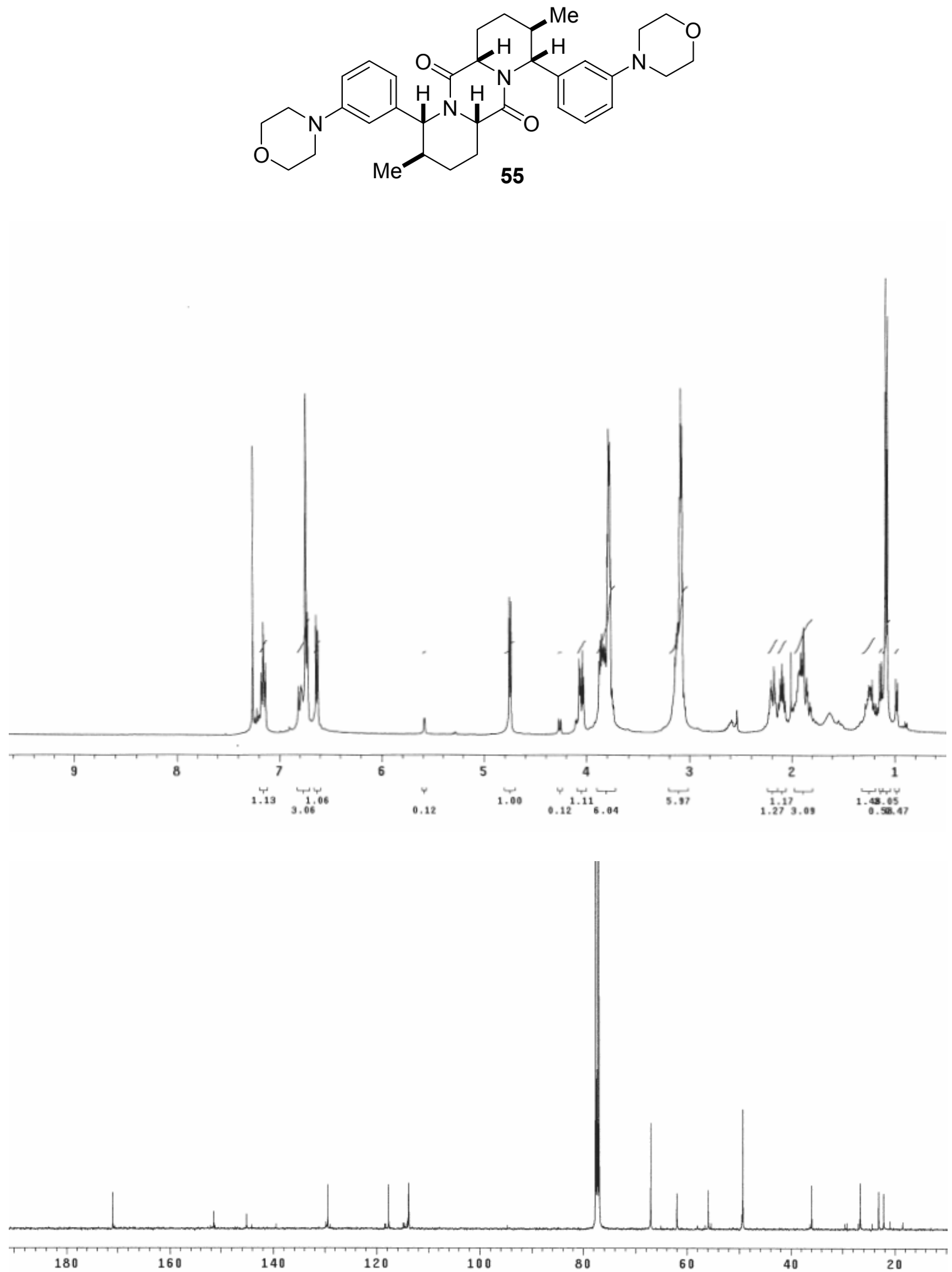

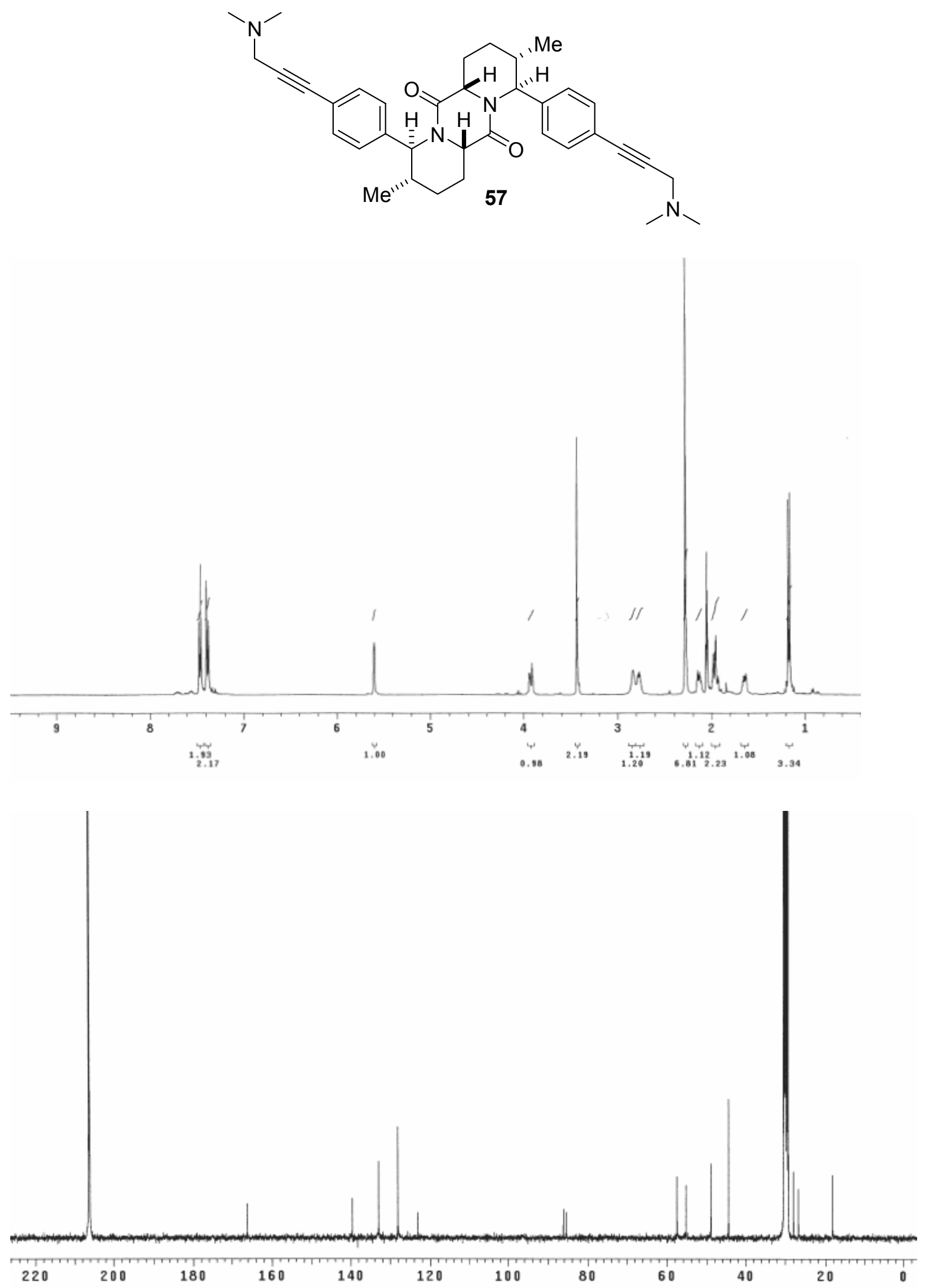

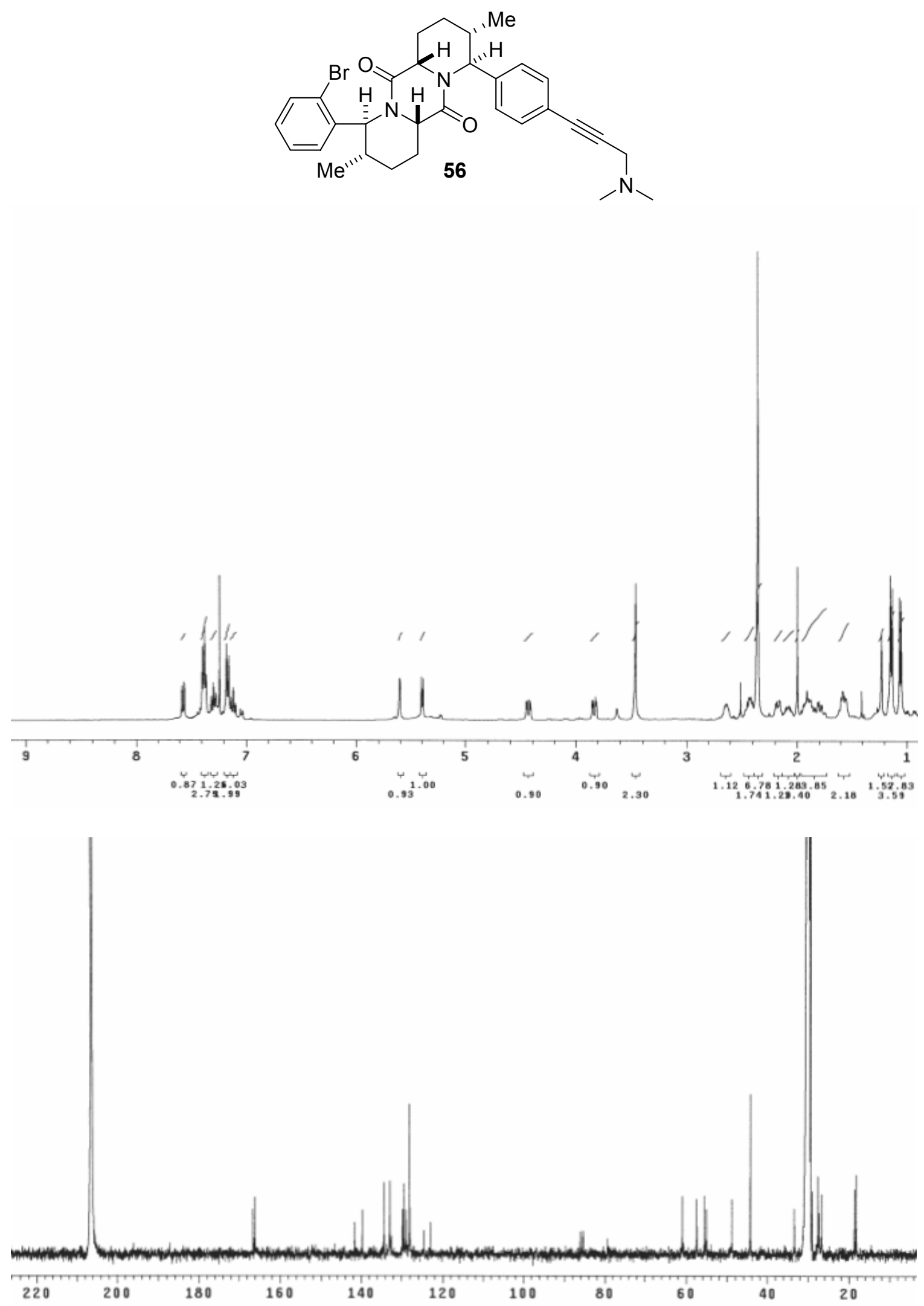

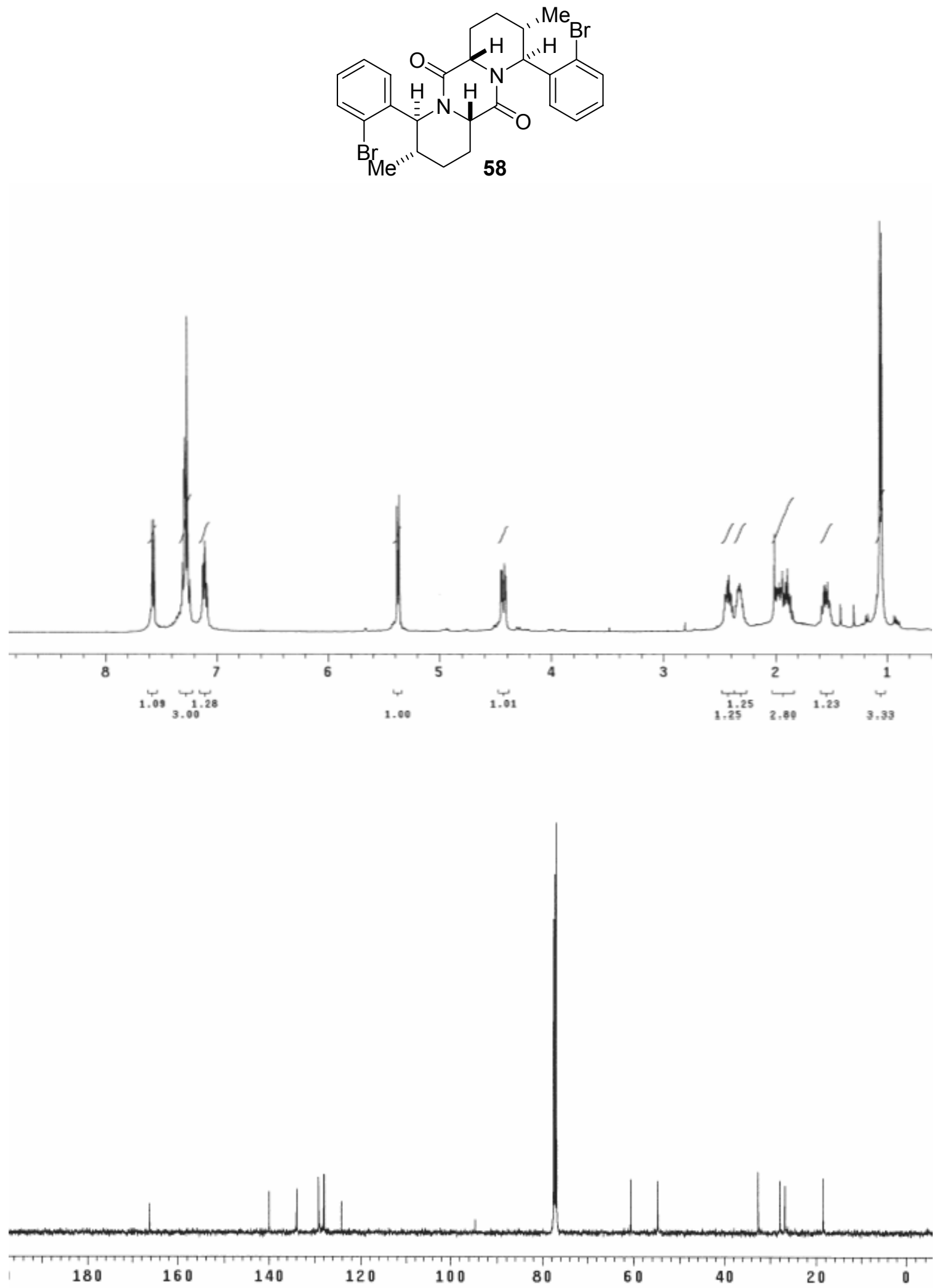

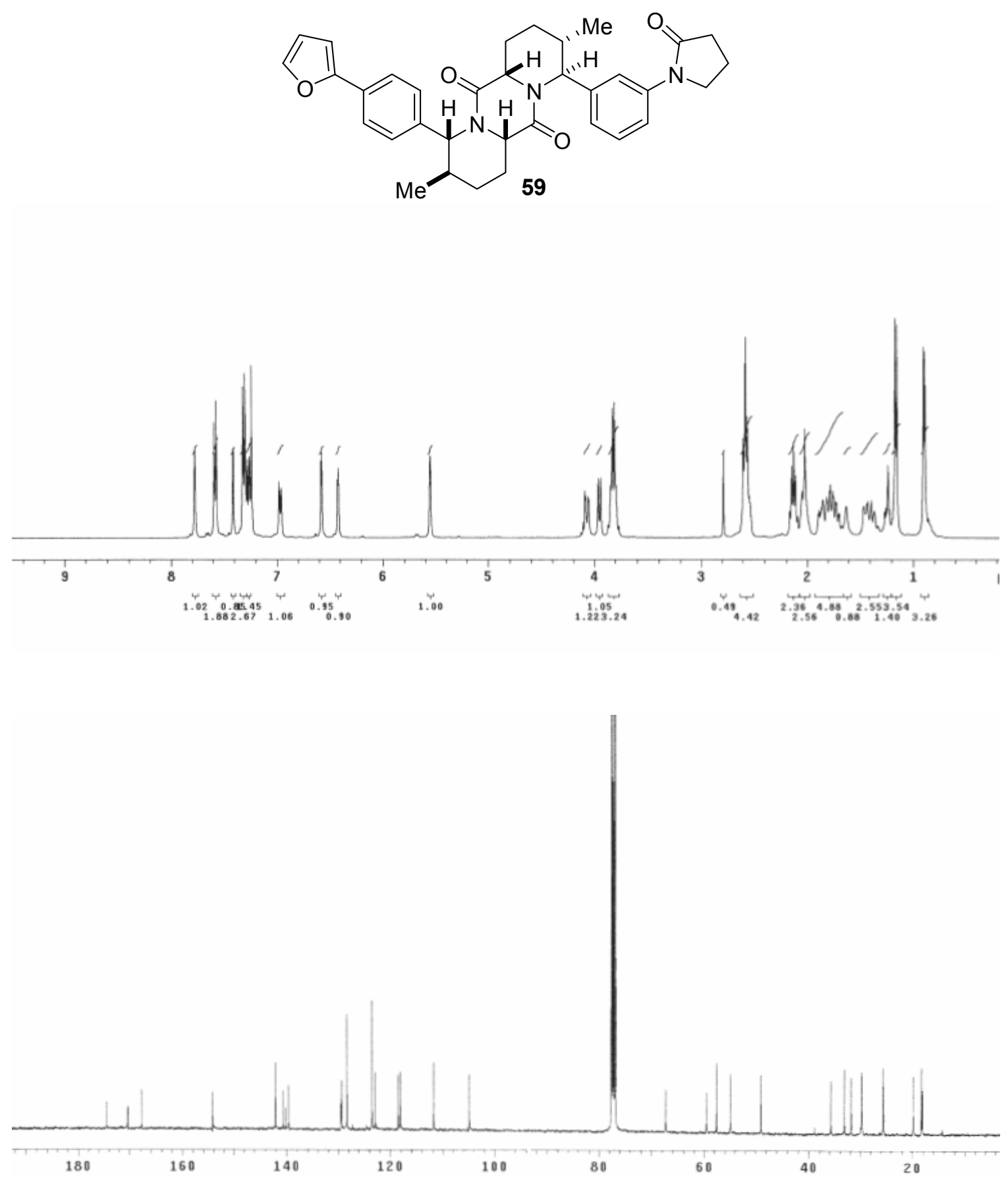

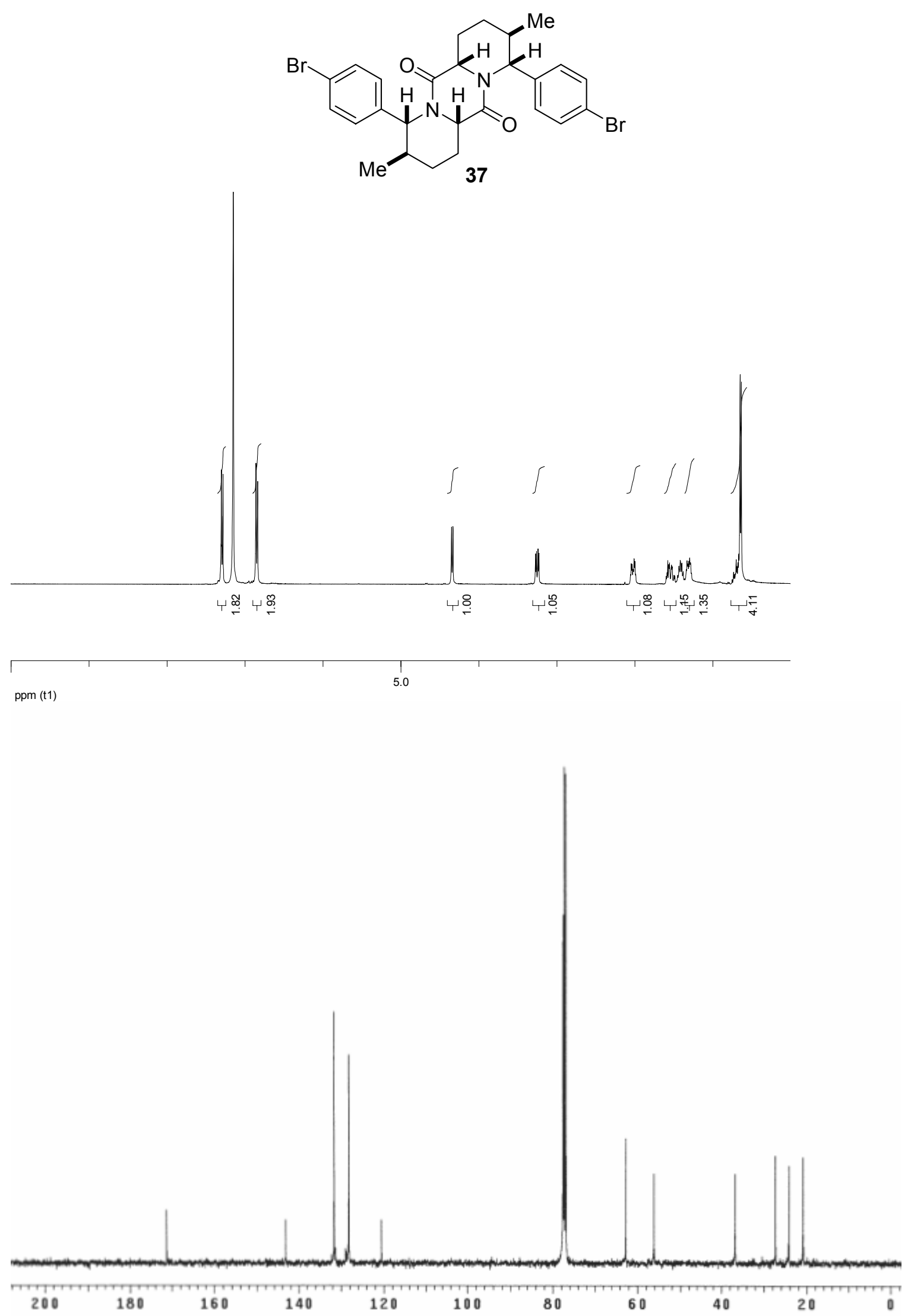

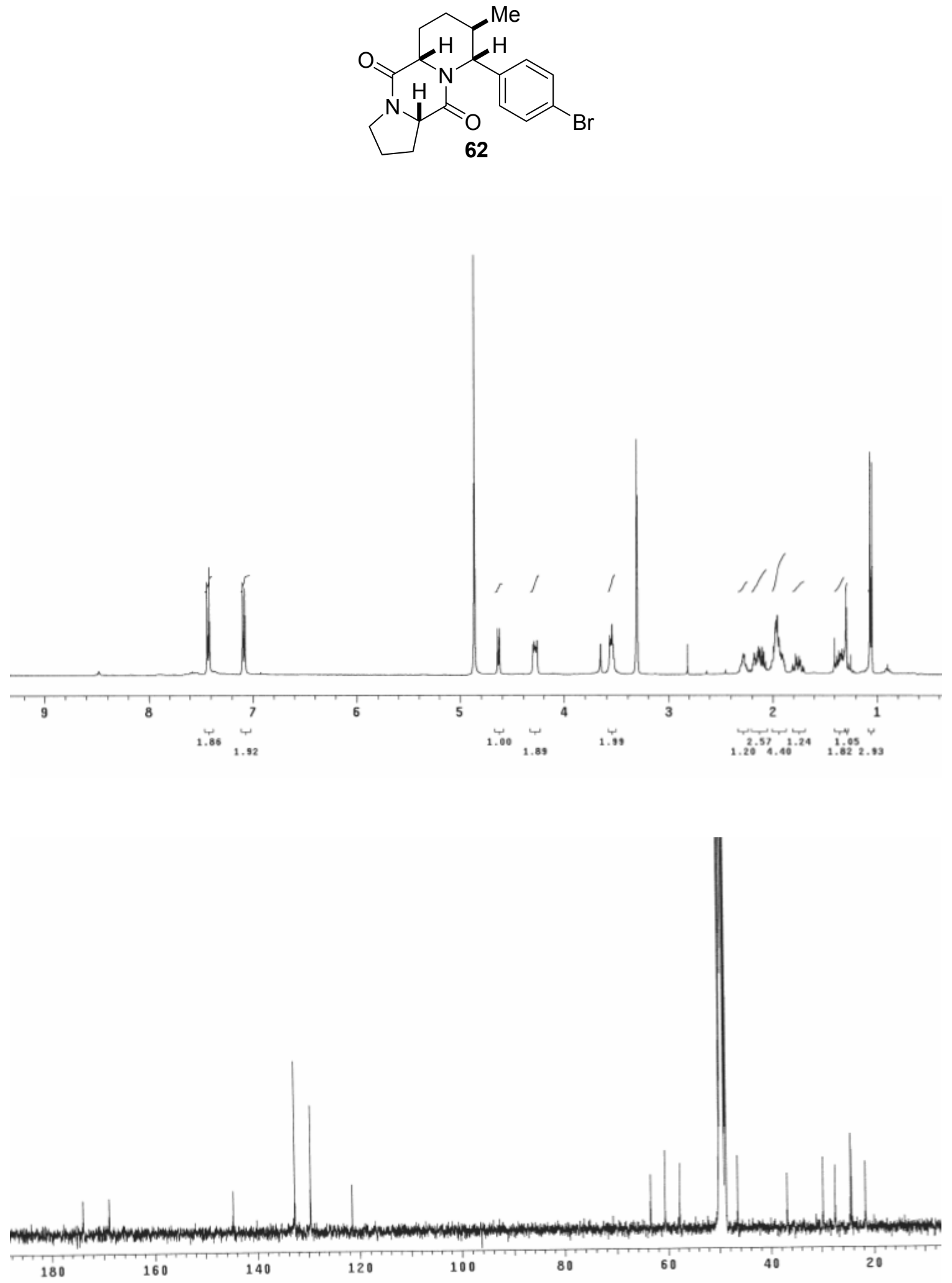

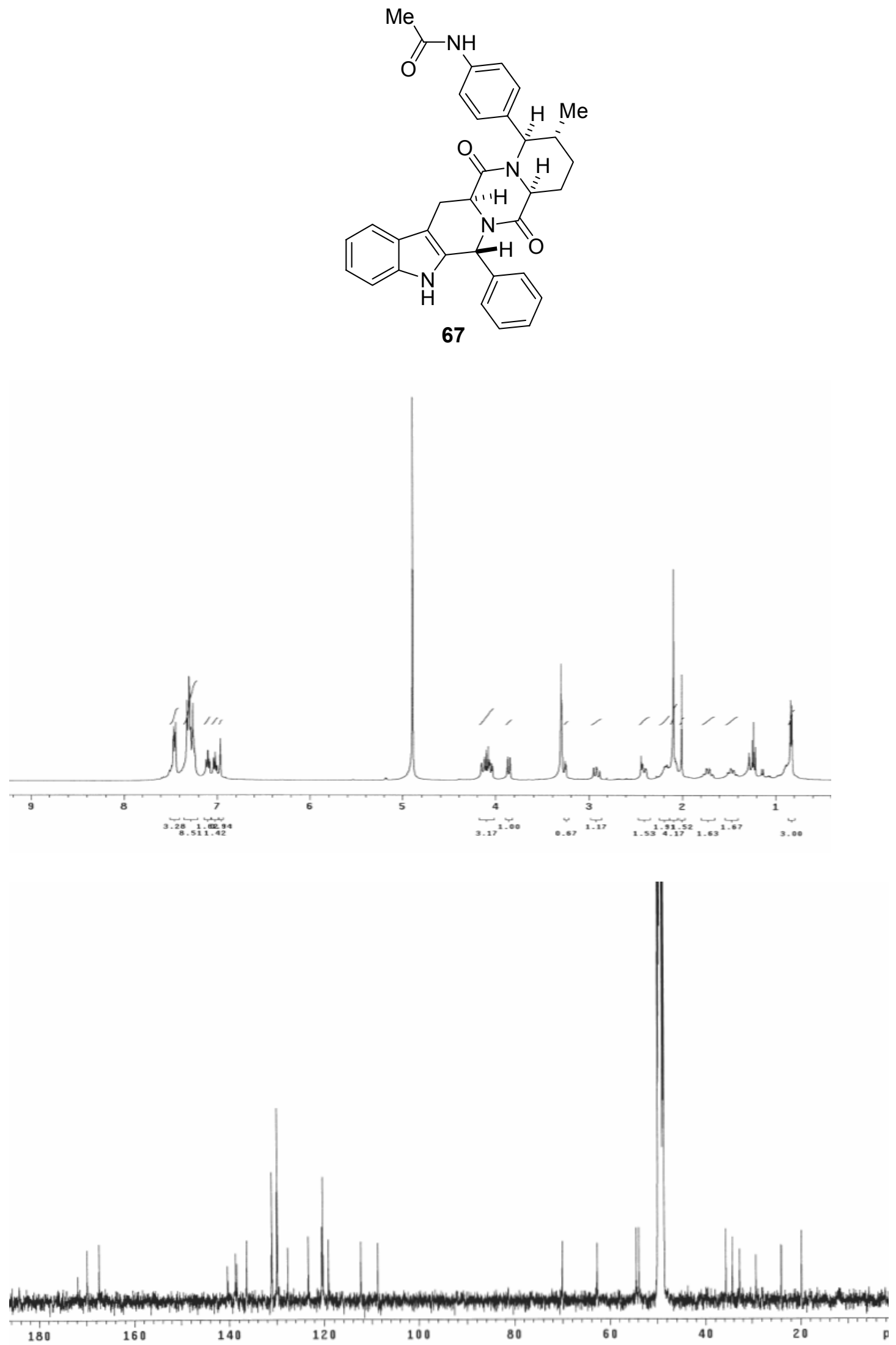

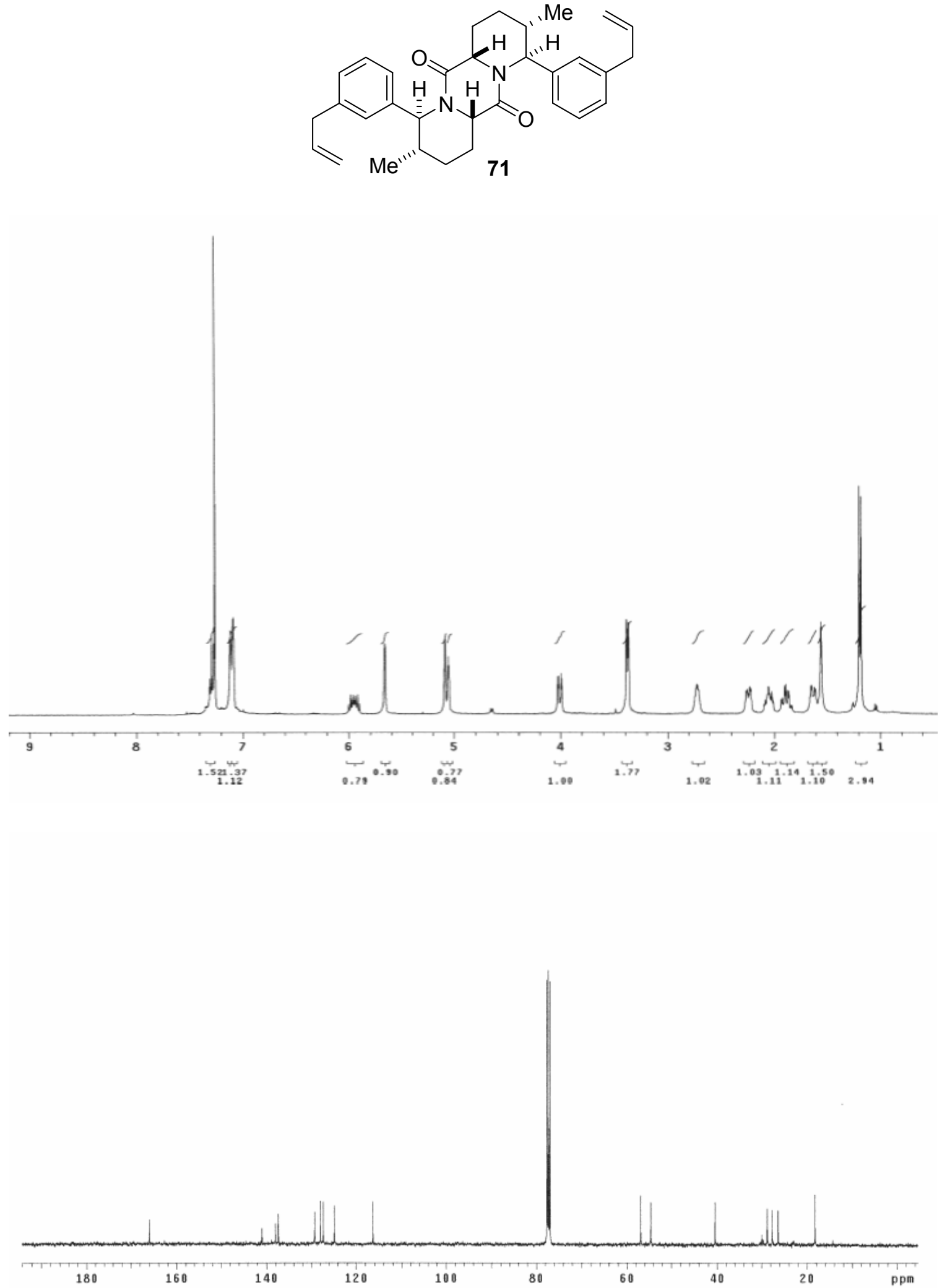

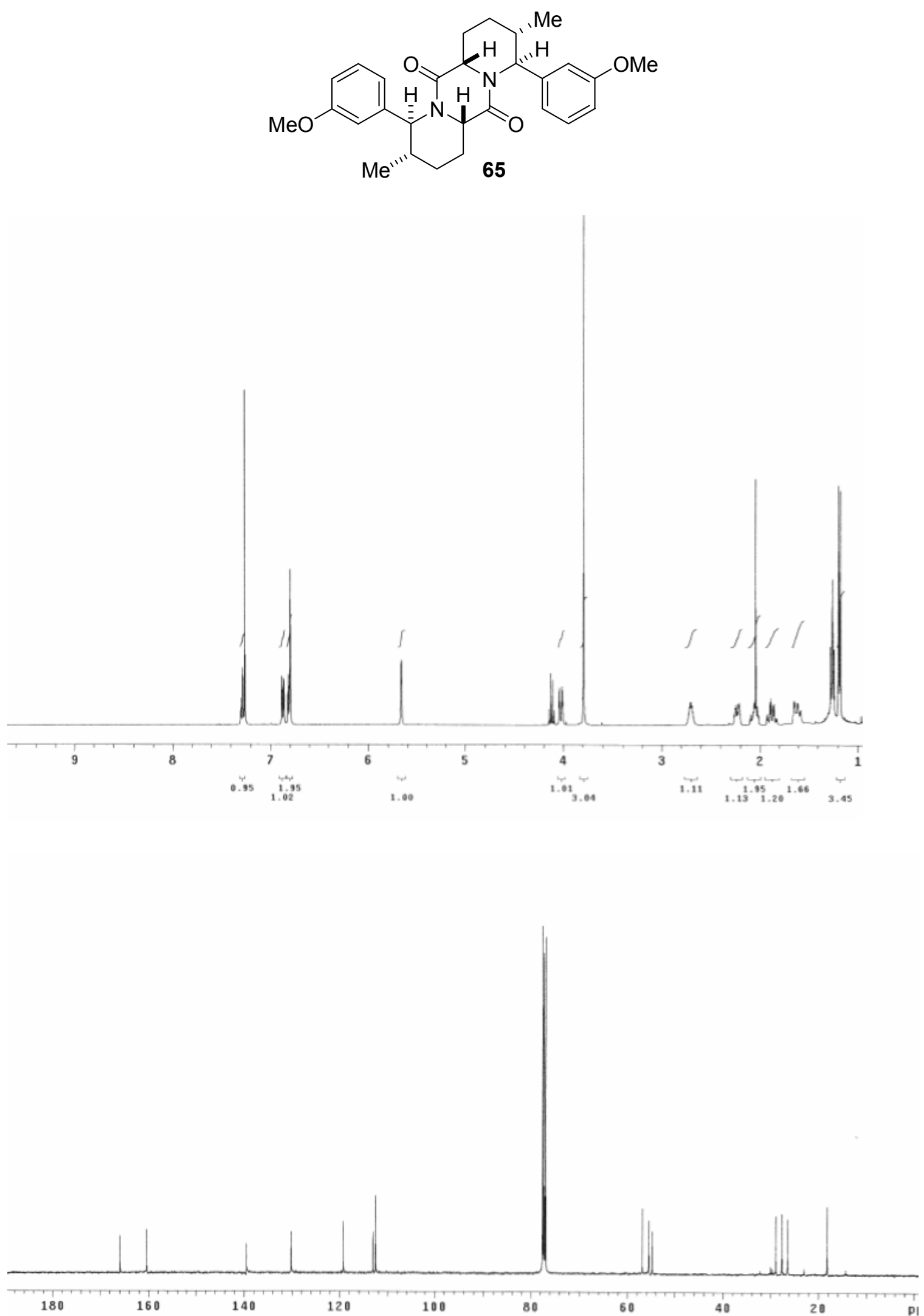

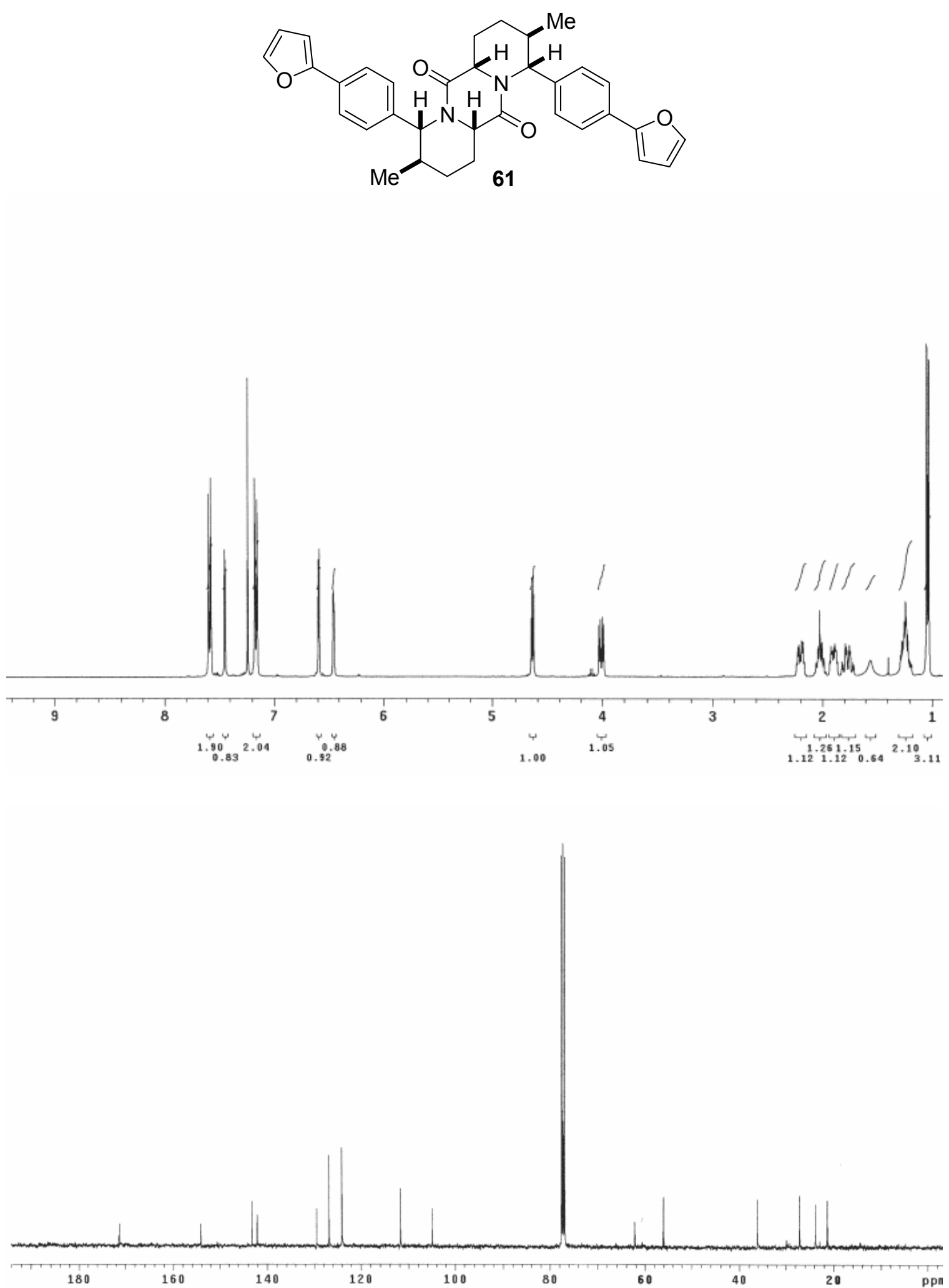


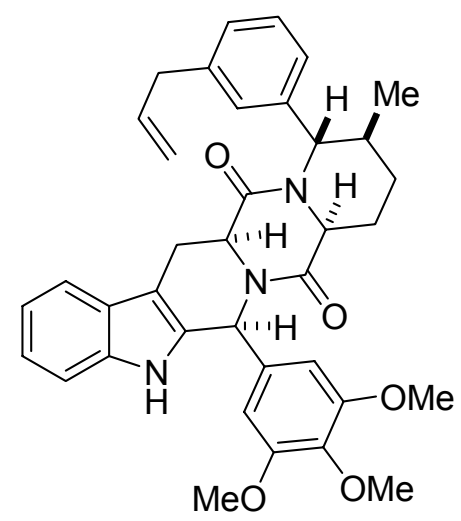

70
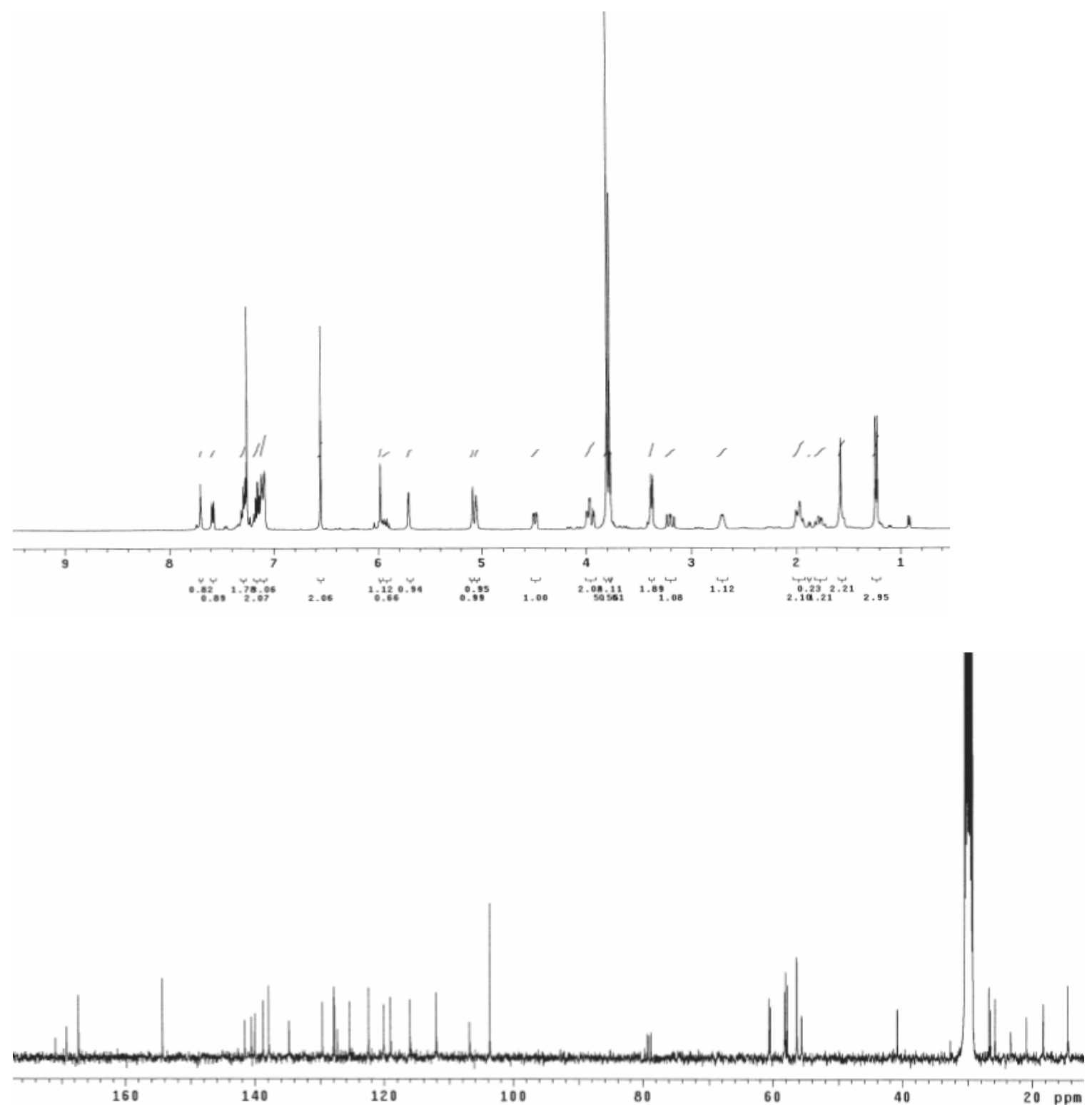

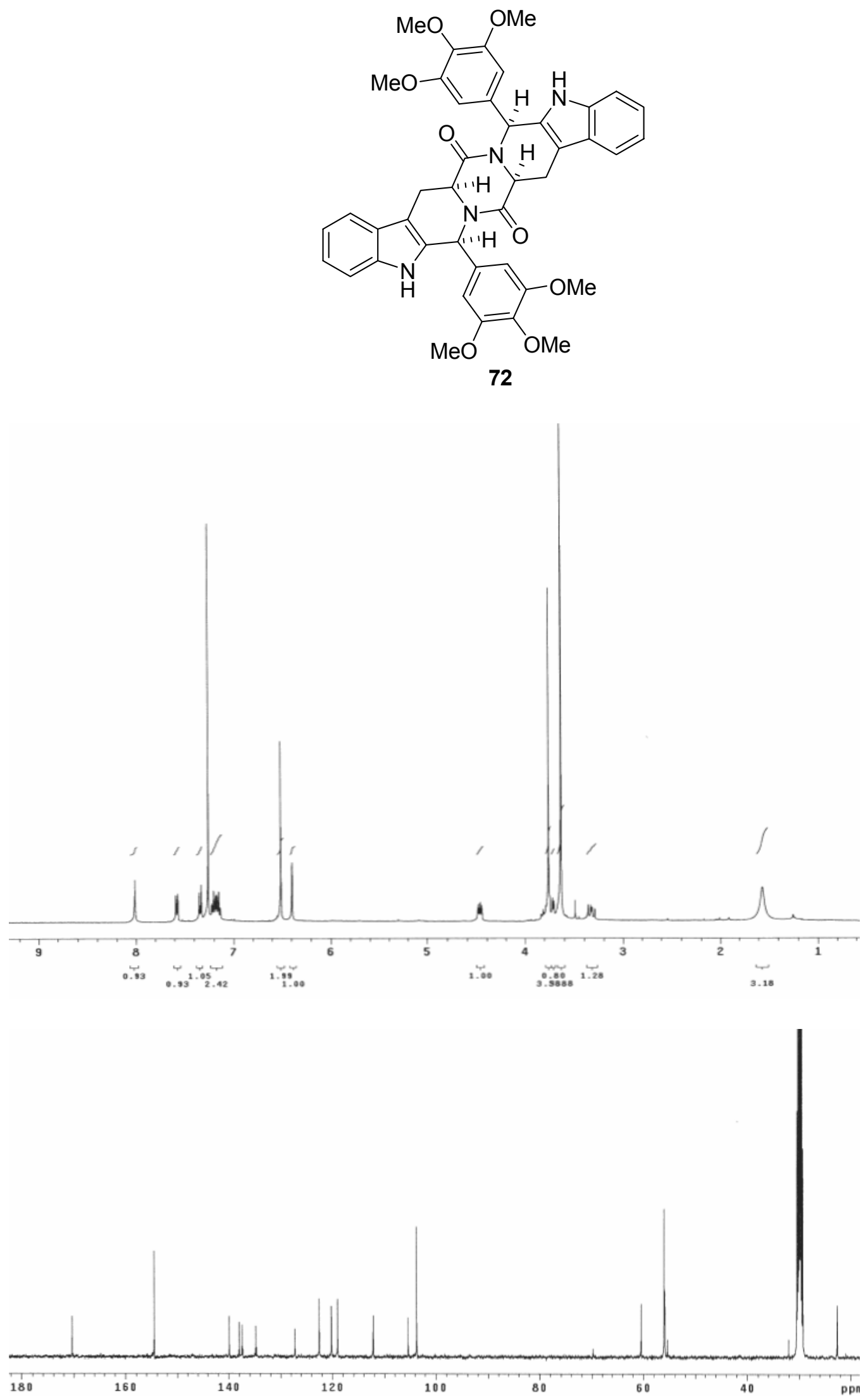


\section{DBU-Mediated Epimerization of Cis-Cis DKP 37.}

1,8-Diazabicyclo[5.4.0]undec-7-ene $(2.7 \mu \mathrm{L}, 0.02 \mathrm{mmol})$ was added to a solution of ciscis DKP $37(10 \mathrm{mg}, 0.02 \mathrm{mmol})$ in $\mathrm{CD}_{3} \mathrm{OD}(1 \mathrm{~mL})$ and heated at $45{ }^{\circ} \mathrm{C}$ for $6 \mathrm{~h}$. The reaction mixture was concentrated and subjected to silica gel chromatography with ethyl acetate in hexane (from $30 \%$ to $50 \%$ ) to give the cis-trans DKP 38- $\mathbf{D}_{2}(4.1 \mathrm{mg}, 41 \%)$, the

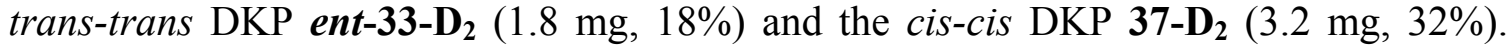
The proton NMR spectra of these deuterated compounds are compared with the corresponding protonated compounds as shown below.
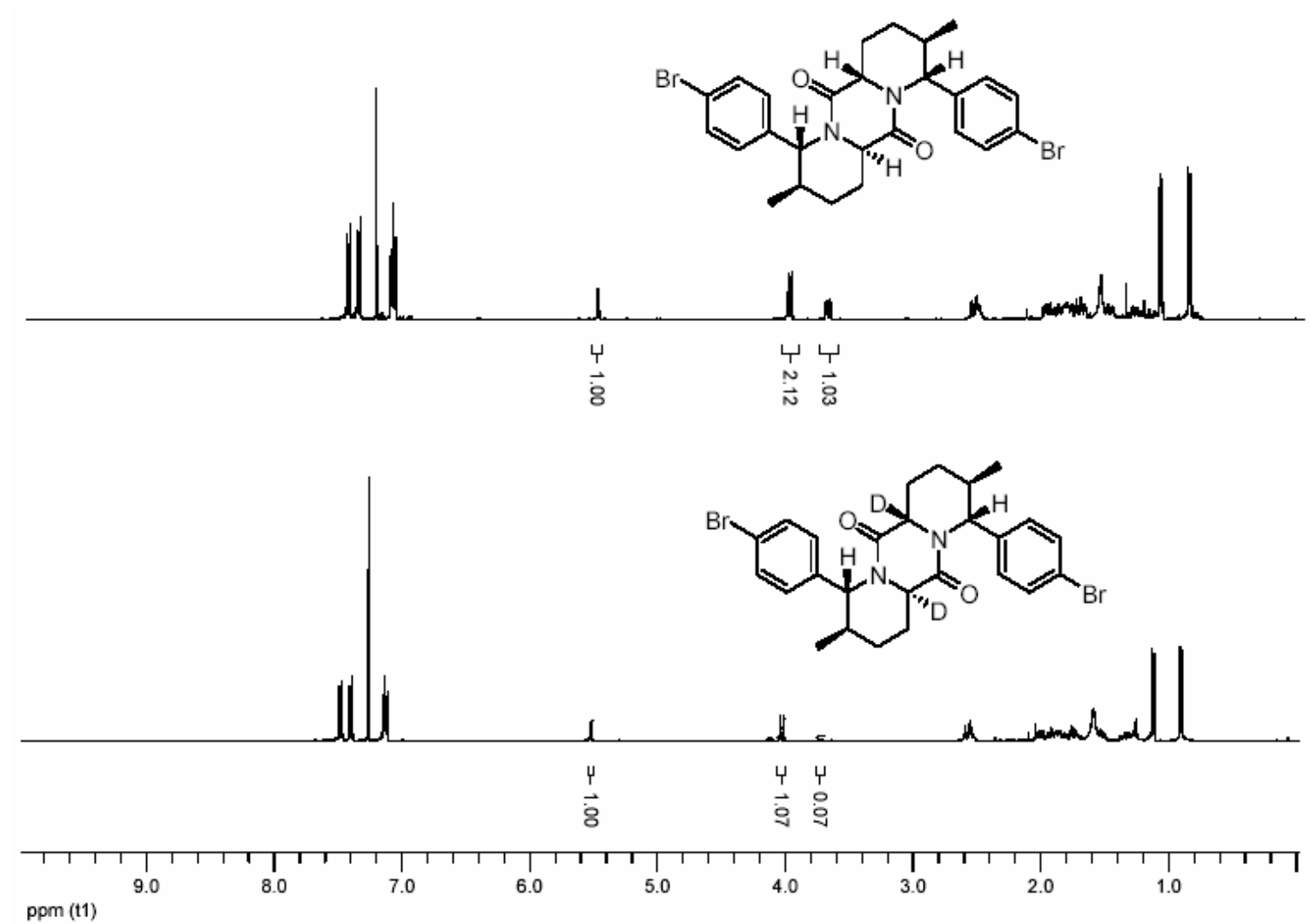

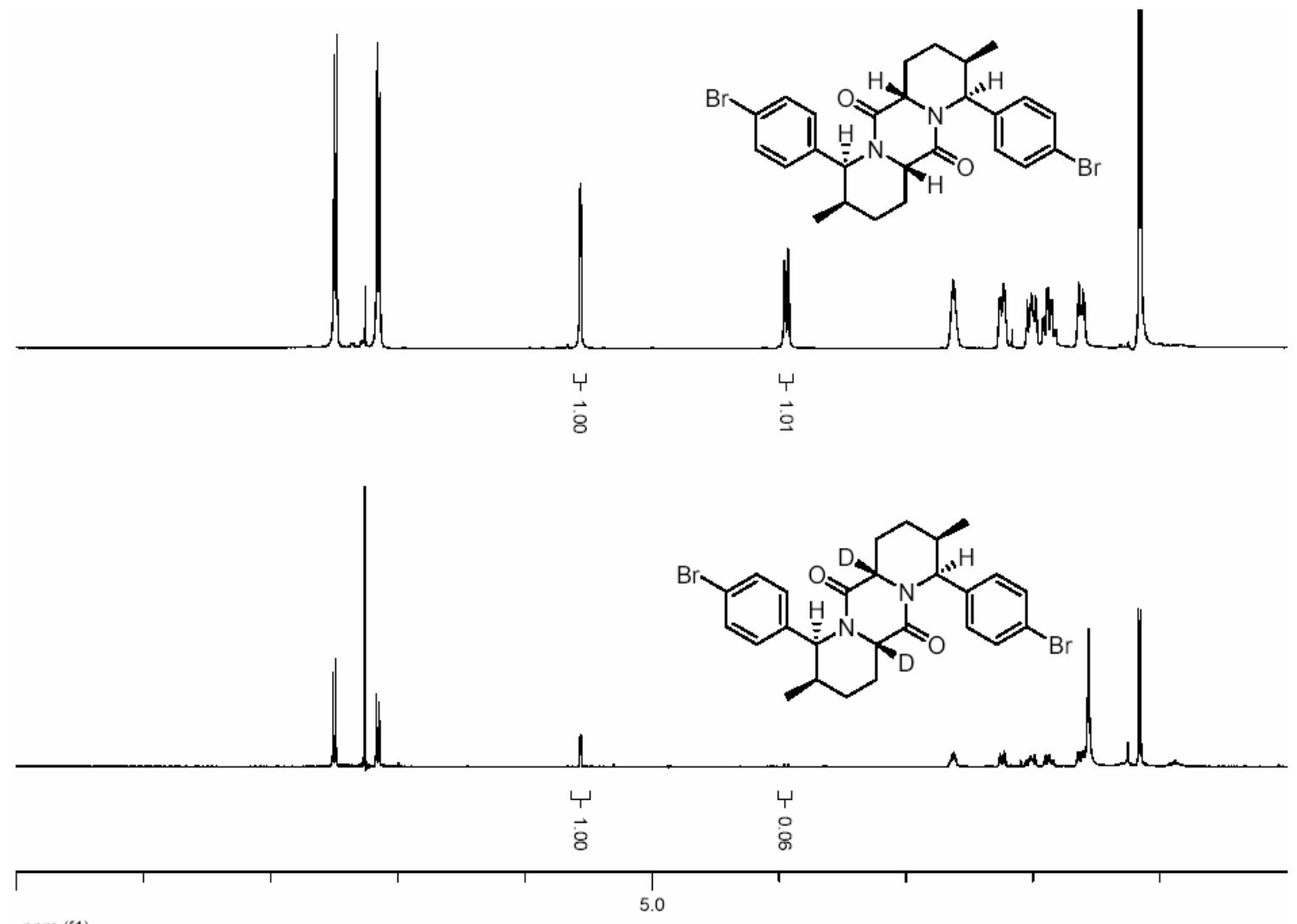

ppm (f1)
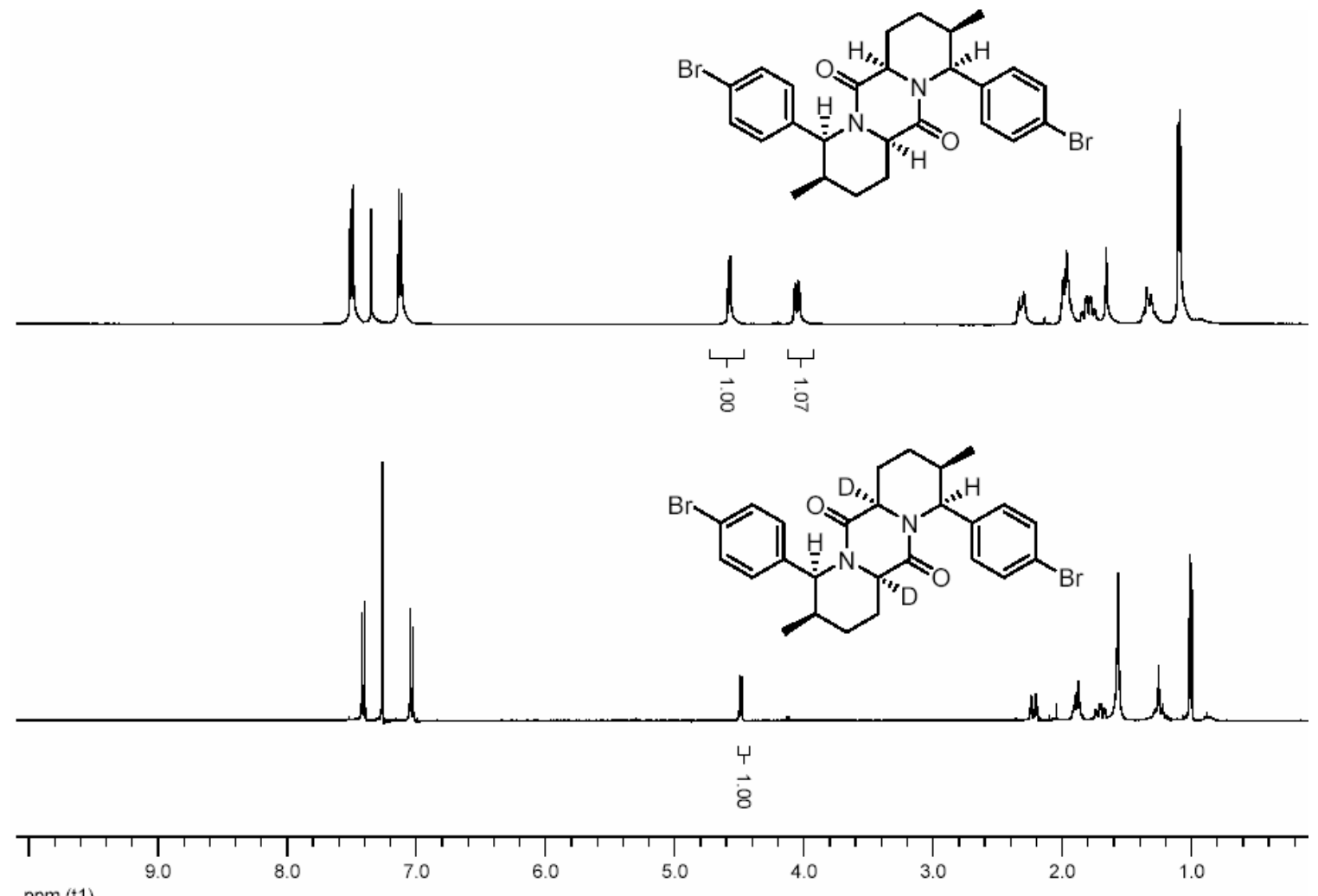


\section{X-ray Crystal Structure of Diketopiperazine 33.}

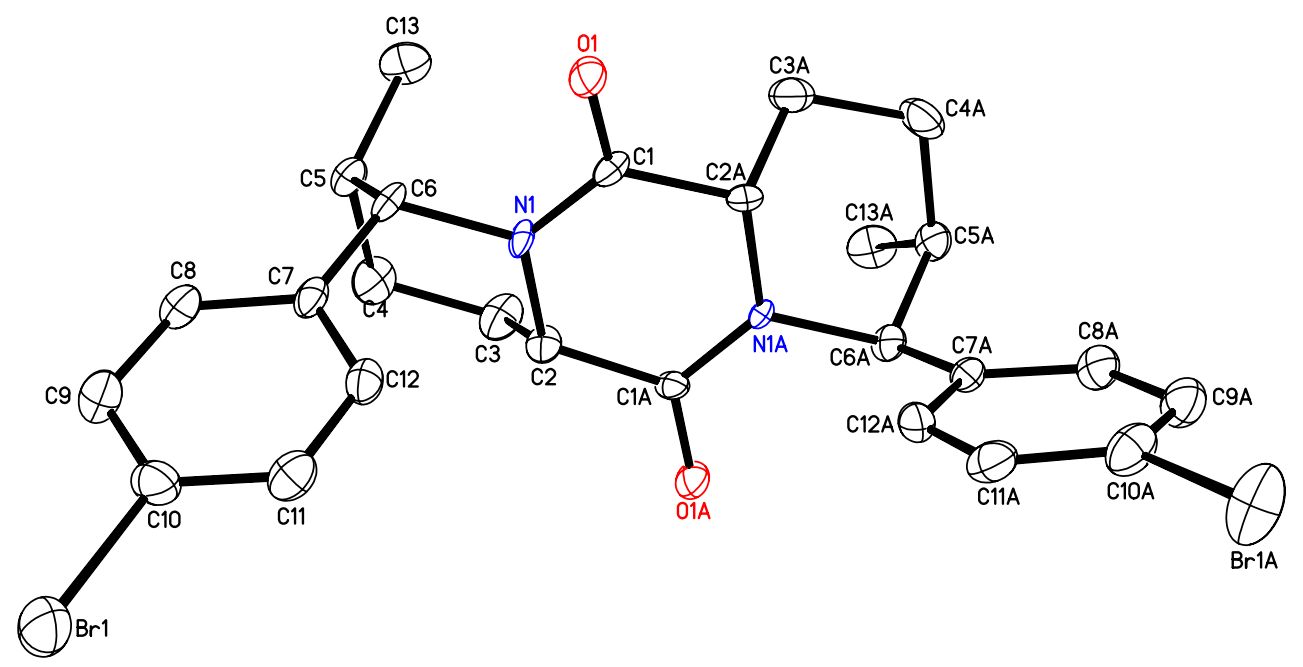

Crystals of compound $\mathbf{3 3}$ suitable for x-ray analysis were obtained by slow evaporation from $\mathrm{CH}_{2} \mathrm{Cl}_{2}$ /isooctane. Crystallographic data have been deposited with the Cambridge Crystallographic Data Centre (CCDC \#259134). Copies of the data can be obtained free of charge on application to the CCDC, 12 Union Road, Cambridge CB21EZ, UK (fax: (+44)-1223-336-033; e-mail: deposit@ccdc.cam.ac.uk.

Table 1. Crystal data and structure refinement for 33.

Identification code

Empirical formula

Formula weight

Temperature

Wavelength

Crystal system

Space group

Unit cell dimensions

Volume

$\mathrm{Z}$

Density (calculated)

Absorption coefficient

$\mathrm{F}(000)$

Crystal size

Theta range for data collection
33

$\mathrm{C} 26 \mathrm{H} 28 \mathrm{Br} 2 \mathrm{~N} 2 \mathrm{O} 2$ * $\mathrm{H} 2 \mathrm{O}$

578.34

173(2) K

$0.71073 \AA$

Tetragonal

$\mathrm{P} 4(1) 2(1) 2$

$\mathrm{a}=6.9396(4) \AA$ $\alpha=90^{\circ}$.

$\mathrm{b}=6.9396(4) \AA$ $\beta=90^{\circ}$.

$\mathrm{c}=50.665(5) \AA$ $\gamma=90^{\circ}$

2439.9(3) $\AA^{3}$

4

$1.574 \mathrm{Mg} / \mathrm{m}^{3}$

$3.353 \mathrm{~mm}^{-1}$

1176

$0.40 \times 0.30 \times 0.15 \mathrm{~mm}^{3}$

2.96 to $26.42^{\circ}$. 
Index ranges

Reflections collected

Independent reflections

Completeness to theta $=26.42^{\circ}$

Absorption correction

Max. and min. transmission

Refinement method

Data / restraints / parameters

Goodness-of-fit on $\mathrm{F}^{2}$

Final $\mathrm{R}$ indices $[\mathrm{I}>2 \operatorname{sigma}(\mathrm{I})]$

$\mathrm{R}$ indices (all data)

Absolute structure parameter

Largest diff. peak and hole $-8<=\mathrm{h}<=6,-7<=\mathrm{k}<=8,-63<=\mathrm{l}<=55$

14382

$2464[\mathrm{R}(\mathrm{int})=0.1101]$

$99.0 \%$

\section{SADABS}

0.6332 and 0.3473

Full-matrix least-squares on $\mathrm{F}^{2}$

2464 / 0 / 151

1.176

$\mathrm{R} 1=0.0674, \mathrm{wR} 2=0.1577$

$\mathrm{R} 1=0.0736, \mathrm{wR} 2=0.1607$

$0.07(3)$

1.159 and -0.935 e. $\AA^{-3}$

Table 2. Atomic coordinates $\left(\mathrm{x} 10^{4}\right)$ and equivalent isotropic displacement parameters $\left(\AA^{2} \times 10^{3}\right)$ for 30. $U(e q)$ is defined as one third of the trace of the orthogonalized $U^{i j}$ tensor.

\begin{tabular}{|c|c|c|c|c|}
\hline & $\mathrm{x}$ & $\mathrm{y}$ & $\mathrm{z}$ & $\mathrm{U}(\mathrm{eq})$ \\
\hline $\operatorname{Br}(1)$ & $12494(1)$ & $-803(1)$ & 1099(1) & $41(1)$ \\
\hline $\mathrm{O}(1)$ & $3343(7)$ & $-1577(7)$ & $189(1)$ & $21(1)$ \\
\hline $\mathrm{N}(1)$ & $5367(7)$ & $-4052(7)$ & $270(1)$ & $13(1)$ \\
\hline $\mathrm{C}(1)$ & $4355(9)$ & $-2916(8)$ & $107(1)$ & $14(1)$ \\
\hline $\mathrm{C}(2)$ & $6697(9)$ & $-5567(8)$ & $186(1)$ & $16(1)$ \\
\hline $\mathrm{C}(3)$ & $5947(11)$ & $-7537(10)$ & $277(1)$ & $26(1)$ \\
\hline $\mathrm{C}(4)$ & $5607(11)$ & $-7540(11)$ & $576(1)$ & $27(1)$ \\
\hline $\mathrm{C}(5)$ & 4303(9) & $-5867(10)$ & $658(1)$ & $19(1)$ \\
\hline $\mathrm{C}(6)$ & $5095(9)$ & $-3912(9)$ & $561(1)$ & $17(1)$ \\
\hline $\mathrm{C}(7)$ & 6899(9) & $-3197(9)$ & $693(1)$ & $17(1)$ \\
\hline $\mathrm{C}(8)$ & $7239(10)$ & $-3501(10)$ & $960(1)$ & $22(1)$ \\
\hline $\mathrm{C}(9)$ & $8870(10)$ & $-2796(10)$ & $1086(1)$ & $26(1)$ \\
\hline$C(10)$ & 10180(10) & $-1755(11)$ & $940(1)$ & $26(2)$ \\
\hline $\mathrm{C}(11)$ & $9887(10)$ & $-1380(10)$ & $676(1)$ & $24(1)$ \\
\hline$C(12)$ & $8266(10)$ & $-2106(9)$ & $560(1)$ & $20(1)$ \\
\hline$C(13)$ & $2198(10)$ & $-6154(11)$ & $568(1)$ & $26(2)$ \\
\hline $\mathrm{O}(1 \mathrm{~S})$ & $-249(8)$ & $-249(8)$ & 0 & $33(2)$ \\
\hline
\end{tabular}




\section{Select LC/MS/ELS Traces for Cyclodimerizations.}

(1)<smiles>CC1CCC(C)C(c2cccc(Br)c2)(c2cccc(N3CCOCC3)c2)N1</smiles>

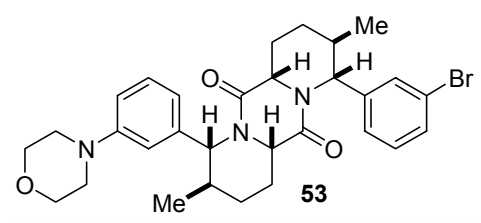

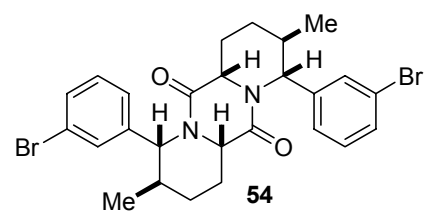

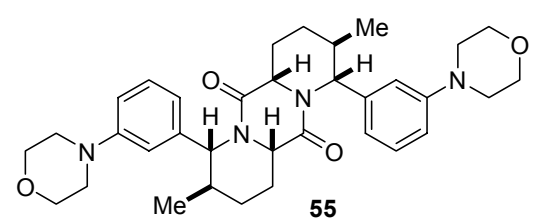

ELSD Onooh ann, $2 \times 4$ )

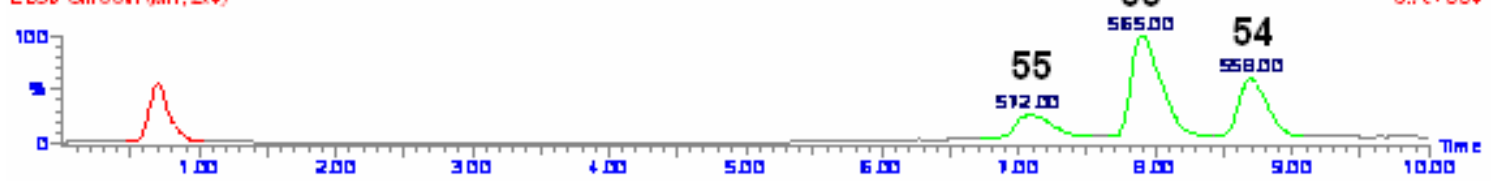

Combine (175:177-(154:155+200:201))

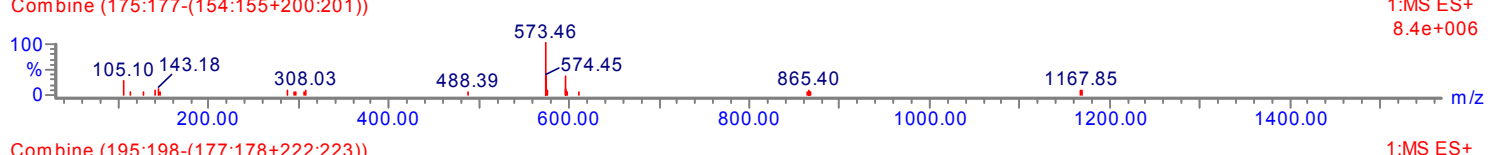

Combine (195:198-(177:178+222:223))

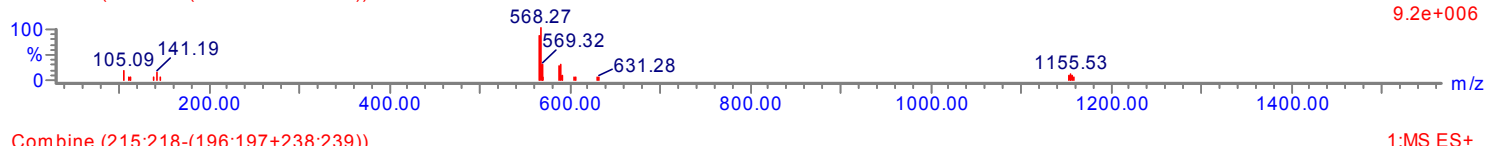

Combine $(215: 218-(196: 197+238: 239))$

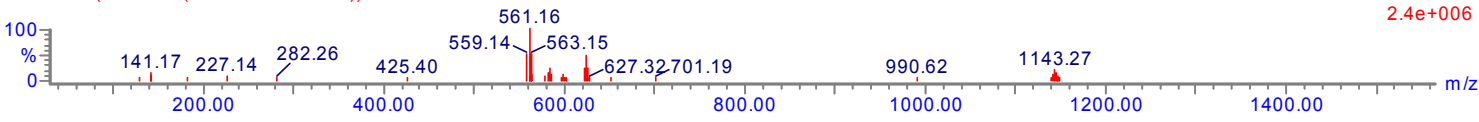

(2)<smiles>CC1CCC(C(=O)O)NC1(c1ccc(-c2ccco2)cc1)c1cccc(N2CCCC2=O)c1</smiles>

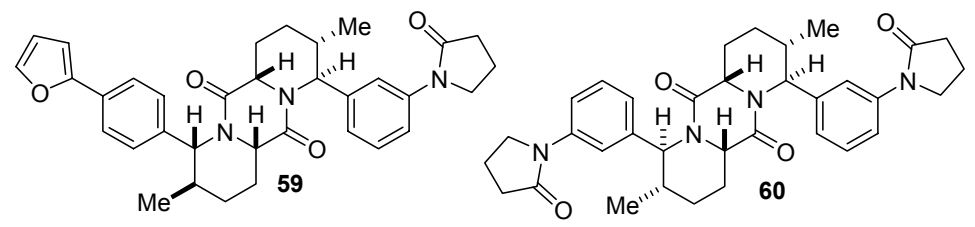

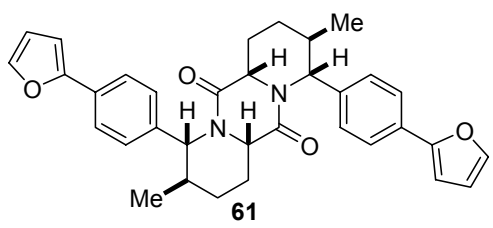

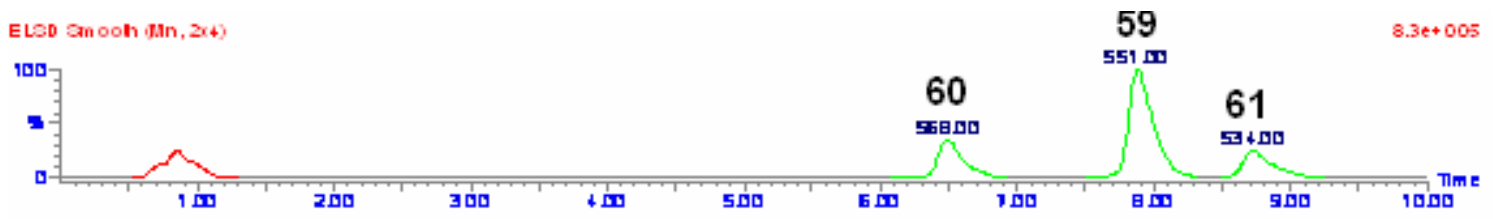




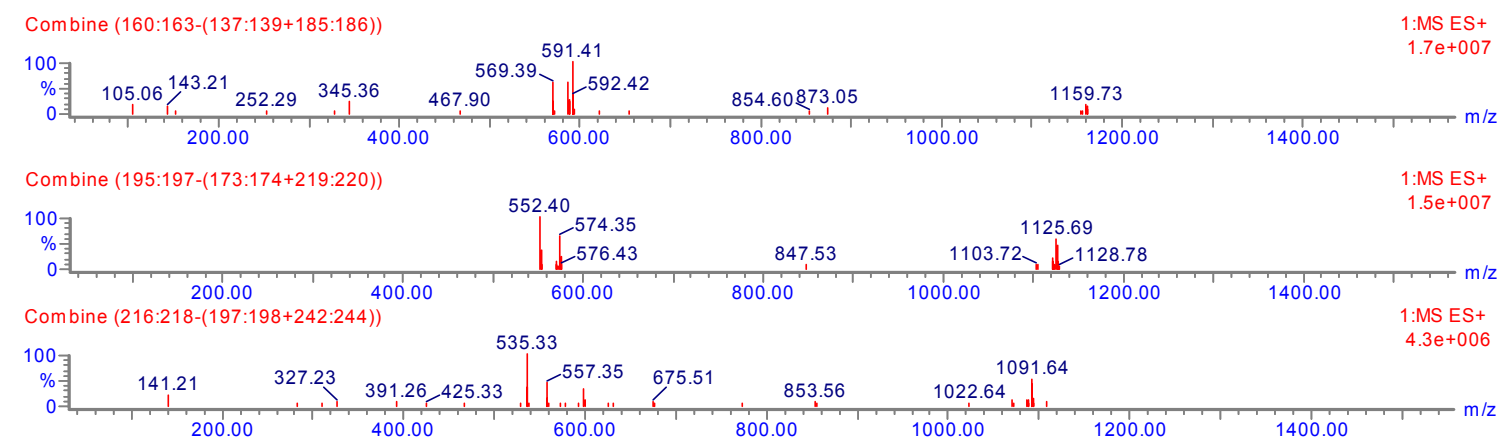

(3)
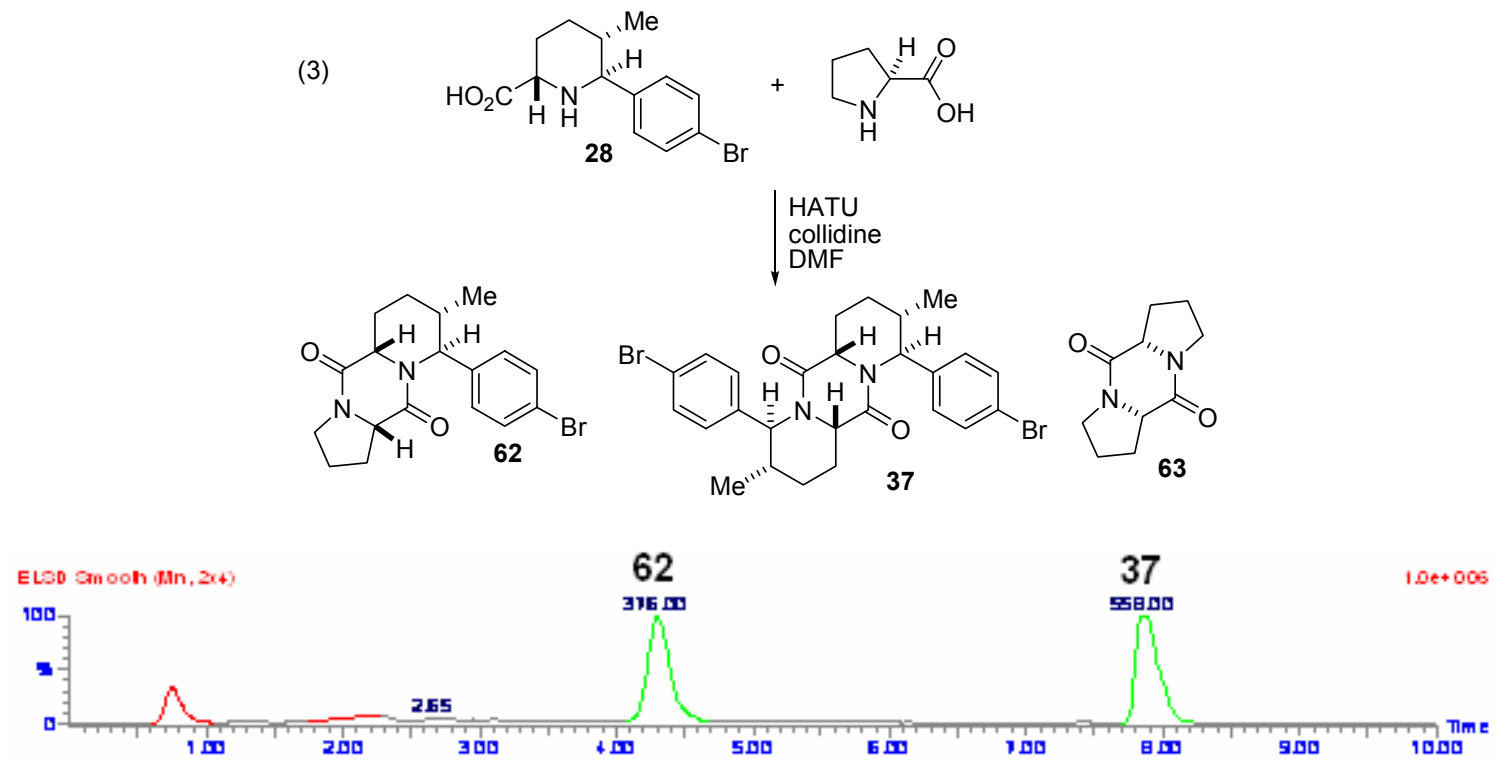

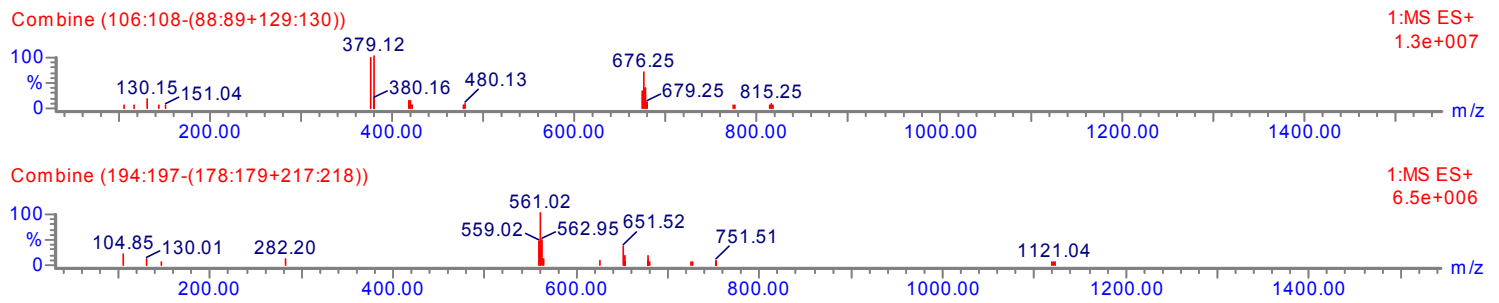


(4)

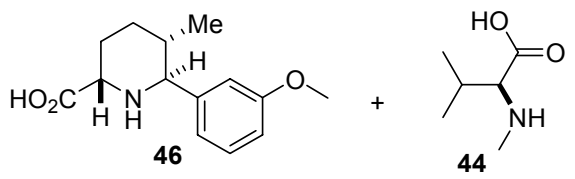<smiles>COc1cccc([C@@H]2C(C)CC[C@]3(C)C(=O)N(C)[C@@H](C(C)C)C(=O)N23)c1</smiles>

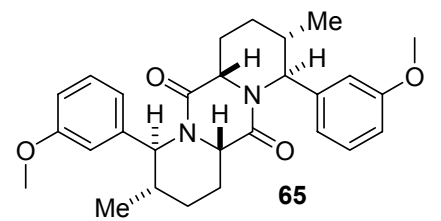
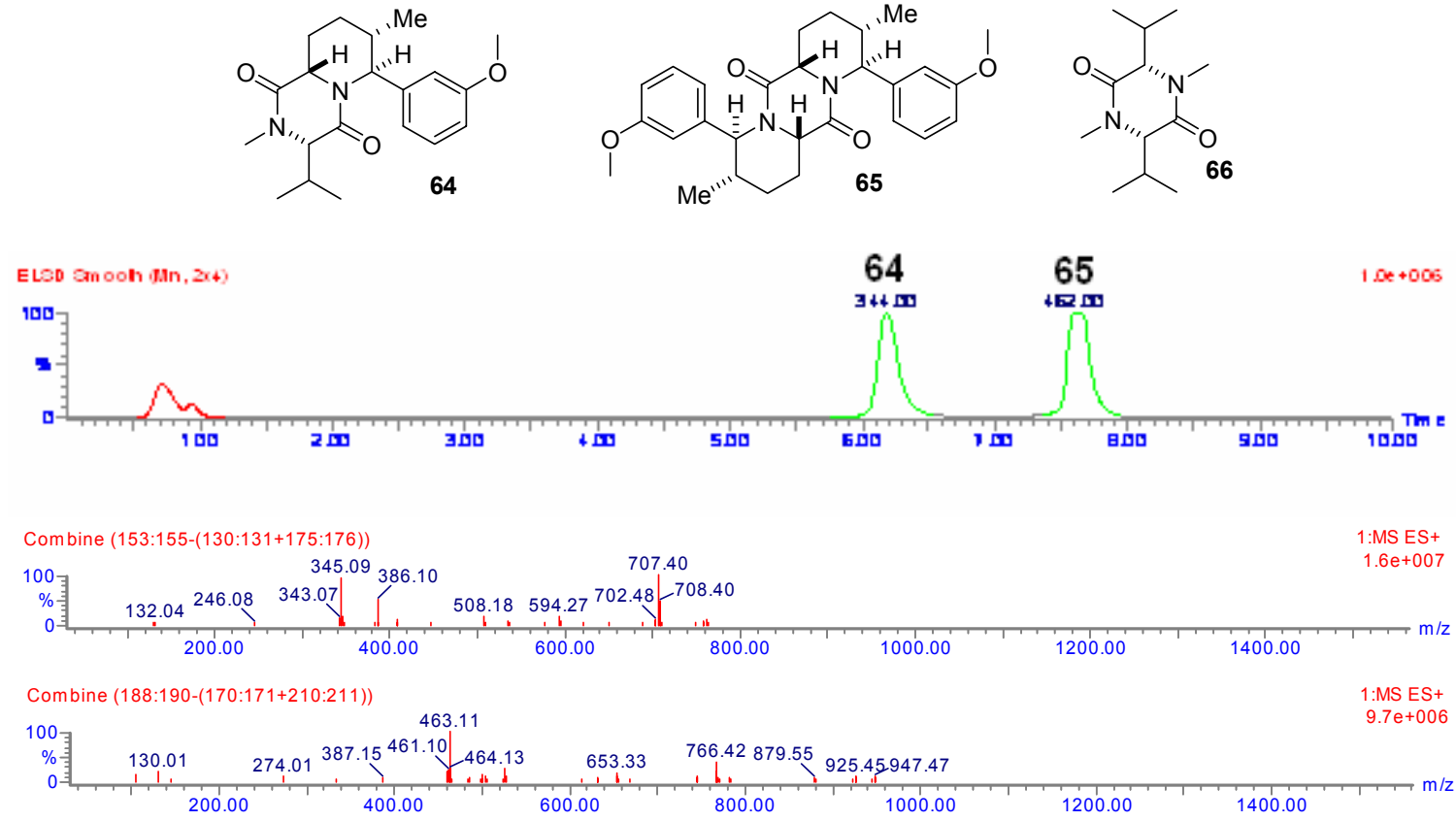

(5)<smiles>[M]C1CCC(NC(C)=O)(c2ccc(NC(C)=O)cc2)C1(C)C=O</smiles>

47

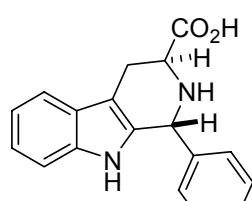

50

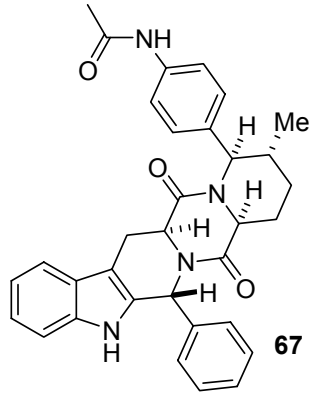

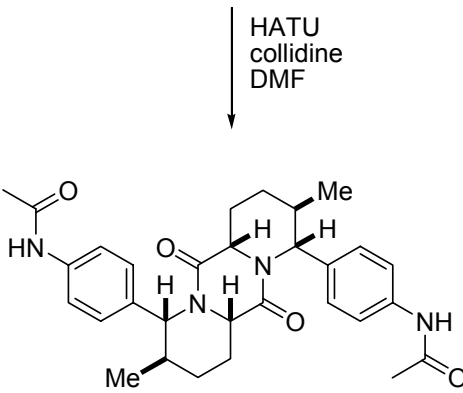

68

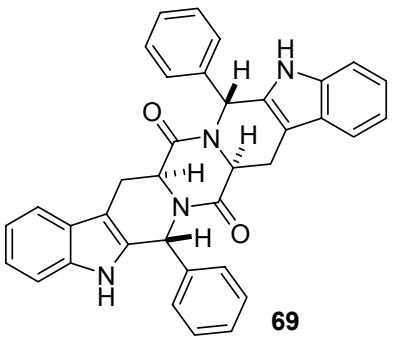

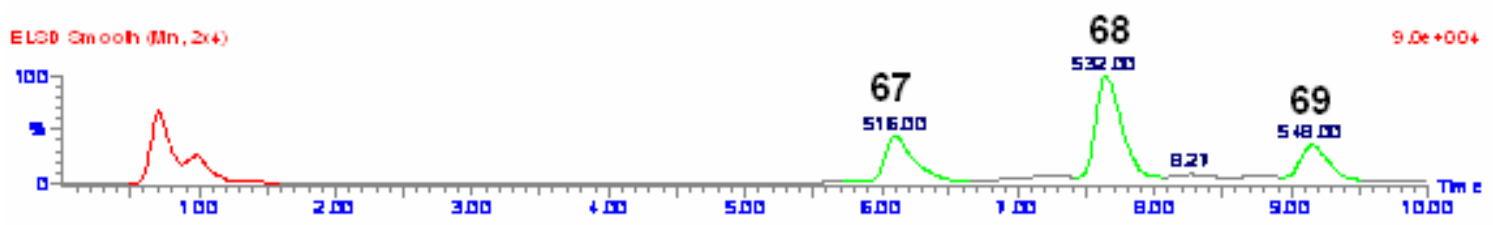




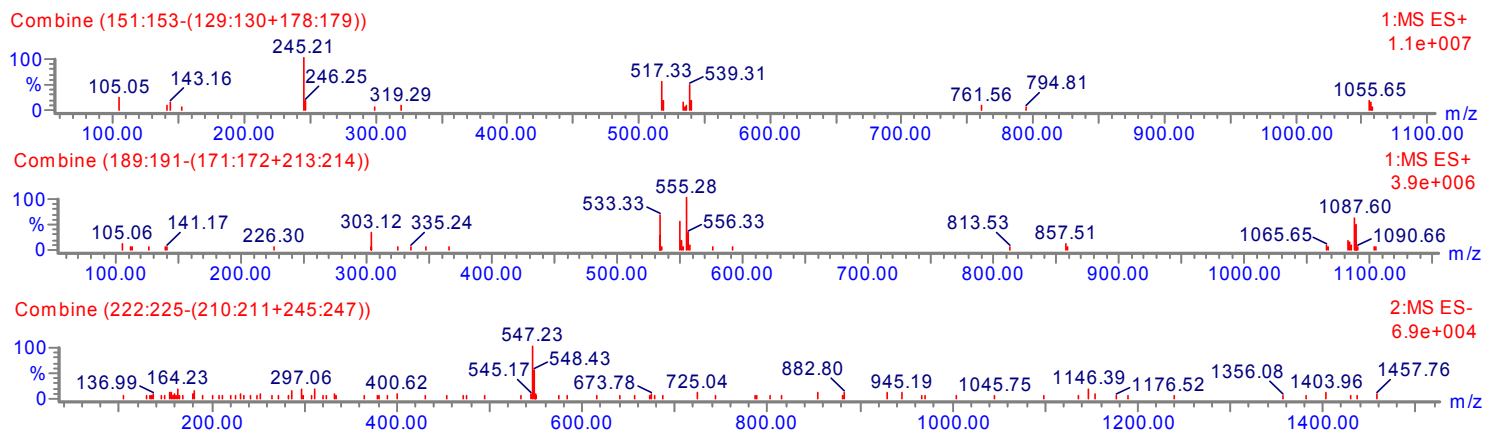

\section{Biological Experiments: GTP $\gamma \mathrm{S}$ protocol.}

For all receptor types $\left(\alpha_{2 \mathrm{~B}}, \alpha_{2 \mathrm{c}}, 5-\mathrm{HT}_{1 \mathrm{~A}}, 5-\mathrm{HT}_{1 \mathrm{E}}\right), 50 \mu \mathrm{L}$ of membranes, equivalent to 20 $50 \mu \mathrm{g}$ of protein, were used in each incubation. The membranes were derived from cloned human receptor preparations (http://pdsp.case.edu/). The membranes were resuspended and diluted right before use, and were incubated in a final volume of $300 \mu \mathrm{L}$ of incubation buffer (final concentrations: $50 \mathrm{mM}$ Tris $\mathrm{HCl}$ buffer, $\mathrm{pH} 7.4 ; 5 \mathrm{mM} \mathrm{MgCl}$; $100 \mathrm{mM} \mathrm{NaCl} ; 1 \mathrm{mM}$ EGTA; $1 \mathrm{mM}$ DTT; $20 \mu \mathrm{M}$ GDP; $300 \mathrm{pM}\left[{ }^{35} \mathrm{~S}\right] \mathrm{GTP} \gamma \mathrm{S}$; and increasing concentrations of agonist). For adrenergic assays, $1 \mu \mathrm{M}$ propranolol was used in all incubations to block $\beta$-adrenergic receptors, and $10 \mu \mathrm{M}$ yohimbine was used to block agonist stimulation of $\left[{ }^{35} \mathrm{~S}\right] \mathrm{GTP} \gamma \mathrm{S}$ binding at $\alpha_{2 \mathrm{~B}} / \alpha_{2 \mathrm{c}}$ receptors. For $5-\mathrm{HT}_{1 \mathrm{~A}}$ and 5-HT $1 \mathrm{E}$ assays, $10 \mu \mathrm{M}$ WAY100635 and $10 \mu \mathrm{M}$ methiothepin were used to block agonist stimulation of $\left[{ }^{35} \mathrm{~S}\right] \mathrm{GTP} \gamma \mathrm{S}$ binding at their respective receptors. $10 \mu \mathrm{M}$ cold GTP $\gamma \mathrm{S}$ was used to measure non-specific binding. Assays were performed by incubating at room temperature for $1 \mathrm{~h}$ and terminated by vacuum filtration through glass fiber filters $(\mathrm{GF} / \mathrm{C}$; Whatman) using a Brandel cell harvester. Filters were washed 3 times with cold harvesting buffer $(50 \mathrm{mM}$ Tris $\mathrm{HCl}, \mathrm{pH}=7.40)$. The filters were counted in $4 \mathrm{ml}$ EcoScint A (National Diagnostics) liquid scintillation cocktails with a liquid scintillation counter. Data was analyzed in Graphpad Prism 4.0. EC-50 values were calculated from the doseresponse cureves. ${ }^{s 5}$

\footnotetext{
${ }^{s 5}$ For details on calculating EC-50 values from dose response curves, see: http://www.graphpad.com/curvefit/introduction89.htm (accessed August 23, 2006)
} 